UCRL-ID-124410 Rev 1

\title{
THE SOVIET PROGRAM FOR PEACEFUL USES OF NUCLEAR EXPLOSIONS
}

\author{
Milo D. Nordyke
}

October, 1996

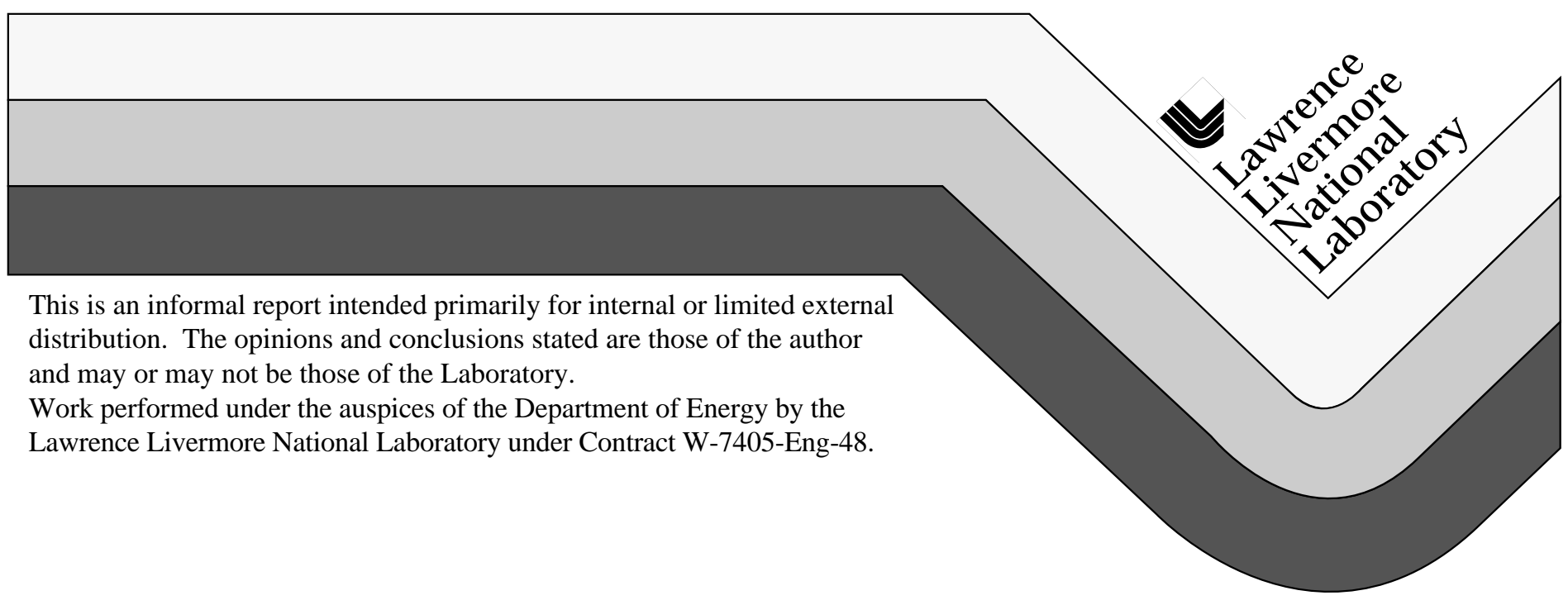




\section{DISCLAIMER}

This document was prepared as an account of work sponsored by an agency of the United States Government. Neither the United States Government nor the University of California nor any of their employees, makes any warranty, express or implied, or assumes any legal liability or responsibility for the accuracy, completeness, or usefulness of any information, apparatus, product, or process disclosed, or represents that its use would not infringe privately owned rights. Reference herein to any specific commercial product, process, or service by trade name, trademark, manufacturer, or otherwise, does not necessarily constitute or imply its endorsement, recommendation, or favoring by the United States Government or the University of California. The views and opinions of authors expressed herein do not necessarily state or reflect those of the United States Government or the University of California, and shall not be used for advertising or product endorsement purposes.

This report has been reproduced directly from the best available copy.

Available to DOE and DOE contractors from the

Office of Scientific and Technical Information

P.O. Box 62, Oak Ridge, TN 37831

Prices available from (615) 576-8401, FTS 626-8401

Available to the public from the

National Technical Information Service

U.S. Department of Commerce

5285 Port Royal Rd.,

Springfield, VA 22161 


\section{The Soviet Program for \\ Peaceful Uses of Nuclear Explosions}

Milo D. Nordyke

October, 1996

UCRL-ID-124410 



\section{Contents}

I. Early History …................................................................................................................... 1

II. The U.S. Plowshare Program ................................................................................................ 4

III. The Soviet Program for the Use of Nuclear Explosions in the National Economy . 9

A. An Historical Perspective .................................................................................... 9

B. Overview of the Soviet PNE Program ............................................................... 11

C. The Nuclear Excavation Program ………………............................................ 12

1. Water Reservoir Construction ................................................................. 12

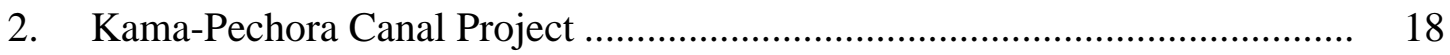

3. Dam Construction ...................................................................................... 23

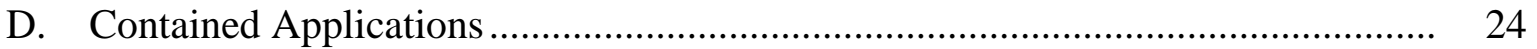

1. Stimulation of Oil and Gas Production ......................................................... 24

2. Cavity Technology Development ……………........................................ 32

3. Extinguishing Runaway Gas Well Fires ....................................................... 34

4. Underground Cavities for Storage of Gas Condensate …………………..... 36

5. Deep Seismic Sounding of the Earth ......................................................... 42

6. Breakage of Ore ............................................................................. 46

7. Disposal of Toxic Waste ........................................................................ 49

8. Transplutonic Element Production.............................................................. $\quad 50$

9. Seismic Decoupling Experiment ............................................................ 54

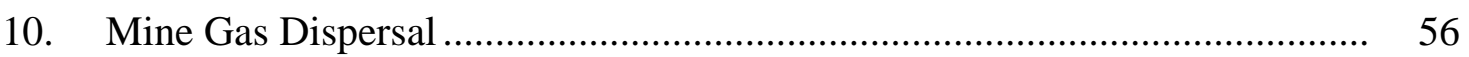

E. Overall Seismic Coupling ……….................................................................... 57

IV. Arms Control Aspects of the Peaceful Uses of Nuclear Explosions ........................... 59

A. Conference on the Discontinuance of Nuclear Weapons Tests ............................. 59

B. Limited Test Ban Treaty (Moscow Treaty) …………………………………..... 62

C. Non-Proliferation Treaty (NPT) ........................................................................ 63

D. Threshold Test Ban (TTB) and the Peaceful Nuclear Explosion Treaties

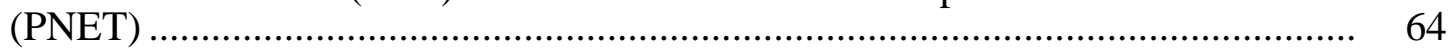

E. Comprehensive Test Ban Treaty Negotiations (CTBT), 1977-80 …………….... 65

F. Current CTBT Negotiations ....................................................................... 66

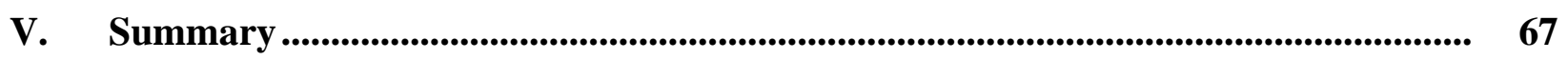

Appendix A Peaceful Nuclear Explosions in the Soviet Union (By Date) .......................... A-1

Appendix B Peaceful Nuclear Explosions in the Soviet Union (By Purpose) ................... B-1

Appendix C The Soviet Program to Develop Nuclear Explosives for Peaceful

Purposes ...................................................................................................................... C-1 


\section{List of Tables}

Table 1. Data on U.S. Peaceful Nuclear Explosions................................................ 7

Table 2. Summary of the applications studied by the Soviet Union's PNE Program............ 12

Table 3. Subsidence Crater Explosions on the Mangyshlak Plateau. ................................ 18

Table 4. Comparative Evaluation of U.S. and Soviet PNE Stimulation Projects. ................ 26

Table 5. Summary of Data on the "Halite" Cavities at Azgir.......................................... 53

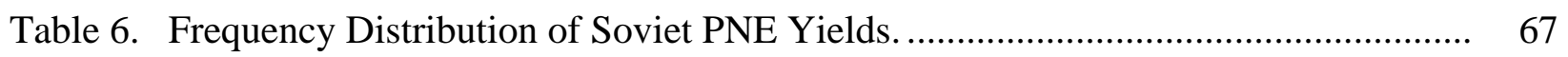

\section{List of Figures}

Figure 1. Location of the 122 PNE sites in the former Soviet Union ............................. 13

Figure 2 Photographic composite of "Chagan" Lake ................................................ 15

Figure 3. Sketch map of the "Taiga" Crater along the proposed alignment of the Kama-Pechora Canal showing the outline of the crater and areas where there

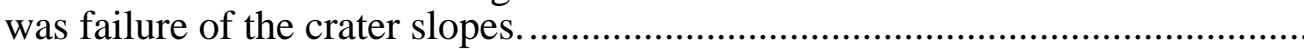

Figure 4. Alteration of the Homogeneous Porous Rock Surrounding a Nuclear Explosion

Figure 5. Various PNE sites north of the Caspian Sea ........................................... 38

Figure 6. Deep Seismic Sounding (DSS) explosions ................................................ 44

Figure 7. Schematics of "Dnepr-1" and "Dnepr-2" experiments ................................. 47

Figure 8. Seismic magnitude vs yield for "Halite" and A-3-1 explosions ....................... 55

Figure 9. Magnitudes vs yield for 102 contained Soviet PNEs .................................... 58

Figure C-1 Map of the Semipalatinsk Test Site (STS) showing the three major areas and the location of the PNE device-development explosions. 


\title{
The Soviet Program for Peaceful Uses of Nuclear Explosions
}

\author{
Milo D. Nordyke
}

\section{Early History}

The concept of utilizing the weapons of war to serve the peaceful pursuits of mankind is as old as civilization itself. Perhaps the most famous reference to this basic desire is recorded in the Book of Micah where the great prophet Isaiah called upon his people "to turn your spears into pitchforks and your swords into plowshares." As the scientists at Los Alamos worked on developing the world's first atomic bomb, thoughts of how this tremendous new source of energy could be used for peaceful purposes generally focused on using the thermal energy generated by the slow fission of uranium in a reactor, such as those being used to produce plutonium, to drive electric power stations.

However, being scientists in a new, exciting field, it was impossible to avoid letting their minds wander from the task at hand to other scientific or nonmilitary uses for the bombs themselves. During the Manhattan Project, Otto Frisch, one of the pioneers in the development of the nuclear fission process in the 1930s, first suggested using an atomic explosion as a source for a large quantities of neutrons that could be used in scientific experiments designed to expand the understanding of nuclear physics. After the war was over, many grandiose ideas appeared in the popular press on how this new source of energy should be harnessed to serve mankind.

Not to be left out of the growing enthusiasm for peaceful uses of atomic energy, the Soviet Union added their visions to the public record. In November 1949, shortly after the test of their first nuclear device on September 23, 1949, Andrei Vishinsky, the Soviet representative to the U.N., delivered a statement justifying their efforts to develop their own nuclear weapons capability. In poetic but somewhat overblown rhetoric, he said:

"The Soviet Union did not use atomic energy for the purpose of accumulating stockpiles of atomic bombs,...it was using atomic energy for purposes of its own domestic economy: blowing up mountains, changing the course of rivers, irrigating deserts, charting new paths of life in regions untrodden by human foot."1

A few years later, a Russian engineer, Professor G. I. Pokrovskiy wrote:

1 United Nations General Assembly, Official Records: Fourth Session, Ad Hoc Political Committee, ThirtyThird Meeting, November 10, 1949, p. 188. 
"Progressive science claims that it is possible to utilize the noble force of the explosions builder for peaceful purposes.... With the help of directional explosions one can straighten out the beds of large rivers...construct gigantic dams...cut canals.... Indeed, the perspectives disclosed due to the new atomic energy are unlimited."2

However, very few of the articles written in the late 1940s and early 1950s had concrete ideas on how the explosive force of the bombs themselves could be used for scientific purposes or to transform the landscape and alter the character of geological formations deep under the earth. One of the first was written by Fred Reines, a young physicist who had come to Los Alamos in 1944 to work on the nuclear weapons program. In June of 1950, he wrote a short article for the Bulletin of the Atomic Scientists examining the possibilities of using atomic explosives for a few, large-scale earth-moving applications, such as making canals, mining, breaking up icebergs, and melting the polar icecap. In general, his outlook was rather pessimistic, concluding that "such uses appear at best to be extremely limited in scope, owing to the radioactivity hazard associated with atomic explosions." 3

With the development of thermonuclear devices, new ideas began to ferment in the minds of the bomb-designers. Thermonuclear devices still required a small fission trigger, but, since the thermonuclear fuel consisted of relatively cheap deuterium and lithium and produced almost no long-lived radioactive byproducts, they offered the possibility of an order-of-magnitude decrease in both the cost of an explosive and the amount of radioactivity associated with a given total yield.

The detonation by the Soviet Union of their first thermonuclear explosion on August 12, 1953, led President Eisenhower to the determination that he needed to take the initiative in dealing with the political aspects of the nuclear arms race. Toward this end, on December 8, 1953, President Eisenhower delivered his now-famous Atoms for Peace speech at the U.N. calling for

“...more than the mere reduction or elimination of atomic materials for military purposes.

It is not enough to take this weapon out of the hands of their soldiers. It must be put into the hands of those who will know how to strip its military casing and adapt it to the arts of peace...this greatest of destructive forces can be developed into a great boon for the benefit of all mankind....

Who can doubt, if the entire body of the world's scientists and engineers had adequate amounts of fissionable material with which to test and develop their ideas,

2 G. I. Pokrovskiy, "Beginning of an Era of Atomic Energy," Tekhnika Molodezhi, 9, 1954.

3 Frederick Reines, “Are There Peaceful Engineering Uses of Atomic Explosives?,” Bulletin of Atomic Scientists, June, 1950, pp. 171-2. 
that this capability would rapidly be transformed into universal, efficient, and economic usage."

This dramatic and stirring call to the world community to begin the process of applying this powerful new source of energy to the peaceful uses of mankind served as a powerful stimulant within the nuclear physics community and nuclear power industry. Following up on Eisenhower's Atoms for Peace speech, in early 1954 the U.S. proposed that the U.N. sponsor a Conference on the Peaceful Uses of Atomic Energy. The first of four such conferences was ultimately held in Geneva, Switzerland, in August of 1955. It was the largest scientific meeting in the world held up to that time, with over 2500 participants in attendance; more than 1000 technical papers were presented. For many Soviet scientists, it was their first opportunity to attend a scientific meeting outside the Soviet Union and to meet their colleagues from the West. ${ }^{4}$

Although no papers were presented at the Geneva Conference on the peaceful uses of nuclear explosions, the general enthusiasm for the integration of peaceful uses of nuclear energy into the fabric of society and the declassification of a broad spectrum of information about the attributes and effects of nuclear fission processes gave rise to an increasing interest in such ideas, particularly within the nuclear weapons community.

Fired by this enthusiasm, in the Spring of 1956, a French scientist named Camille Rougeron wrote a monograph conjuring up images of a wide variety of applications for such explosionsbuilding dams, changing the course of rivers, melting glaciers, breaking up ice jams, changing the climate, constructing underground power plants driven by the heat of thermonuclear explosions, and breaking rock for mining. 5 Rougeron's "dreams" added little in the way of quantitative analysis of such applications, but they did serve to raise the expectations of the general public for some peaceful benefit from the nuclear tests being fired in the Pacific and at the Nevada Test Site.

At about the same time, the Soviet engineer G. I. Pokrovskiy again wrote of his vision of using compact, powerful, low-cost nuclear explosives for removing overburden from valuable ore deposits or excavating canals:

"With the data now available, we can say that radioactive contamination in a nuclear explosion should not be considered an insurmountable obstacle to the use of such explosives in mining and construction. On the basis of the many advantages of nuclear explosions, we conclude that the time is ripe to begin actual experiments in this field." 6

4 Bertrand Goldschmidt, The Atomic Complex, American Nuclear Society, 1982, pp. 257-62.

5 Camille Rougeron, Les Applications de L'Explosion Thermonucléaire, Editions Berger-Levrault, Paris, 1956.

6 G. I. Pokrovskiy, "On the Use of Nuclear Explosives for Industrial Purposes," Gornyi Zhurnal, Vol. 1, pp. 29-32, 1956; also translation AEC-tr-4005. 


\section{The U.S. Plowshare Program}

In spite of Pokrovskiy's enthusiasm, little of substance was done over the next ten years in the Soviet Union to further explore his vision. In the U.S., however, the AEC formally established a program for nonmilitary uses of nuclear explosions in the summer of 1957. Named Project Plowshare, the emphasis in the first year was placed on studies aimed at further fleshing out the physics and engineering aspects of using underground nuclear explosions for power generation, on beginning nuclear design work on very low fission explosives especially designed for nuclear excavation, and on finding a suitable site for a near-term demonstration of this new technology.

In the Fall of 1957, the AEC carried out the world's first underground nuclear explosion, the Rainier event, a 1.7-kt test emplaced in a tunnel $274 \mathrm{~m}$ below a mesa at the Nevada Test Site (NTS). Although it was a weapons test, the purpose was primarily to document the effects of an underground nuclear explosion. Results from the Rainier test gave the Plowshare project a tremendous boost of enthusiasm and confidence that a variety of peaceful uses for nuclear explosions were possible and could be implemented safely. Before Rainier, all the ideas for peaceful uses were based on theoretical conjecture about the interaction of nuclear explosions with their surroundings. Now the scientists had actually fired an underground explosion, and everything happened about as expected. Thus, Rainier validated many of the Plowshare concepts that had been only sketchy ideas in scientists' minds and gave new confidence that these ideas would work.

In an angry press conference following the presentation of results by Gerry Johnson at the Second International Conference on the Peaceful Uses of Atomic Energy in Geneva in September 1958, Vasiliy Emelyanov, the Chief Soviet Delegate to the Conference, attacked the U.S. Plowshare Program as a subterfuge for continued nuclear weapons testing and scoffed at Plowshare's potential. He disavowed past statements by Soviet scientists, engineers, and politicians expressing interest in such applications and condemned such explosions "as a 'cover' to evade suspension of bomb tests" which "do not reach practical ends, but only political ends."7

Undeterred by Emelyanov's negative comments, the U.S. proceeded with development of the Plowshare Program. The first field experiment sponsored by the Plowshare Program was Project Gnome in 1961, a 3.1-kt explosion at a depth of $367 \mathrm{~m}$ in a bedded salt formation near Carlsbad, New Mexico. The general purpose was to study the effects of a nuclear explosion in salt, a unique medium that is able to sustain extremely large cavities without collapse, with a view to the use of such cavities for a variety of peaceful purposes. At that time, the possible use of such cavities for decoupling the seismic signal from clandestine nuclear weapons tests was also a controversial arms control issue in the test ban negotiations that were on-going in Geneva. The U.S. invited observers from all the U.N. countries to view the Gnome explosion, but the Soviet Union, consistent with their Geneva position, refused to participate. The Gnome explosion was a technical success, providing much data on scientific experiments and the effects of nuclear

7 Murray Marder, "Reds Attack Peaceful U.S. Atom Blasts," Washington Post, Sept. 4, 1958, p. 1. 
explosions in salt. It also resulted in a public relations disaster when a leak developed in the tunnel stemming, and a cloud of radioactive gases escaped shortly after the explosion. 8

Over the next 15 years, the U.S. Plowshare Program studied a variety of possible applications for peaceful nuclear explosions. Table 1 provides a list of the field experiments sponsored by the U.S. Plowshare Program. In the early years, primary emphasis was placed on the development of technologies for nuclear excavation, the application that appeared most economically attractive and technically straightforward. Following an abortive plan to excavate a demonstration harbor in northern Alaska that was abandoned in 1962, almost all excavation research was directed at the technical challenges of using nuclear explosions to excavate a new sea-level canal through the Central American Isthmus to replace the Panama Canal. This effort was in direct support of the Atlantic-Pacific Interoceanic Canal Study Commission (APICSC), appointed by President Lyndon Johnson in 1965, and continued until the Commission delivered its final report in December, 1970.

As part of this effort, Plowshare carried out six nuclear cratering experiments between 1961 and 1968 with yields ranging from 0.1 to $100 \mathrm{kt}$. All were conducted at the NTS. In an effort to ameliorate the primary hazard from nuclear excavation-the radioactivity released to the atmosphere - a major part of this program was the development of special ultralow-fission nuclear explosives designed for excavation applications. This special excavation explosive development program required nine tests at NTS from 1963 to 1970 and resulted in an explosive design with various yields with a fission yield so low that each explosive would release as little as 20 tons of fission products to the atmosphere when used in a cratering application. With the conclusion of the APICSC study and the rising public sensitivity to environmental contamination, the nuclear excavation portion of the U.S. Plowshare Program was phased out in the early 1970s.

Starting with the Gnome experiment in 1961, the Plowshare Program provided continued support for scientific experiments, primarily as additions to weapons tests, utilizing the extremely high fluxes of neutrons available within and near nuclear explosions to conduct experiments impossible with other neutron sources. In the early 1960s, a major program effort was undertaken to look at the possibility of using these high neutron fluxes to produce heavy transplutonic elements well beyond the end of the Periodic Table. The ultimate goal was the use of multiple neutron captures to reach the predicted "island of stability" at element 114. Between 1962 and 1969, Plowshare supported the design and fielding of five dedicated experiments and "add-ons" to some 10 weapons tests at NTS in a futile attempt to reach this elusive goal.

Among the industrial applications utilizing a completely contained explosion, the most intense studies were directed at the stimulation of gas production from low-permeability gas reservoirs,

8 D. Rawson, C. Boardman, and N. Jaffe-Chazan, The Environment Created by a Nuclear Explosion in Salt, PNE-107F, 1965; D. Rawson, Review and Summary of Some Project Gnome Results, AGU 44, pp. 129-35, 1963; M. Nathans, Isotope Program - Project Gnome, PNE-102F, Jan. 1965. 
the recovery of oil from the vast oil shale deposits in Colorado, the breakage of copper ore preparatory to in-situ leaching, and the creation of cavities for the storage of oil.

Only gas stimulation found sufficient industrial support to proceed to actual field experiments. ${ }^{9}$ From 1967 to 1973 , three joint industry-government experiments were carried out in very low permeability gas fields (See Table 1). In all cases, the explosions were carried out without incident, and significant increases were realized in the production of gas over that experienced from nearby conventional wells. ${ }^{10}$

The most significant radiological concern was the incorporation of tritium produced by the nuclear explosive into the gas produced from the stimulated region. To reduce emplacement costs and tritium levels to the lowest possible levels, the Plowshare Program developed a special nuclear explosive less than $200 \mathrm{~mm}$ (7.8 in.) in diameter that produced an extremely small amount of tritium $(<0.2 \mathrm{~g})$, primarily from the medium surrounding the explosive. Three of these special explosives were used in the same hole for the Rio Blanco event, one above the other spaced about $130 \mathrm{~m}$ apart.

Although projected public radiation exposures from commercial use of stimulated gas had been reduced to less than $1 \%$ of background, 11 it became clear in the early 1970 s that public acceptance within the U.S. of any product containing radioactivity, no matter how minimal, was difficult if not impossible. In addition, the economic viability of nuclear gas stimulation would require the stimulation of hundreds of wells over several decades, a prospect that proved daunting to potential industrial sponsors in light of growing public concerns about environmental quality. Following completion of the post-shot gas-production testing of Rio Blanco in December, 1974, the gas stimulation program, together with the studies of other potential Plowshare applications, was rapidly phased down, and the U.S. Plowshare Program was terminated in 1977.

9 In the mid-1960s, the Johnson administration established a policy that $50 \%$ of the field costs of any Plowshare industrial experiment must be paid by an appropriate industrial sponsor. In 1967, following the Gasbuggy experiment, this policy was changed to $90 \%$, which significantly discouraged any further industrial interest in participating in Plowshare experiments.

10 F. Holzer, GASBUGGY Experiment, UCRL-71624, Mar. 1969; D. Rawson, et al., Postshot Geologic Investigations-Project GASBUGGY, UCRL-71354, September 1968; C. Smith, Jr., Project GASBUGGY Gas Quality Analysis and Evaluation of Radiochemical and Chemical Analytical Results, UCRL-50635, Rev. 1, Nov. 1969; L. Aamodt, "RULISON; Underground Engineering Explosive and Emplacement Considerations," IAEA-PL-429/3(I), IAEA Peaceful Nuclear Explosions II, Jan. 1971; C. Smith, Gas Analysis Results for Project RULISON Production Testing Samples, UCRL-51153, Nov. 1971; W. Woodruff, and R. Guido, "Project RIO BLANCO Part I: Nuclear Operations and Chimney Reentry," IAEA-TC-1-4/4, IAEA Peaceful Nuclear Explosions IV, Jan. 1975; J. Toman, "Project RIO BLANCO Part II: Production Test Data \& Preliminary Analysis of Top Chimney/Cavity," IAEA-TC-1-4/5, IAEA Peaceful Nuclear Explosions IV, Jan. 1975.

11 H. Tewes, Survey of Gas Quality Results from Three Gas-Well Stimulation Experiments by Nuclear Explosions, UCRL-52656, Jan. 1979. 
Table 1. Data on U.S. Peaceful Nuclear Explosions.

\begin{tabular}{|c|c|c|c|c|c|}
\hline $\begin{array}{c}\text { Name or } \\
\text { designator }\end{array}$ & Date & $\begin{array}{c}\text { Yield } \\
(\mathrm{kt})\end{array}$ & $\begin{array}{c}\text { Depth of } \\
\text { burial }(\mathrm{m})\end{array}$ & Geology & Purpose \\
\hline
\end{tabular}

I. Development of Nuclear Excavation Technologya

\begin{tabular}{|l|l|c|c|l|l|}
\hline Sedan & $06 / 07 / 62$ & 104 & 193.6 & Alluvium & $\begin{array}{l}\text { Nuclear cratering and scaling laws to } \\
\text { 100-kt level. }\end{array}$ \\
\hline Sulky & $12 / 18 / 64$ & 0.09 & 27.1 & Granite & $\begin{array}{l}\text { Cratering mechanics at a deep scaled } \\
\text { depth-of-burial. }\end{array}$ \\
\hline Palanquin & $04 / 14 / 65$ & 4.3 & 85.7 & Rhyolite & $\begin{array}{l}\text { Cratering mechanics at a deep scaled } \\
\text { depth-of-burial in rhyolite. }\end{array}$ \\
\hline Cabriolet & $26 / 01 / 68$ & 2.2 & 51.8 & Rhyolite & $\begin{array}{l}\text { Nuclear cratering at optimum depth in } \\
\text { hard, dry rock. }\end{array}$ \\
\hline Buggyb & $12 / 03 / 68$ & 5.5 & 41.2 & Basalt & $\begin{array}{l}\text { Nuclear row-charge cratering in hard, dry } \\
\text { rock. }\end{array}$ \\
\hline Schooner & $12 / 08 / 68$ & 30 & 111.3 & $\begin{array}{l}\text { Bedded } \\
\text { Tuff }\end{array}$ & $\begin{array}{l}\text { Nuclear cratering explosion with a } \\
\text { moderate yield in wet rock. }\end{array}$ \\
\hline
\end{tabular}

\section{Contained Experiments}

\begin{tabular}{|l|l|l|l|l|l|}
\hline Gnome & $10 / 12 / 61$ & 3.0 & 360.9 & $\begin{array}{l}\text { Bedded } \\
\text { Salt }\end{array}$ & $\begin{array}{l}\text { Explosion effects in a salt medium. } \\
\text { Recoverability of isotopes from salt. } \\
\text { Scientific experiments with neutrons from } \\
\text { a nuclear explosion. } \\
\text { Recoverability of heat from a nuclear } \\
\text { explosion in salt. }\end{array}$ \\
\hline Marvel & $09 / 21 / 67$ & 2.2 & 175.9 & Alluvium & $\begin{array}{l}\text { Hydrodynamic flow of energy from a } \\
\text { nuclear explosion down a 1 m diameter } \\
\text { pipe. }\end{array}$ \\
\hline Gasbuggy & $12 / 10 / 67$ & 29.0 & 1292.4 & Shale & Nuclear gas stimulation. \\
\hline Rulison & $10 / 09 / 69$ & 40.0 & 2568.1 & $\begin{array}{l}\text { Shale/- } \\
\text { Sandstone }\end{array}$ & \begin{tabular}{l} 
Nuclear gas stimulation. \\
\hline Rio Blanco c
\end{tabular} \\
\hline $05 / 17 / 73$ & 99 & 1898.9 & $\begin{array}{l}\text { Shale/- } \\
\text { Sandstone }\end{array}$ & $\begin{array}{l}\text { Nuclear stimulation of a thick gas-bearing } \\
\text { formation with multiple nuclear } \\
\text { explosions. }\end{array}$ \\
\hline
\end{tabular}

a This list does not include the 0.5-kt Dannyboy nuclear cratering experiment in basalt on May 3, 1962, which was sponsored by the U.S. Department of Defense.

b Buggy consisted of five 1.1-kt explosives spaced $45.7 \mathrm{~m}$ apart in an east-west line.

c Rio Blanco consisted of three 33-kt explosives spaced about $130 \mathrm{~m}$ apart in a vertical line at depths of 1780.0, 1898.9, and $2039.1 \mathrm{~m}$ below the surface. The indicated depth is the depth of the middle explosive. 
In summary, during its 20-year life, the U.S. Plowshare Program carried out ten field experiments, five nuclear cratering events, and five contained explosions. Only four Plowshare events were conducted off the Nevada Test Site, one to better understand the effects of a nuclear explosion in salt and three for nuclear gas stimulation.

In addition to these experiments, the program also fully funded 16 device development tests at NTS. Five of these tests, together with eight add-ons to weapons tests, were in pursuit of the goal of developing super-heavy transplutonic elements. Nine were for the purpose of developing an ultralow-fission thermonuclear explosive for use in nuclear excavation projects, and one each were for the development of special emplacement techniques and for a small-diameter, ultralowtritium-producing explosive for hydrocarbon applications such as Rio Blanco. 


\section{The Soviet Program for the Use of Nuclear Explosions in the National Economy}

\section{A. An Historical Perspective}

The Soviet Union did not immediately follow the U.S. lead in 1958 in establishing a program to investigate the peaceful uses of nuclear explosions. Presumably, their political position in support of a comprehensive nuclear test ban, which would have banned or strongly discouraged such explosions, forestalled any efforts to establish such a program until the mid-1960s.

At some point during this time frame, the Soviet Union formally established "Program No. 7-Nuclear Explosions for the National Economy." Alexander D. Zakharenkov, a chief weapons designer at the Chelyabinsk-70 nuclear weapons laboratory was named to head the program, and Oleg L. Kedrovskiy was to be the chief scientist. Initially, the Soviet program was focused on two applications, nuclear excavation and oil stimulation, as the U.S. Program had been. However, interest in other applications quickly developed, and within 5 years the Soviet program was actively exploring six or seven applications involving participation by some 10 different Ministries. ${ }^{12}$

One of the first steps in developing such a program was initiated by Efrim P. Slavskiy, former Minister of the Medium Machine Building Ministry (the ministry responsible for the entire Soviet nuclear weapons program). ${ }^{13} \mathrm{He}$ was undoubtedly aware of the activities of the U.S. Plowshare program and was reported to be an avid supporter of using nuclear explosions for industrial purposes. On his directive on January 15, 1965, his Ministry sponsored a large-yield (140-kt) cratering explosion carried out at a depth of $178 \mathrm{~m}$ on the edge of the Semipalatinsk Test Site (STS) in northern Kazakhstan, which formed a large lake. Minister Slavskiy was reported to have been the first person to have taken a swim in the crater lake. ${ }^{14}$

Later in 1965, in cooperation with the Ministry of the Oil Industry, Program No. 7 began field experiments looking at the possibility of using nuclear explosions to increase oil production as well as planning experiments in salt to produce cavities. The nuclear weapons laboratory at Arzamas-16 (All-Soviet Institute of Experimental Physics-VNIIEF) near Gorky initially played the major role in Program No. 7, adapting military explosions to peaceful applications. The laboratory at Chelyabinsk-70 (All-Soviet Institute of Technical Physics-VNIITF) soon became involved and, over the years, became the most active participant in the program, particularly in

12 Yu. V. Dubasov, et al., "Nuclear Explosion Technologies: Features of the Conduct of Nuclear Explosions for Peaceful Purposes," Bulletin of the Center for Public Information on Atomic Energy, 1/94, pp. 30-35, 1994, Moscow.

13 Nuclear Explosions in the USSR - Publication 4-Peaceful Uses of Nuclear Explosions, Ed. V. N. Mikhailov, p. 4, VNIPIpromtekhnologiy and Khlopina Radium Institute, Moscow, 1994.

14 Personal communication, Roland Timerbaev, formerly in the Soviet Foreign Ministry. 
the design of special nuclear explosives for particular applications. ${ }^{15}$ Models of the special nuclear explosives can be seen in the Chelyabinsk-70 Nuclear Weapons Museum in Snizhinsk.

In November of 1965, a conference was held in the Soviet Union to consider possible industrial and scientific uses for nuclear explosions. The meeting included the leading scientists and weapons designers in the Soviet nuclear weapons program, including Andrei Sakharov. The scientists evinced great interest in such a program, including the development of special explosives to facilitate the fielding of nuclear explosives in unique industrial situations and to reduce the radioactivity produced by such explosions. The ideas discussed ranged from scientific experiments and industrial applications utilizing the unique physical and electromagnetic properties of nuclear explosions to control asteroids and power rockets in deep space. ${ }^{16}$

In the middle of 1966, a crisis in the gas industry suddenly offered an opportunity for a new application for peaceful nuclear explosions, the extinguishing of runaway gas wells. Successfully closing several such wells in 1966 and 1967 gave growing confidence to the leaders of the program, and they began to think about a broad spectrum of new applications.

In the Spring of 1969, the Soviet Union approached the U.S. with a proposal to engage in a series of bilateral discussions on peaceful nuclear explosions. The first of a series of four such meetings was held in Vienna, Austria, on April 14-16, 1969. Subsequent meetings were held in Moscow (February 12-17, 1970), Washington (July 12-23, 1971), and Vienna (January 15-17, 1975). ${ }^{17}$ In the course of these meetings with scientists from the U.S. Plowshare Program, Soviet scientists cautiously unveiled some of the technical details of the first few PNE experiments as well as general plans for several applications they were developing. In the early 1970s, the Soviet Union also provided information on the scope and technical results of some of their program activities through a series of Panel Meetings on Peaceful Nuclear Explosions at the International Atomic Energy Agency (IAEA) in Vienna, Austria. ${ }^{18}$

A few articles appeared in the Russian press in the early seventies describing the general purposes of the Soviet PNE Program, but no specifics on locations or results were given. Several articles were written in the U.S. in the mid-seventies and early eighties describing what was

15 Personal communication with Boris V. Litvinov, Chief Weapons Designer at the Chelyabinsk Nuclear Weapons Laboratory, May 1994.

16 Mikhailov, Nuclear Explosions in the USSR, p. 4 (see footnote 13 for complete reference).

17 A. Holzer, and G. Werth, Summary of the Technical Aspects of the U.S.-U.S.S.R. Talks of April 14-16, 1969 at Vienna, Austria, UCID-15499, July 1, 1969; G. Werth, Highlights of the Second Stage of Soviet-American Technical Talks on the Use of Peaceful Nuclear Explosions for Peaceful Purposes, UCID-15606, Feb. 24, 1970; M. D. Nordyke, Technical Summary of the Third Stage of the Soviet-American Talks on the Peaceful Uses of Nuclear Explosions, UCRL-51113, Aug. 23, 1971.

18 Peaceful Nuclear Explosions, Phenomenology and Status Report, 1970, proceeding of a panel held at IAEA, March 2-6, 1970; Peaceful Nuclear Explosions II, Their Practical Applications, proceeding of a panel held at IAEA, January 18-22, 1971; Peaceful Nuclear Explosions III, Applications, Characteristics and Effects, proceeding of a panel held at IAEA, November 27-December 1, 1972; Peaceful Nuclear Explosions IV, proceeding of a panel held at IAEA, January 20-24, 1975; and Peaceful Nuclear Explosions V, proceeding of a panel held at IAEA, November, 22-24, 1976. 
known at that time about the program from these meetings and from seismic signals coming out of the Soviet Union. 19,20,21 However, since the mid-seventies, little technical information about the program was made available until the advent of "glasnost" in the late 1980s. Since that time, there have been news reports and commentaries by environmental groups about the Soviet PNE Program in the newly "opened" press, but there has been little authoritative information. However, a recently published book by the Khlopina Radium Institute 22 and several articles in the Information Bulletin of Center for Public Information on Atomic Energy, published by the Russian Atomic Energy Ministry, have provided a good look into the overall scope, technical details, and industrial results of this program.

\section{B. Overview of the Soviet PNE Program}

Since its inception in 1965, the Soviet PNE program carried out 122 explosions involving approximately 128 explosives to study some 13 potential uses. ${ }^{23}$ Five applications were put into industrial use (e.g., cavities for storing gas condensate and deep seismic sounding of the Earth's mantle). Table 2 summarizes these explosions in terms of their general purpose. In all, PNE explosions were carried out at 115 sites located throughout the former Soviet Union. Two sites were re-entered for subsequent explosions, utilizing the cavities produced in salt by earlier explosions. Tests carried out at the test sites for the development of special nuclear explosives or emplacement techniques for PNEs are not included in the above totals.

The Soviet program came to an end with the adoption by the Soviet Union of a unilateral moratorium on the testing of nuclear weapons at Soviet Test Sites in 1989. Although it primarily was designed to support the Soviet Union's call for a world-wide ban on all nuclear weapons tests, the Soviet Union apparently also applied the moratorium to nuclear explosions for peaceful purposes.

19 M. D. Nordyke, "A Review of Soviet Data on the Peaceful Uses of Nuclear Explosions," Annals of Nuclear Energy, Vol. 2, pp. 657-673, 1975.

20 I. Y. Borg, "Peaceful Nuclear Explosions in Soviet Gas Condensate Fields," LLNL Energy and Technology Review, May, 1983, UCRL-52000-83-5, pp. 30-38.

21 J. F. Scheimer, and I. Y. Borg, "Deep Seismic Sounding with Nuclear Explosives in the Soviet Union," Science, Vol. 226, No. 4676, Nov. 16, 1984.

22 Mikhailov, Nuclear Explosions in the USSR, p. 4 (see footnote 13).

23 These totals do not include a seismic event at 0900 GMT on July 19, 1982 at seismic coordinates $62.532 \mathrm{~N}$ and 47.813 E about $200 \mathrm{~km} \mathrm{NNE}$ of the city of Kotlas with a seismic magnitude of 4.4. This event is not listed as a PNE by documents from the Ministry of Atomic Energy, but it is included in PNE lists compiled by Sultanov et al. under the name "Komipetroleum" (See D. D. Sultanov, et al., Investigation of Seismic Efficiency of Soviet Peaceful Nuclear Explosions Conducted Under Various Geological Conditions, Russian Academy of Sciences, Institute for Dynamics of the Geosphere, July 28, 1993.) 
Table 2. Summary of the applications studied by the Soviet Union's PNE Program.

\begin{tabular}{|l|r|l|}
\hline \multicolumn{1}{|c|}{ Purpose } & Number & \multicolumn{1}{|c|}{ Sponsoring Ministry } \\
\hline Cratering Applications & 5 & Medium Machine Building \\
Water Reservoir Construction & 3 & Medium Machine Building \\
Kama-Pechora Canal Project & 2 & MMB and Non-Ferrous Metals Ind. \\
Dam Construction & $\mathbf{1 0}$ & \\
\hline Total Cratering Applications & & \\
\hline Contained Applications & 12 & Oil/Gas Industry \\
Oil Stimulation & 3 & Medium Machine Building \\
Cavity Technology Development & 5 & Gas Industry \\
Elimination of Gas Well Fires & 25 & Gas Industry \\
Cavities for Underground Storage & 9 & Geology/Gas Industry . \\
Gas Stimulation & 39 & Geology \\
Deep Seismic Sounding & 2 & Mineral Fertilizer . \\
Ore Breakage & 2 & Oil Refining and Chemical \\
Toxic Oil Field Waste Disposal & 13 & Medium Machine Building \\
Heavy Element Production & 1 & Medium Machine Building \\
Decoupling Experiment & 1 & Coal Industry \\
Prevention of Coal Gas Explosion & $\mathbf{1 1 2}$ & \\
\hline Total Contained Applications & $\mathbf{1 2 2}$ & \\
\hline Total Peaceful Nuclear Explosions & & \\
\hline
\end{tabular}

Data on the 122 explosions of the Soviet "Program for the Utilization of Nuclear Explosions in the National Economy" are presented in Appendix A. The numbers of the explosions are given in chronological order, along with their names, dates and times, seismic locations, magnitudes, and general geographic locations. Actual times and locations are also provided, when available. Figure 1 is a map of the former Soviet Union showing the geographic locations of the 122 PNE sites. Appendix B lists the 122 explosions grouped chronologically within some 13 different applications. The information provided includes the yield, depth of burial, geological medium surrounding the emplacement point, general comments about the explosions, and the sponsoring ministries. The remainder of this report discusses the activities for each application from an historical perspective.

\section{The Nuclear Excavation Program}

\section{Water Reservoir Construction}

One of the first applications considered for peaceful nuclear explosions in the Soviet Union was the development of water reservoirs to improve agriculture in such vast arid areas of Siberia as the Semipalatinsk, Kustanay, Tselinograd, Pavlodar, and Gur'ev regions. Many rivers and streams in these regions flow during times of high rainfall but are dry the remainder of the year. 


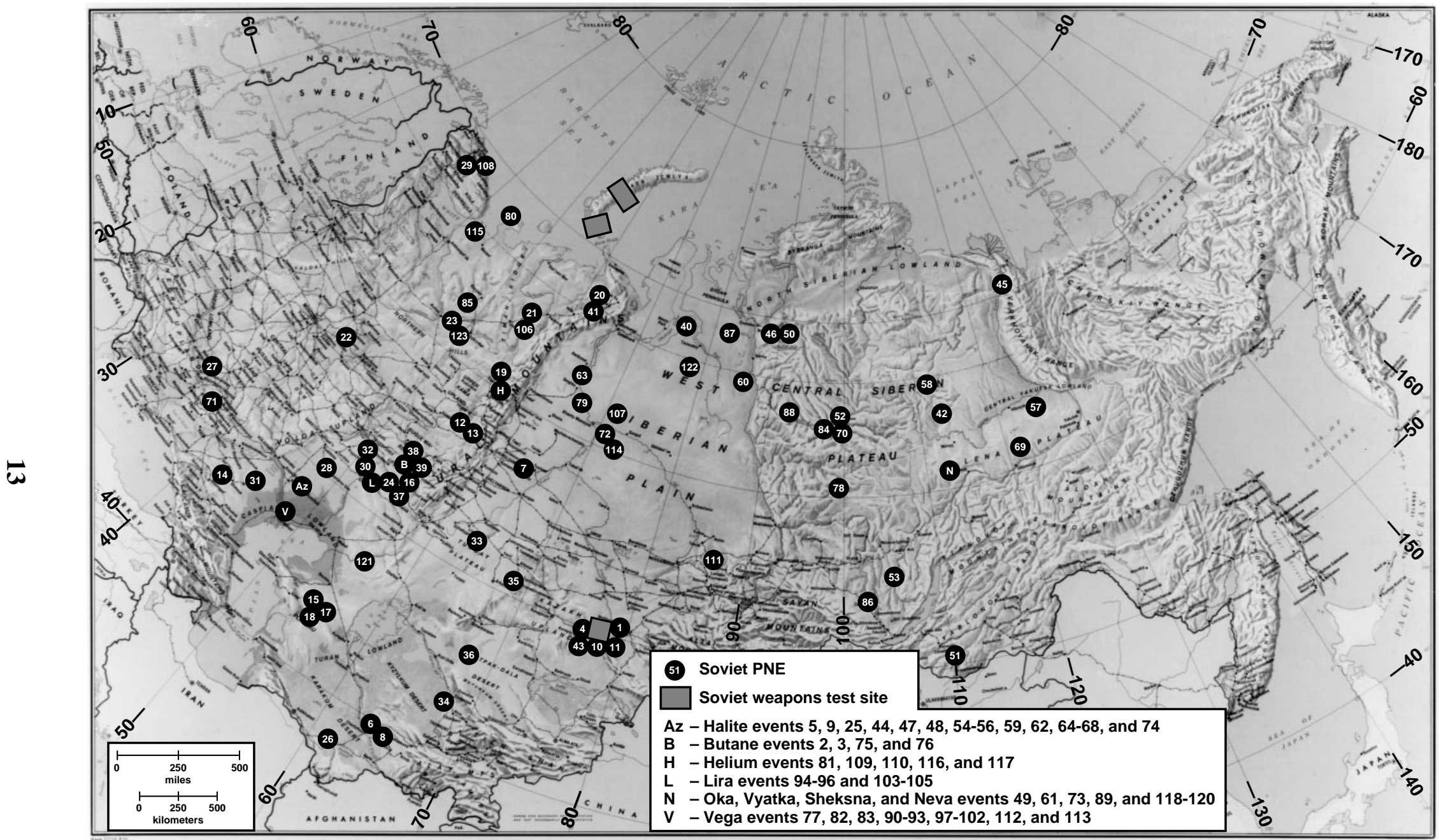

Figure 1. Map of the Former Soviet Union showing the geographic location of the 122 PNE sites. Sites of multiple explosions have been indicated by a letter indicated in legend. 
The suggested application envisaged creating nuclear craters within or adjacent to these intermittent streams with volumes of 3 to 5 million cubic meters of storage capability.

Chagan. The first experiment in the Soviet PNE Program on January 15, 1965, was directed at the general goal of obtaining data on the use of nuclear explosives for cratering purposes as well as the specific purpose of demonstrating the usefulness of nuclear explosives in creating water storage reservoirs (see Section A.1 of Appendix B). This experiment utilized a 140-kt explosive placed 178 m deep in Hole 1004 on the edge of the Semipalatinsk Test Site (STS) in Kazakhstan. The site was chosen to be in the dry bed of the Chagan River so that the crater lip would form a dam in the river during its period of high flow in the spring.

The crater formed by the Chagan explosion had a diameter of $408 \mathrm{~m}$ and a depth of $100 \mathrm{~m}$, remarkably similar to the Sedan crater at NTS. A major lake $\left(10,000,000 \mathrm{~m}^{3}\right)$ was quickly formed behind the 20-35 m high upraised lip. Shortly after the explosion, earthmoving equipment was used to cut a channel through the lip so that water from the river could enter the crater. Spring melt soon filled the crater with 6.4 million $\mathrm{m}^{3}$ of water, and the reservoir behind the crater was filled with 10 million $\mathrm{m}^{3}$ of water. Subsidence of the crater slopes subsequently reduced the crater storage capacity by about $25 \%$. A few years later, a water-control structure was built on the left bank of the river to control water levels in the reservoirs. Both reservoirs exist today in substantially the same form and are still used to provide water for cattle in the area (see Fig. 2).

The crater dimensions for the Chagan crater compared very well with the 100-kt Sedan crater at NTS, even though the media were quite different and the scaled depth-of-burial of Chagan was almost 20\% less than that at Sedan. Whereas the medium at Sedan was dry desert alluvium with a moisture content below $1 \%$, the medium at Chagan was saturated siltstone with a $12 \%$ water content.

The nuclear explosive used for the Chagan test was reported to be a low-fission design, which had a pure thermonuclear secondary driven by a fission primary with a yield of about 5-7 kt. ${ }^{24}$ Approximately $20 \%$ of the radioactive products of the explosion escaped into the atmosphere, resulting in dose levels on the lip of the crater of 20-30 R/hr several days after the explosion, most of which was from $\mathrm{Co}^{60}$ (5.26 year half-life). Today, the dose level on the lip is reported to be $\sim 2.6 \mathrm{mR} / \mathrm{hr}^{25}$ Beyond a restricted area 100-150 $\mathrm{m}$ from the lip, the dose rate is at background levels $(15-20 \mu \mathrm{R} / \mathrm{hr}) .{ }^{26}$ Radioactivity levels in the lake water in the crater are reported to be about 300 pCi/liter. ${ }^{27}$

24 The History of Soviet Nuclear Weapons, Draft Outline VNIIEF/VNIITF, Moscow, 19923; USSR Nuclear Weapons Tests and Peaceful Nuclear Explosives, 1949 Through 1990, RFCN-VNIIEF, Sarov, 15RN5-85165062-1, 1996.

25 Y. V. Dubasov, et al., "Underground Explosions of Nuclear Devices for Industrial Purposes on the Territory of the USSR in 1965-1988," Bulletin of the Center for Public Information on Atomic Energy, 1/94, pp. 1829, Moscow, 1994.

26 Mikhailov, Nuclear Explosions in the USSR, p. 67 (see footnote 13).

27 "IAEA Clears Semipalatinsk Area Conditionally for Living," Nucleonics Week, January 26, 1995, pp. 6-7. 


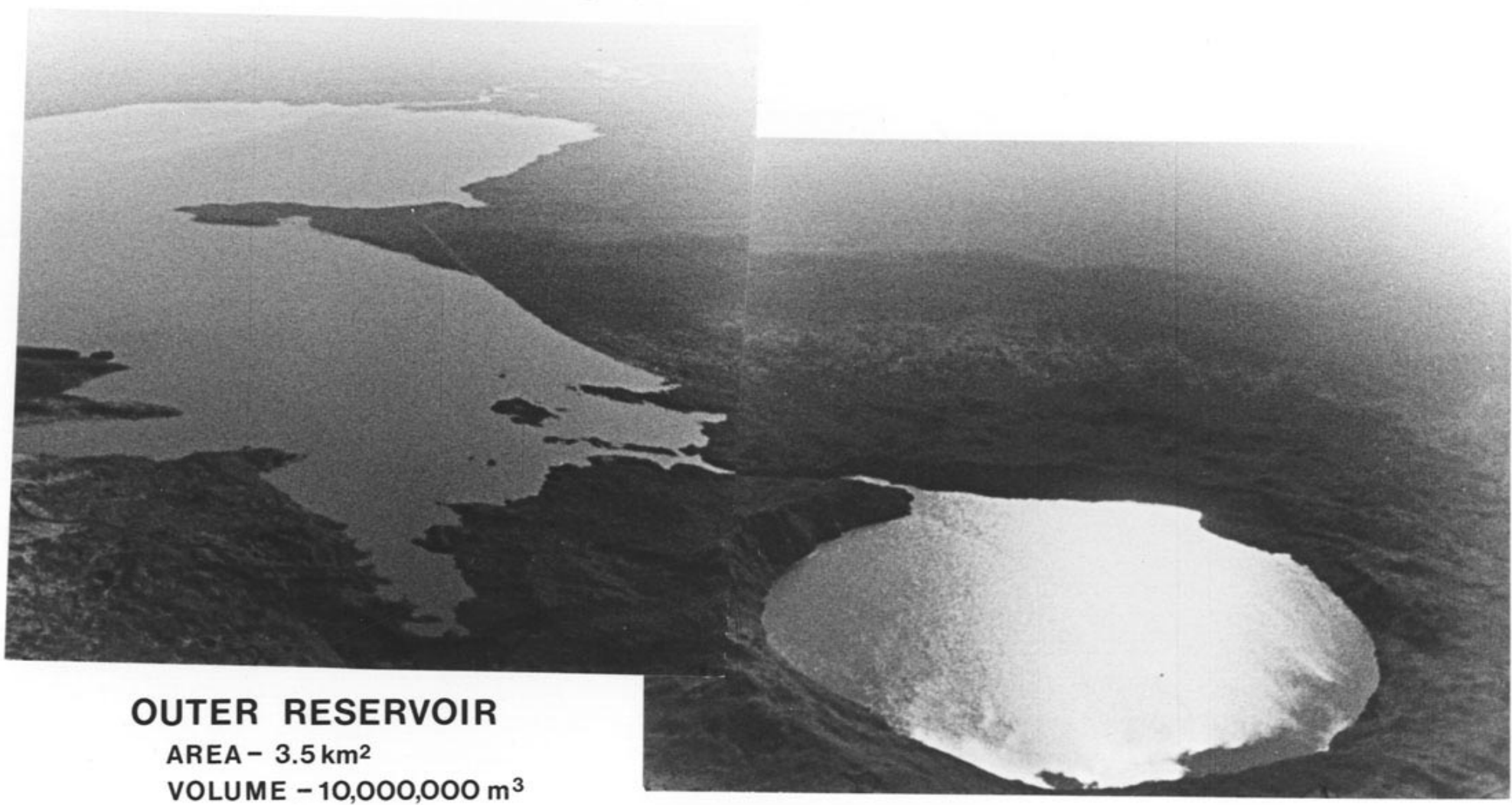

\section{INNER RESERVOIR \\ LIP HEIGHT - 20-35m LIP DIAMETER - $520 \mathrm{~m}$ AREA - $0.14 \mathrm{~km}^{2}$ VOLUME - 7,000,000 $\mathrm{m}^{3}$}

Figure 2. Photographic composite of "Chagan" Lake showing the "Inner Reservoir," formed by the Chagan crater, and the "Outer Reservoir", formed by the blockage of the Chagan River by the lip of the crater. The channel constructed through the lip into the crater shortly after the explosion is visible in the center of the photograph. The channel and control structure to bypass water around the dam is located to the left of the crater lip in the right side of the photograph. 
Radioactivity from the Chagan test was detected over Japan by both the U.S. and Japan in apparent violation of the 1963 Limited Test Ban Treaty (LTBT). The U.S. complained to the Soviet Union about the explosion, interpreting it as an accidental venting of a high-yield weapons test and asking for an explanation. The Soviets responded that the explosion "was carried out deep underground. The quantity of radioactive debris that leaked into the atmosphere was so insignificant that the possibility of its fallout outside the territorial limits of the Soviet Union should be excluded." After several subsequent interactions, the issue was closed without further explanation. 28

Soviet scientists attributed the venting of $20 \%$ of the radioactivity in the Chagan test to the fact that the scaled depth-of-burial of the charge, $42 \mathrm{~m} / \mathrm{kt}^{1 / 3.4}$, was somewhat less than optimum. The fact that the rock surrounding the explosion was water-saturated almost certainly contributed to the relatively high escape fraction.

Sary-Uzen'. Later that same year, on October 10, 1965, Soviet scientists decided to carry out a second nuclear cratering experiment at a scaled depth that was thought to be closer to optimum than the Chagan test. For this explosion, a 1.1-kt explosive was emplaced in Hole 1003 at a depth-of-burial of $48 \mathrm{~m}$ (scaled depth-of-burst $=46.7 \mathrm{~m} / \mathrm{kt}^{1 / 3.4}$ ) in the dry bed of the Sary-Uzen' stream on the western edge of the Semipalatinsk Test Site. At shot depth, the geologic medium was a weak siltstone rock, similar to sandstone. However, it was overlain by about $10 \mathrm{~m}$ of claylike material. The explosion produced a crater with an initial diameter of $107 \mathrm{~m}$ and depth of $31 \mathrm{~m}$.

The dimensions of the initial Sary-Uzen' crater compared favorably with U.S. experience in dry alluvium. However, within three months, the crater flooded with artesian water from the shallow water table, resulting in sluffing of the slopes of the crater, which reduced the depth of the crater to $20 \mathrm{~m}$ and increased the diameter to $124 \mathrm{~m}$. Soviet scientists had pre-emplaced a high-explosive line-charge under one area of the expected lip, and this was detonated several minutes after the nuclear explosion. This line-charge produced a "canal" through the crater lip to allow stream flow to enter the crater without any personnel re-entering the crater area.

For the Sary-Uzen' cratering explosion, only $3.5 \%$ of the radioactivity produced in the explosion escaped into the atmosphere. Five days after the test, the dose rate on the lip was 2$3 \mathrm{R} / \mathrm{hr}$. Today it is reported to be $50 \mu \mathrm{R} / \mathrm{hr}$. Beyond the lip area, dose rates are at background. ${ }^{29}$

Although the Soviets professed to see a widespread need in arid regions of the USSR for more than 50 water storage reservoirs with storage capacities in the range of 3-5 million $\mathrm{m}^{3}$, which would require cratering explosions of 20-50 kt, no further experimentation or application of the technologies demonstrated in Chagan and Sary-Uzen' were carried out. 
Holes 2-T, 1-T, and 6-T. Several years after the Chagan and Sary-Uzen' experiments, the Soviet PNE program carried out three additional experiments that they reported were directed at the development of water reservoirs in arid locales. For some years, Soviet scientists had noted the U.S. experience at NTS, where large-yield nuclear explosions in alluvial media resulted in large subsidence craters on the surface above the explosion with essentially no release of radioactive material.

Such craters result from the collapse of an explosion cavity and all the material lying above it, so that at the surface above, a large fraction of the volume of the cavity appears in the form of a conical subsidence. This can only occur when the medium above the cavity is of such a nature that it doesn't "bulk" 30 when it collapses into the explosion cavity. The deep alluvial deposits at NTS are ideally suited for the formation of subsidence craters. The resulting crater has no upraised lip, and the diameter and depth can vary greatly, even in the same media.

The Soviets believed such structures might be useful for water reservoirs. Because the geological media at their test sites at Semipalatinsk and Novaya Zemlya were all igneous or sedimentary rocks, they had not experienced this phenomenon. They decided to gain some direct experience at a remote site on the Mangyshlak Plateau mid-way between the Aral and the Caspian Seas where they had found a weak, high-porosity sedimentary formation at the appropriate depth.

Three experiments described as being for the purpose of studying the formation of subsidence craters were carried out, beginning in the Winter of 1969 (See Table 3). The first two explosions, in Holes 2-T and 6-T, at scaled depths of burial of 130 and $113 \mathrm{~m} / \mathrm{kt}^{1 / 3}$, respectively, produced subsidence craters with radii somewhat larger but not inconsistent with U.S. experience. The crater depths were significantly smaller than subsidence crater depths in U.S. experience. These differences could well be the result of differences in the physical properties of the media between the explosion and the ground surface. The lack of a crater for the explosion in Hole 1-T, whose scaled depth of burial was almost $50 \%$ greater than 6-T, is not surprising and also consistent with U.S. experience.

Even though these craters had volumes of more than $500,000 \mathrm{~m}^{3}$, there is no reported attempt to use them for water storage or any other use. There was also no further experimentation or application of nuclear excavation to the creation of water storage reservoirs. The explosions were completely contained without leakage, and radiation levels in the area are reported to be at background. The site is closed. ${ }^{31}$

30 "Bulking" refers to the increase in volume of a solid when it is broken up into small, randomly shaped pieces.

31 Dubasov, Underground Explosions, p. 25 (see footnote 25). 
Table 3. Subsidence Crater Explosions on the Mangyshlak Plateau.

\begin{tabular}{|c|c|c|c|c|c|c|}
\hline Name & Date & $\begin{array}{c}\text { Yield } \\
(\mathbf{k t})\end{array}$ & $\begin{array}{c}\text { Depth of } \\
\text { burst } \\
(\mathbf{m})\end{array}$ & $\begin{array}{c}\text { Scaled depth } \\
\text { of burst } \\
(\mathbf{m} / \mathbf{k t} \mathbf{3})\end{array}$ & $\begin{array}{c}\text { Diameter } \\
(\mathbf{m})\end{array}$ & $\begin{array}{c}\text { Depth } \\
(\mathbf{m})\end{array}$ \\
\hline $2-\mathrm{T}$ & $12-06-69$ & 31 & 407 & 130 & 300 & 13.8 \\
$6-\mathrm{T}$ & $12-12-70$ & 84 & 497 & 113 & 500 & 12.8 \\
$1-\mathrm{T}$ & $12-23-70$ & 75 & 740 & 175 & - & - \\
\hline
\end{tabular}

In recent years, there have been several unconfirmed newspaper reports that the actual purpose of these three explosions on the Mangyshlak Plateau was a search for a new test site capable of testing megaton-scale nuclear weapons. ${ }^{32,33}$ The history of Soviet weapons testing would appear to be consistent with such a scenario.

In the late 1960s and early 1970s, both the U.S. and the Soviet Union were developing megaton-scale warheads for the new generations of heavy missiles, and a need existed for a highyield test site. At STS, the relative proximity of the large city of Semipalatinsk limited the yields that could be fired without significant seismic damage to buildings in that city. At the Novaya Zemlya Test Site, at the north end of Southern Novaya Zemlya along the Matochkin Shar Strait, nuclear devices were emplaced in tunnels. Terrain and permafrost significantly limited the maximum yields that could be fired without venting to the atmosphere. If the Mangyshlak Plateau was indeed a candidate, the three tests carried out there would appear to be reasonable candidates to explore its suitability for high yields.

Presumably, the site proved unsuitable, perhaps because of the proximity $(230 \mathrm{~km})$ of the large city and breeder reactor facility at Shevchenko on the shore of the Caspian Sea. In 1972, a year and a half after the last explosion on the Mangyshlak Plateau, the Soviet military opened a new test site at the southern end the Novaya Zemlya at Chernaya Bay with a small weapons test, followed a year later with several high-yield tests, including a multi-megaton explosion on October 27, 1973. Over the next two years, they fired three more high-yield nuclear weapons tests at this site. The 150-kt limitation of the TTBT, which became effective in April of 1976, precluded the necessity for a high-yield site, and no further tests occurred at this new test site.

\section{Kama-Pechora Canal Project}

Soon after the first two excavation explosions in 1965, another project became the primary focus of the Soviet nuclear excavation program - the construction of a canal to divert water from the Arctic region into the Volga River basin and Caspian Sea. Stimulated by a steady decline in the level of the Caspian Sea over the preceding 35 years as a result of climatic anomalies and municipal and agricultural uses of water from the Volga-Kama River system, a number of water management agencies in the Soviet Union had proposed diversion of water from the Pechora

32 Oleg Stefashin, “Unknown New Test Site,” Izvestiya, 23 Jan. 1991, p. 2; from JPRS-TAC-91-004, p. 33.

33 Yuri Lushin, “A Big Secret 'For Peaceful Purposes,”' OGONEK, No. 2, Jan. 92, pp. 4-15. 
River in the Komi Republic, which flows northward into the Barent and Kara Seas, through a 112-km-long canal into the Kama and thence south to the Volga River and the Caspian Sea. ${ }^{34,35}$

Perhaps driven to compete with U.S. proposals to use nuclear excavation to construct a new sea-level canal to replace the Panama Canal, Soviet PNE program scientists proposed to use nuclear explosions to construct the central $65-\mathrm{km}$ of the Pechora-Kama canal where it passes though higher elevations. Their proposals envisaged the use of several hundred nuclear explosives, firing up to 20 at one time with aggregate yields of as much as $3 \mathrm{Mt}$. Preliminary cost estimates indicated that the use of nuclear excavation would reduce the cost of the canal by a factor of 2 to 3 compared to usual construction methods.

"Tel'kem-1" and "Tel'kem-2." As an initial step in considering the use of nuclear excavation for this project, Soviet scientists carried out a pair of cratering experiments in the Tel'kem area on the southeastern corner of the STS (see Section A.2, Appendix B). The first, "Tel'kem-1" on October 21, 1968, was a 0.24-kt explosion at optimum depth for cratering in a saturated quartzose sandstone (35 m). The second, "Tel'kem-2" on November 12, 1968, consisted of three 0.24-kt explosives in a row, $40 \mathrm{~m}$ apart, at the same depth-of-burst as "Tel'kem-1."

As expected, "Tel'kem-2" produced a linear crater $142 \mathrm{~m}$ long, 60-70 m wide, and $16 \mathrm{~m}$ deep, about 20 to $30 \%$ narrower and about $25 \%$ shallower than expected on the basis of "Tel'kem-1." However, when judged relative to the "Sary-Uzen" crater, "Tel'kem-2" has about the expected dimensions. The results were also quite consistent with the U.S. Buggy row-charge cratering explosion when consideration is given to the differences in the geological media.

Radiation levels on the lip are reported to be $30 \mu \mathrm{R} / \mathrm{hr}$, only slightly above regional background levels. Beyond the limits of throwout from the crater, the levels are at regional background. ${ }^{36}$

"Taiga." In the Fall of 1969, the Soviet Government Planning Agency, GOSPLAN, approved going forward with the Pechora-Kama Canal ${ }^{37}$, and planning within the Soviet PNE Program took on a greater urgency. One problem had been identified that concerned PNE scientists. The northern $30 \mathrm{~km}$ of the section of the canal being considered for nuclear excavation was described as sandstone, siltstone, and argillite rock, media somewhat similar to the cratering media at STS. However, the southern $35-\mathrm{km}$ portion was largely saturated alluvial deposits, which could present difficult slope stability problems. Because of concerns over the stability of the slopes of a nuclear canal in this portion of the canal, the Ministry of Reclamation and Water Resources sponsored a nuclear row-charge experiment code-named "Taiga" for the southern end of the

34 V. V. Kireev, "Group Excavation by Nuclear Explosions in Alluvial Media," IAEA-TC-1-4/14 in Peaceful Nuclear Explosions IV, IAEA panel, pp. 399-419, 1995.

35 P. P. Micklin, "Dimensions of the Caspian Sea Problem," Soviet Geography, Vol. XIII, No. 9, Nov. 1972, pp. 589-602.

36 Dubasov, Underground Explosions, p. 25 (see footnote 25).

37 A. Pankov, "The Pechora Will Flow into the Caspian," Vodnyy Transport, Dec. 4, 1969, p. 2. 
portion being considered for nuclear excavation. The site was about $100 \mathrm{~km}$ north of the city of Krasnovishersk in the Perm Oblast'. The alluvial deposits in this area varied in depth between 90 and $130 \mathrm{~m}$, being underlain by sandstone and argillites and marl. The water table was reported to be from 5 to $17 \mathrm{~m}$ deep.

Three explosives with yields of $15 \mathrm{kt}$ each were emplaced at depths of about $127 \mathrm{~m}$, roughly at the base of the alluvial deposits, to be fired simultaneously. The scaled depths of burial were about $57 \mathrm{~m} / \mathrm{kt}^{1 / 3.4}$, which placed them somewhat deeper than optimum. The spacing between the explosives was about $165 \mathrm{~m}$, a spacing expected to enhance crater width by about $10 \%$ compared to a single crater diameter.

The explosives used for the "Taiga" experiment were of a special design in which the fission yield had been significantly reduced over that used for the "Chagan" event in January 1965. The design used was tested in Hole 125 at the "Sary-Uzen" portion of the STS on November 4, 1970, ${ }^{38,39}$ several months before the "Taiga" event. Although specific details of the explosives used for "Taiga" have not been provided, MinAtom has reported that special nuclear explosives for excavation were developed in the 1970s in which the fission contribution was reduced to about $0.3 \mathrm{kt}$ with the remainder of the energy coming from thermonuclear reactions. ${ }^{40}$

The "Taiga" explosion was carried out on February 23, 1971, about $100 \mathrm{~km}$ north of the city of Krasnovishersk in the Perm Oblast'. It produced a row crater about $700 \mathrm{~m}$ long and $340 \mathrm{~m}$ wide, almost 50\% larger than expected. However, its depth was only about $10-15 \mathrm{~m}$. The final pan-shaped configuration was the result of extensive failure of the saturated alluvial slopes. Figure 3 is a sketch map of the crater and the surrounding lip and throwout area. The final crater slopes stabilized at an angle of about 8-10 degrees. ${ }^{41}$ Although Soviet scientists remained optimistic in interpreting the results of the experiment, by almost any measure, the results of "Taiga" indicated that nuclear excavation was probably not appropriate for the southern portion of the canal.

Even though the Soviets used a new, low-fission explosive for the "Taiga" experiment that produced up to an order-of-magnitude less fission product radioactivity than the one used for the "Chagan" experiment, it was detected outside the Soviet Union by several countries, including the U.S. and Sweden, who lodged protests regarding violation of the LTBT. On site, the dose rate on the crater lip at about 1 hour after the explosion was 50-200 R/hr. Eight days after the explosion, at distances up to $8 \mathrm{~km}$ downwind from the crater, the dose rates were $23-25 \mu \mathrm{R} / \mathrm{hr}$, only about twice natural background for the European part of Russia. Within the fallout pattern,

38 Mikhailov, Nuclear Explosions in the USSR, p. 23 (see footnote 13).

39 V. V. Gorin, et al., "Semipalatinsk Test Site: A Chronology of Underground Nuclear Explosions and Their Primary Radiation Effects (1961-1989)," Bulletin of the Center for Public Information on Atomic Energy, No. 9, pp. 21-32, Moscow, 1993.

40 History of Soviet Nuclear Weapons, p. 46 (see footnote 24).

41 Mikhailov, Nuclear Explosions in the USSR, p. 70 (see footnote 13). 


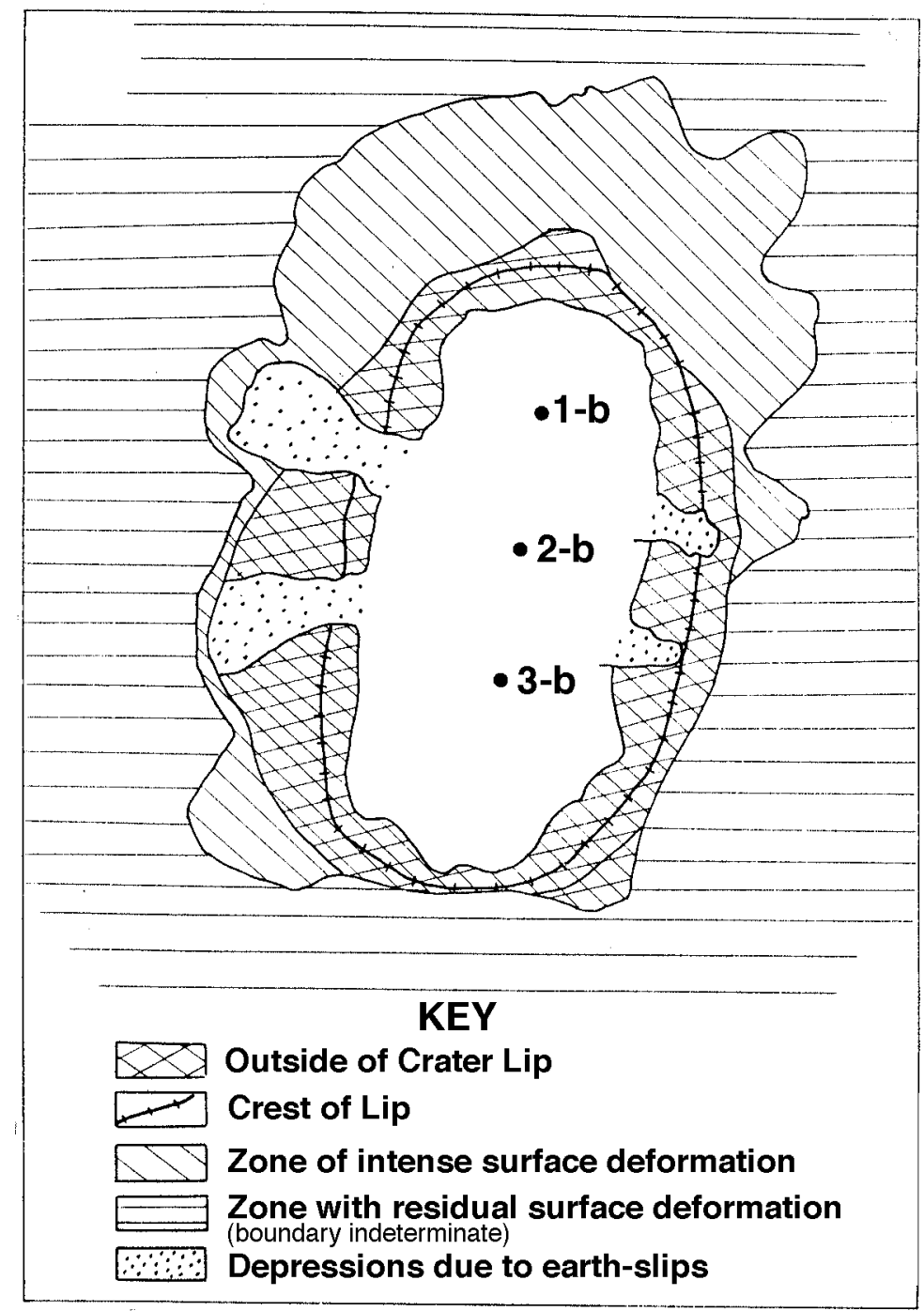

Figure 3. Sketch map of the "Taiga" Crater along the proposed alignment of the KamaPechora Canal showing the outline of the crater and areas where there was failure of the crater slopes (from Ref. 34).

the contour representing an accumulated dose of 0.5 Rem over the first year (about twice background) extended some 25 kilometers. ${ }^{42,} 43$

Today, the general dose rate on the lip is $40-200 \mu \mathrm{R} / \mathrm{hr}$ with isolated hot spots of up to $1 \mathrm{mR} / \mathrm{hr}$. On the surface of the water, the dose rate is about $50 \mu \mathrm{R} / \mathrm{hr}$. Radiation levels in the crater area are determined by the long-lived radionuclides ${ }^{60} \mathrm{Co},{ }^{137} \mathrm{Sr},{ }^{90} \mathrm{Sr}$, and tritium. In the lake, all the gamma-radiation emitters, ${ }^{90} \mathrm{Sr}$, and tritium are below standards for drinking water.

42 Ibid., p. 91.

43 V. V. Chelyukanov, et al., "On Radiation Conditions in the Perm Oblast," Bulletin of the Center for Public Information on Atomic Energy, No. 2, pp. 72-74, Moscow, 1993. 
A restricted area has been established within 2-300 meters of the crater, beyond which the radiation levels are reported to be at background levels and undetectable in vegetation. ${ }^{44,45}$

The disappointing technical results of the "Taiga" experiment, in and of themselves, did not appear to discourage Soviet interest in using nuclear excavation for this project. For some time, Soviet scientists continued to discuss the project in general, and the use of nuclear excavation in particular. For example, the results of the "Taiga" experiment were presented at the fourth IAEA meeting on PNEs in January, 1975, together with a restatement of plans to proceed with the project. 46

One of the principle motivations behind the Soviet interest in having U.S./Soviet PNE bilateral discussions in the early 1970s derived from their desire to jointly develop general health and safety guidelines for carrying out PNEs such as those for the Kama-Pechora Canal. They also wished to use this interaction to develop an "understanding" with the U.S. on how such largescale cratering projects could be rationalized to be in conformance with the LTBT limitation on radioactivity from nuclear explosions across national borders. Although, there were differences in the English and Russian text of the LTBT that were less restrictive in Russian, it was clear that a project of the magnitude of Kama-Pechora could not be done without some "understanding" or perhaps modification of the LTBT. ${ }^{47}$

Another indication of their continuing interest in the project was the Soviet insistence that the Peaceful Nuclear Explosions Treaty, which was negotiated in 1975-76 as a companion to the Threshold Test Ban Treaty limiting nuclear weapons tests to $150 \mathrm{kt}$, permitted aggregate yields for PNEs that were significantly greater than $150 \mathrm{kt} .{ }^{48}$ The Kama-Pechora Canal project was repeatedly cited as the raison d'etre for this provision.

However, in the late 1970s and early 1980s, opposition began to develop in academic and governmental circles to many of the large-scale water diversion projects that were being proposed by the Soviet government. Primary concerns were about the environmental effects and possible climatological and hydrologic changes resulting from transfer of significant volumes of

44 Dubasov, Underground Explosions, p. 25 (see footnote 25).

45 Chelyukanov et al., Radiation Conditions (see footnote 43).

46 Kireev, "Group Excavation" (see footnote 34).

47 The English language version of the LTBT prohibits any nuclear explosion that "causes radioactive debris to be present outside the territorial limits of the State" conducting the explosion, whereas the Russian text refers to the presence of "radioactive fallout." Thus, the Russian text would appear to permit nuclear explosions which resulted in radioactive gases that crossed borders but not nuclear explosions that led to detectable fallout beyond the border.

48 The Peaceful Nuclear Explosions Treaty provides that no group nuclear explosion may have any single explosion greater than $150 \mathrm{kt}$ and the total yield of any group explosion cannot exceed $1500 \mathrm{kt}$. These yield limits would appear to be adequate to carry out the Kama-Pechora project. 
water from the Arctic to the southern portion of the country. ${ }^{49}$ By the mid-1980s, these plans were largely abandoned, including any use of nuclear excavation for the Pechora-Kama Canal.

\section{Dam Construction}

“Crystal." Several years after the "Taiga" explosion, on October 10, 1974, Soviets scientists carried out another small-excavation type nuclear explosion $3 \mathrm{~km}$ northeast of the small settlement of Udachnyy in Yakutia in Siberia and $90 \mathrm{~km}$ northeast of the town of Aikhal. This explosion was under the sponsorship of the Ministry of Light Metallurgy and a local combine called Yakutalmaz, a diamond-mining enterprise. The purpose of the explosion was to create a small dam in the Deldyn river. This area in Siberia is in the permafrost region, and the rivers and streams only flow for a few months in the summer. The intent was to produce a small lake that would retain the tailings from the diamond mine for subsequent enrichment by Yakutalmaz (see Section A.3, Appendix B).

For this experiment, a 1.7-kt explosive was placed at a depth of $98 \mathrm{~m}$, a scaled depth-of-burst about twice that of "Chagan" and "Sary-Uzen'." The explosion produced a dome-shaped mound with a diameter of $180 \mathrm{~m}$, which rose to a height of $60 \mathrm{~m}$ and then settled back to an average height of $10 \mathrm{~m}$ above the original surface. ${ }^{50}$ It is reported that the dome did not rupture, and all the refractory radionuclides were contained underground, although there would have been escape of gaseous radionuclides such as $\mathrm{Cs}^{137}, \mathrm{Xe}^{133}, \mathrm{Kr}^{85}$, and perhaps tritium through fractures in the dome. There is no information regarding the use of the "dam" or the lake behind it for its intended purpose. 51

Gamma-radiation surveys in 1990 reported the general level was $15-30 \mu \mathrm{R} / \mathrm{hr}$ with a peak level of $110 \mu \mathrm{R} / \mathrm{hr}$ after the dam was covered by a meter of soil. ${ }^{52}$ Another source reports radiation levels in 1991 on the uplifted dome to be predominantly background levels (9-15 $\mu \mathrm{R} / \mathrm{hr}$ ) except for a limited area northeast of the dome where it reached a level of $50-60 \mu \mathrm{R} / \mathrm{hr}$. After it was covered with $6 \mathrm{~m}$ of rock from a nearby quarry, the level dropped to background level. No radionuclides were detected in water samples taken from the dam, drilling or earthwork in the dam, or within $100 \mathrm{~m}$ of the dam. ${ }^{53}$

"Lazurite." A few months later on December 7, 1974, Soviet scientists carried out a second experiment with a deeply buried cratering explosion on the edge of the STS, a few kilometers

49 Philip P. Micklin, “A Preliminary Systems Analysis of Impacts of Proposed Soviet River Diversions 0n Arctic Sea Ice,” EOS, Vol. 62, No. 19, May 12, 1981.

50 Mikhailov, Nuclear Explosions in the USSR, p. 71 (see footnote 13).

51 There have been reports that the experiment was a failure and that the dome subsided to its original level. See “Focus' Ne Ydalsya," in Atom bez Gripha "Sekretno”: Tochki Zreniya, A. Emel'yanenkov and V. Popov, Ed. H\&P Druck, Berlin, 1992.

52 K. V. Myasnikov, et al., "Underground Explosion in the Arctic for Peaceful Purposes," in Nuclear Explosions in the USSR - Publication 1: The Northern Test Site, Ed. V. N. Mikhailov, VNIPIpromtekhnologiy and Khlopina Radium Institute, Moscow, 1992. (See JPRS-UEQ-93-009-L). 
south of the "Sary Uzen"" crater. Their intent was to produce an upthrust dome similar to "Crystal" on a slope that would subsequently slide down the slope and form a landslide dam, similar to what Soviet engineers had done with large chemical explosions on a number of occasions, most notably near Alma Ata in Kazakhstan and on the Vakhsh River in Tadzhikistan. 54

For the "Lazurite" experiment, a 1.7-kt explosive was placed under a $20^{\circ}$ slope consisting of quartzite and flinty slate. It was positioned $75 \mathrm{~m}$ from the slope in a vertical direction and $70 \mathrm{~m}$ in the line of least distance to the slope. The scaled depth of burst was about 5-10\% greater than that for the U.S. explosion Sulky, which produced a mound of broken rock.

The "Lazurite" explosion also produced a mound of broken rock, which had a diameter of $200 \mathrm{~m}$ and a height of $14 \mathrm{~m}$. No description of the dam that was formed by "Lazurite" has been published. There was very little venting, and radiation levels on the mound immediately after the explosion were reported to be three to four orders of magnitude less than for cratering explosions such as 'Sary Uzen'. ${ }^{55}$ Radiation levels today are described as being at background, but monitoring of the site is continuing. 56

The Soviet interest in nuclear excavation appeared to come to an end with the "Lazurite" explosion. All tests after "Lazurite" were designed to be completely explosions. However, as mentioned above, their planning and public positions continued through the mid-1970s to include strong emphasis on nuclear excavation and the Kama-Pechora Canal.

\section{Contained Applications}

\section{Stimulation of Oil and Gas Production}

While MinAtom's Program No. 7 for the "Utilization of Nuclear Explosions in the National Economy" was planning the nuclear excavation program and the "Chagan" cratering explosion, the Soviets also began to consider the use of PNEs for various industrial applications. The first area to receive serious study was the application of nuclear explosions for the stimulation of oil production, carried out in cooperation with the Ministry of Oil Production (see Section B.1, Appendix B).

Experience has shown that the efficiency of recovering oil from carbonate oil reservoirs is, in general, fairly low $(<40 \%)$. Several secondary recovery techniques are practiced with varying degrees of success, depending on the nature of the reservoir and the character of the oil. These methods include water and gas injection, fire or hot-water flooding, hydrofracturing to increase

54 M. Dokuchayev, “The Blast at Medeo,” Nauka i Zhizn', No. 3, 1967, pp. 100-8; Ya. A. Yulish, "Baipazinskiy Hydroelectric Power Installation on the Vakhsh River," Gidrotekhnika i Melioratsiya, No. 7, pp. 1-10, 1971. 
the permeability of the formation, and the introduction of gas into the oil to reduce its viscosity. However, many fields resist such conventional techniques.

"Butane." The first oil field considered for treatment was the Grachevka reservoir, located about $150 \mathrm{~km}$ north of the city of Orenburg in the Bashkir Republic, near the southern end of the Ural Mountains. This formation has been described as a solution gas drive reservoir in which ultimate recovery had been projected as $\sim 25 \%$ of the in-place resources. The reservoir is a limestone reef at a depth of 1000-1500 m overlain by interbedded anhydrite and halite layers, which formed a "gas cap." The oil-producing section is isolated from an underlying pressurized water zone by a bitumenized or oxidized layer $25-50 \mathrm{~m}$ thick. 57

Production from this reservoir in the first few years after it was opened increased rapidly to several hundred tons of oil per month as new holes were drilled into the reservoir. But after three years, production began to sharply decrease as the gas/oil ratio began to rise significantly. By the seventh year, production was down to about 100 tons/month, and the gas/oil ratio had risen from 100 to $500 \mathrm{~m}^{3}$ of gas/ton of oil. The apparent cause was the development of channeling and the escape of dissolved gas from the deposit, leaving the oil behind. To reverse these trends, Program No. 7 and the Oil Production Ministry decided to make their first attempt at nuclear stimulation with this field.

The first stage of the "Butane" project involved the simultaneous detonation on March 30, 1965, of two 2.3-kt nuclear explosions about $200 \mathrm{~m}$ apart at depths of 1375 and $1341 \mathrm{~m}$ in the Grachevka formation. This depth placed the explosions and the associated collapse chimney totally within the oil deposit. A second explosion, which was a single 7.6-kt nuclear explosion at a depth of $1350 \mathrm{~m}$ and located $350 \mathrm{~m}$ west of one of the two 2.3-kt explosions, was carried out later that year on June 6, 1965.58 Because of the small yield and perhaps the porous carbonate rock, these explosions were not detected by world-wide seismic networks. The locations given in Appendix A are based on the geographical location provided in footnote 13. The devices used for this experiment have been described as specially designed and tested for this application.59

Over the next few years, increased production was reported for some 20 wells within 300 $470 \mathrm{~m}$ of the stimulation wells. The oil/gas ratio dropped sharply, and oil production increased about $40 \%$ over previous projections. Results available to date indicate that the stimulation will increase the ultimate recovery from the formation by 40-50\%. Table 4 summarizes the results of the first 8 years of production from the "Butane" project as well as the results of other oil and gas stimulation projects in comparison with the U.S. gas stimulation projects. 60

57 S. A. Orudjev, "Underground Nuclear Explosions to Stimulate Oil Field Development," Proceeding of the 8th World Petroleum Congress, Moscow, June 1971.

58 Nordyke, Review of Soviet Data on PNEs, p. 666 (see footnote 19).

59 Mikhailov, Nuclear Explosions in the USSR, p. 40 (see footnote 13).

60 Ibid., pp. 40-42. 
Table 4. Comparative Evaluation of U.S. and Soviet PNE Stimulation Projects.

\begin{tabular}{|c|c|c|c|c|c|c|c|}
\hline \multirow[b]{2}{*}{$\begin{array}{l}\text { Projects } \\
\text { studied }\end{array}$} & \multicolumn{4}{|c|}{ Characteristics of the Natural Collectors } & \multirow[b]{2}{*}{$\begin{array}{c}\text { Number } \\
\text { of } \\
\text { explosions }\end{array}$} & \multirow[b]{2}{*}{$\begin{array}{l}\text { Increase in } \\
\text { hole } \\
\text { production }\end{array}$} & \multirow{2}{*}{$\begin{array}{c}\text { Additional } \\
\text { Fuel* recovery } \\
\text { per explosion, } \\
\left(\mathbf{1 0}^{\mathbf{3}} \mathbf{~ m}^{3}\right)\end{array}$} \\
\hline & $\begin{array}{l}\text { Rock } \\
\text { type }\end{array}$ & $\begin{array}{c}\text { Porosity } \\
(\%)\end{array}$ & $\begin{array}{c}\text { Permea- } \\
\text { bility } \\
\text { (mDarcies) }\end{array}$ & $\begin{array}{l}\text { Saturating } \\
\text { fluid }\end{array}$ & & & \\
\hline Butane & Limestone & $15-20$ & $4-64$ & Oil and gas & 5 & $1.4-1.5$ & 80 \\
\hline Helium & Limestone & $8-10$ & $5-20$ & Oil & 5 & $1.6-1.8$ & - \\
\hline Grifon & Limestone & $10-15$ & $20-40$ & Water & 2 & $1.5-1.6$ & 120 \\
\hline Neva & Limestone & $10-12$ & $0.2-0.4$ & Oil and gas & 6 & $>20$ & 80 \\
\hline Angara & $\begin{array}{l}\text { Sandstone } \\
\text { shale, } \\
\text { alevrolite }\end{array}$ & $10-12$ & $0.1-0.2$ & Oil & 1 & 15 & - \\
\hline Benzene & $\begin{array}{l}\text { Sandstone } \\
\text { shale, } \\
\text { alevrolite }\end{array}$ & 25 & $0.01-0.02$ & Water $^{* *}$ & 1 & - & - \\
\hline Gasbuggy & Sandy shale & $10-12$ & $0.1-0.2$ & Gas & 1 & $6-8$ & - \\
\hline Rulison & Sandy shale & $7-9$ & $0.2-0.4$ & Gas & 1 & $10-15$ & - \\
\hline $\begin{array}{l}\text { Rio-Blanco } \\
\text { (string) }\end{array}$ & Sandy shale & $4-6$ & 0.1 & Gas & 3 & $10-15$ & - \\
\hline
\end{tabular}

* Oil + Gas; $1 \mathrm{~m}^{3}$ of oil $=1000 \mathrm{~m}^{3}$ of gas.

** Explosion was placed below the productive section (from Ref. 13, p. 43).

The "Butane" explosions were apparently completely contained, and radiation levels in the area are reported to be at background levels. Within the collapse chimney region, tritium produced by the nuclear explosions diffused into the gas cap above the oil-bearing horizons and appeared in gas produced with the oil. Initially the average tritium level in the gas from the field was measured at $0.03 \mu \mathrm{Ci} /$ liter. Within 3 years, it had stabilized at about $0.003 \mu \mathrm{Ci} /$ liter. Tritium levels in the oil were less than $3 \mu \mathrm{Ci} /$ liter, which is approximately the same level as in the gas on a unit weight basis. Only trace amounts $(<0.1 \mu \mathrm{Ci} /$ /iter $)$ of the fission product radionuclides $\mathrm{Cs}^{137}$ and $\mathrm{Sr}^{90}$ were reported. ${ }^{61,62}$

On June 16 and 25 in 1980, two additional 3.0-kt explosions were carried out in the "Butane" reservoir at depths of about $1400 \mathrm{~m}$. These two explosions were also not detected by the worldwide seismic networks, and the locations given in Appendix A are based on geographic information in footnote 13. No additional information has been made available on the specific purpose or results of these explosions.

61 Ibid., p. 101.

62 For comparison purposes, the initial tritium levels in gas from the three U.S. gas stimulation experiments were $0.7,0.175$, and $0.028 \mu \mathrm{Ci} /$ liter in Gasbuggy, Rulison, and Rio Blanco. The internal dose from the use of natural gas for cooking in an unvented kitchen which had a tritium level of $0.01 \mu \mathrm{Ci} /$ liter is estimated to be $1.3 \mathrm{mrem} / \mathrm{year}$, or less than $1 \%$ of natural background levels of exposure. (See Barton, et al., "Calculational Techniques for Estimating Population Doses from Radioactivity in Natural Gas from Nuclearly-Stimulated Wells,” IAEA-TC-1-4/3 in Peaceful Nuclear Explosions IV, IAEA Panel, pp. 343-354, 1995.) 
"Grifon." Four years after the first "Butane" explosions, the Soviet Oil Ministry sponsored stimulation of another oil reservoir, but of a different type. The second effort, project "Grifon," sought to stimulate the Osinskii deposit, $100 \mathrm{~km}$ southwest of the city of Perm on the western slope of the Urals. The Osinskii reservoir was a carbonate reef deposit being produced through the use of water injection into wells surrounding the oil reservoir. 63,64

On September 8 and 26 in 1969, two 7.6-kt explosions were fired $1200 \mathrm{~m}$ apart at depths of 1212 and $1208 \mathrm{~m}$ in the middle of this reservoir. At these depths, the explosions were about $70 \mathrm{~m}$ below the water-oil contact at the base of the reservoir. The collapse chimneys would have been expected to extend 50-80 m into the oil-bearing formation. Although little production data have been made available, Soviet scientists stated that early results indicated an increase of 30-60\% in production. ${ }^{65}$ As shown in Table 4, results indicate a production increase of $50-60 \%$ over that for the previous 20 years.

The "Grifon" explosions were completely contained, but post-shot drilling into the chimney region and removal of water from the explosion region led to contamination of the surface area and equipment that was later decontaminated, and the site is reported to be at background levels. The primary radiation hazard to production from this site is associated with the presence of $\mathrm{Cs}^{137}, \mathrm{Sr}^{90}$, and tritium in the water underlying the oil that is being used to pressurize the field. However, radioactivity levels in oil produced from the field are reported by MinAtom to be similar to those reported for the "Butane" field.

However, there are reports in the Russian press that describe a less optimistic situation. A recent article by Academician Yanshin states that studies of the environmental effects of PNEs in the Perm area in 1991-92 indicated that by 1978, radionuclides $\mathrm{Cs}^{137}$ and $\mathrm{Sr}^{90}$ began to appear in holes near the explosion sites. 66 Over the next ten years, the area of contamination had spread to some 65 production holes and represented a threat of contaminating the nearby Votkinsk water reservoir, the Kama River, and even the Volga River basin. In the region of the emplacement holes, radiation levels were reported to be about $60 \mu \mathrm{R} / \mathrm{hr}$ and at specific injection holes 20-50 $\mu \mathrm{R} / \mathrm{hr}$. In some areas, radiation levels were reported to be as high as $3 \mathrm{mR} / \mathrm{hr} .67,68 \mathrm{There}$ are reports that the refineries in Perm have refused to accept oil from the Osin field, and several

63 Nordyke, Review of Soviet Data on PNEs, pp. 665-666 (see footnote 19).

64 Orudjev, "Underground Nuclear Explosions" (see footnote 57).

65 Ibid.

66 Acad. A. Yanshin, “The Nuclear 'Genie' is Escaping from the Earth,” Delo (Moscow), No. 13 (47), March, 1994, p. 4. Yanshin is also Chairman of the Scientific Council of the Russian Academy of Sciences for Problems of the Biosphere.

67 B. Golybov, "Point of View of the Experts," Atom bez Gripha 'Sekretno': Tochki Zreniya, A. Emel'yanenkov and V. Popov, Ed. H\&P Druck, Berlin, 1992, pp. 67-8.

68 V. Yakimets, “A Hundred Test Sites in the Former USSR,” Spasenie No. 19-20, June 1992, p. 4. 
holes have been closed. ${ }^{69}$ MinAtom confirms that oil from the "Grifon" site is not acceptable to regional refineries. 70

Project "Takhta-Kagulta," One month after the first two "Grifon" oil stimulation explosions, on September 26, 1969, the Soviet PNE program, with the sponsorship of the Soviet Ministry of Gas Production, carried out their first effort directed at stimulating the production of gas from low-permeability gas reservoirs. The site of this test was in the Takhta-Kagulta gas field in southern Russia on the northern slopes of the Caucasus Mountains about $90 \mathrm{~km}$ northeast of the city of Stavropol'.

The Takhta-Kagulta gas field is a very large geologic structure in which the production horizon is a very thin 5- to 13-m-thick section consisting of clayey siltstone lying at a depth of about 700-750 m. ${ }^{71}$ The test was a single 10-kt nuclear explosion at a depth of $712 \mathrm{~m}$.

During the second US/USSR Bilateral Meeting in February 1970, Soviet scientists revealed to the Americans that such an experiment had been carried out, but no additional information on the results were made available at that time or since. Moreover, this was the only test reported to have been sponsored by the Gas Ministry. The extremely thin nature of the production horizon would appear to make this a poor candidate for nuclear stimulation since the "collapse chimney" would be expected to be 5-10 times taller than the thickness of the deposit. The lack of information on the results of this test would appear to confirm a very disappointing result. No escape of radioactivity has been reported, and the site is closed. ${ }^{72}$

Project "Neva." In the Fall of 1976, the Soviet PNE program, this time with the sponsorship of the Ministry of Geology, began a new gas stimulation project, subsequently referred to as the "Neva" project. This project consisted of a series of explosions in a hydrocarbon reservoir at a site located about $120 \mathrm{~km}$ south-southwest of the Siberian town of Mirnyy in the Siberian Yakut Republic. The producing formation at the "Neva" site, named the Sredne-Botuobinsk reservoir, consists of a dolomite and limestone section capped by a salt layer at a depth of 1500-1600 m containing both oil and gas, although prior to nuclear stimulation, it was only considered for gas production. 73

At the time of the first experiment, code-named "Oka," on November 5, 1976, the field was under active development. The "Oka" explosion was $15 \mathrm{kt}$ at a depth of $1522 \mathrm{~m}$. Initially, production tests several months after the explosion were conducted in a pre-existing exploratory hole $120 \mathrm{~m}$ from the "Oka" hole. Whereas preshot gas production from this hole had been 3000$5000 \mathrm{~m}^{3} /$ day, periodic post-shot production over a 75 -day period produced over $100,000 \mathrm{~m}^{3} /$ day

69 Yanshin, "The Nuclear 'Genie"” (see footnote 66).

70 Mikhailov, Nuclear Explosions in the USSR, p. 44 (see footnote 13).

71 V. G. Vasil'yev, Gas Deposits of the USSR, pp. 92-3, Nedra, Moscow, 1968.

72 Mikhailov, Nuclear Explosions in the USSR, p. 145 (see footnote 13).

73 A. Ye. Kiselev, and V. V. Minner, "Lithologic Composition and Reservoir Properties of the Osin Horizon of the Sredne-Botuobinsk Field," Nauka, 1979, pp. 76-82. 
as well as 20-22 $\mathrm{m}^{3} /$ day of oil. Production testing from the "Oka" emplacement hole over a three and a half month period resulted in over $100,000 \mathrm{~m}^{3}$ /day of gas, but no oil which was accumulated in the central chimney region. At the end of the test period, the flow rate was still $50,000 \mathrm{~m}^{3} /$ day.

The second explosion in the Sredne-Botuobinsk formation, code-named "Vyatka," was carried out on October 7, 1978, near "Oka." It had a yield and depth of burial similar to "Oka" and was also $120 \mathrm{~m}$ from another exploratory hole, which had no significant production before "Vyatka." Post-shot production from the "Vyatka" emplacement hole averaged 60,000 m³/day over a twomonth period and was still $38,000 \mathrm{~m}^{3}$ / day at the end of the testing period. ${ }^{74}$

The third explosion, "Sheksna," was fired exactly one year later on October 7, 1979, with about the same yield but about 50-70 m deeper than "Oka" and "Vyatka." No specific results of production testing in the vicinity of "Sheksna" have been provided.

Three more explosions, "Neva-1, Neva-2, and Neva-3," were carried in 1982 and 1987 to extend the stimulation of the Sredne-Botuobinsk formation over a larger area. In November, 1987, the Soviets carried out the seventh and last explosion at the Sredne-Botuobinsk site, "Neva-4," which MinAtom lists as a stimulation explosion. However, the yield of the explosion, $3.2 \mathrm{kt}$, and its depth of $815 \mathrm{~m}$ in a salt formation would suggest that this explosion was, in reality, a storage cavity used to dispose of radioactive and toxic wastes generated by the stimulation and production activities at the site. This is supported by the fact that Table 6 from Ref. 13 lists only 6 stimulation explosions at the "Neva" site.

The overall results of stimulation at the "Neva" site are shown in Table 4 in comparison with other USSR and U.S. stimulation projects. It shows that the permeability of the SredneBotuobinsk reservoir was comparable with that of the U.S. Gasbuggy and Rulison reservoirs, but the results of stimulation were about 2-3 times greater than those realized in the U.S.

experiments. This difference could well be due the fact that the Sredne-Botuobinsk reservoir was limestone and dolomite, whereas the American reservoirs were primarily shale. Based on the fact that only 4 out of 40 exploratory holes had commercial production potential, nuclear stimulation has made the field commercially valuable. The value of the nuclear stimulation of the field was calculated to be worth 100,000,000 rubles (1980). In addition, whereas the field was regarded as only a gas field prior to stimulation, commercially significant volumes of oil were recovered from the field. ${ }^{75}$

Along with the mechanical alteration of the rock surrounding the explosion, Soviet scientists also report the discovery of a new phenomena, the permanent electrical polarization of the rock (see Fig. 4). The region of anomalous polarization extends to distances of $200-250 \mathrm{~m} / \mathrm{kt}^{1 / 3}$ from the explosion. It is directed toward the explosion point and facilitates the motion of oil toward

74 O. L. Kedrovskiy, On the Exploitation of Oil and Gas Deposits in Low Permeability Reservoirs, Geologiya Nefti i Gaza, No. 11, 1980, pp. 43-46.

75 Mikhailov, Nuclear Explosions in the USSR, pp. 42-46 (see footnote 13). 


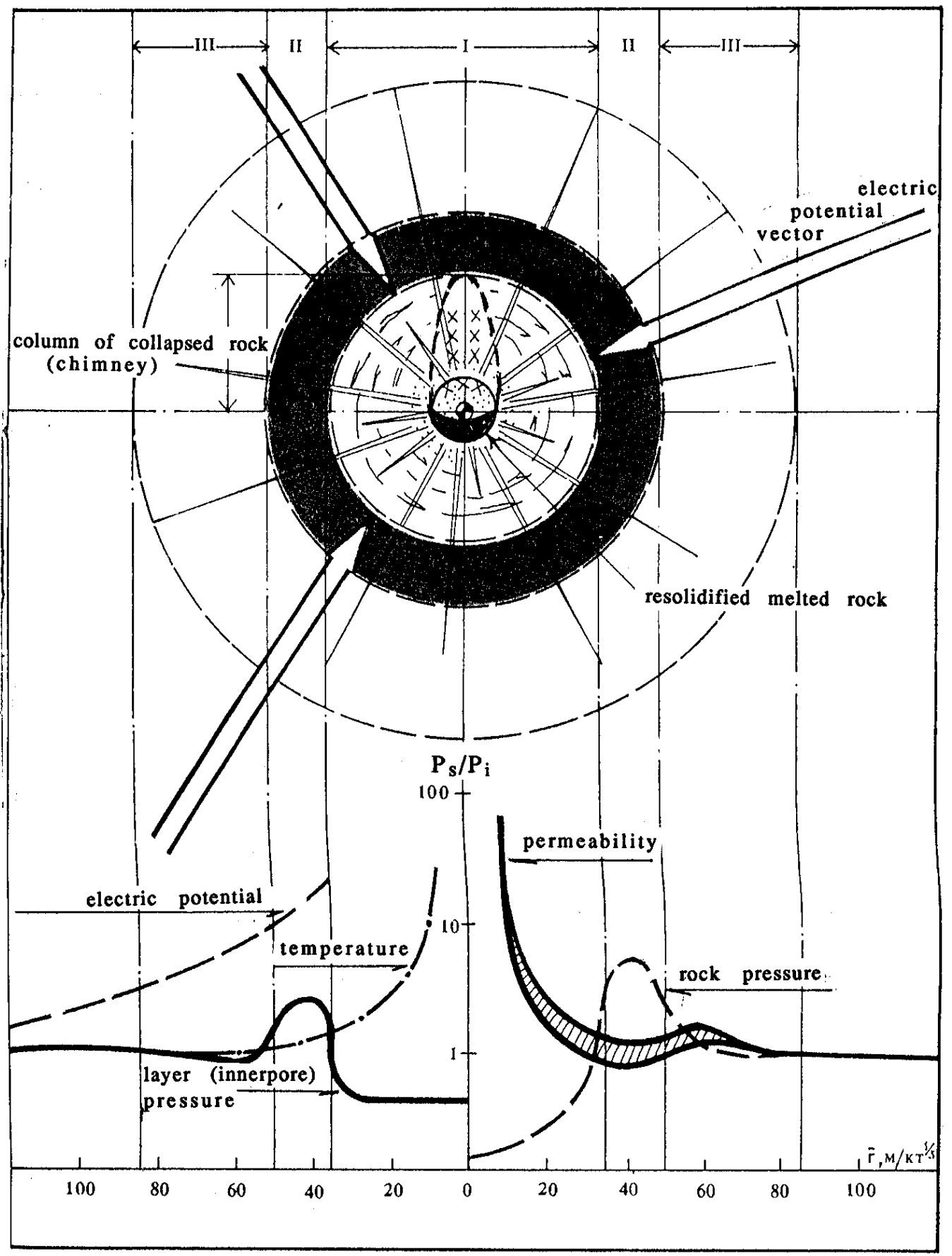

Figure 4. Sketch showing (top) the physical-mechanical alteration of homogeneous porous rock surrounding a nuclear explosion, and (bottom) changes in the basic properties of the rock including rock and pore pressure, permeability, temperature, and electrical polarization. The three large arrows indicate the vector of electric polarization field in the rock created by the explosion. The horizontal axis (bottom) is the cube-root scaled radius from the explosion. The associated vertical scale is the logarithm of the ratio of the post-shot values to their pre-shot values. 
the center of the explosion. This phenomenon was first noted during work on the "Neva" project. Studies indicated that the strength of the polarization is dependent on the properties of the rock and is significant only for low-permeability reservoirs. There are no reports on whether this phenomenon was looked for or found at the other stimulation sites. 76,77

MinAtom reports that all 7 explosions carried out at this site were totally contained. Access to the emplacement holes has been closed, and they have been cemented (perhaps with the exception of "Neva-4"). Work at the site could be resumed. Radiation levels at the site are at background levels. 78

Project "Helium." In 1981, the Soviet PNE program began a new oil stimulation project called Project "Helium" in the Tyazhskii carbonate oil reservoir near the town of Krasnovishersk on the western slope of the Urals, about $800 \mathrm{~km}$ north of the first oil stimulation project, "Butane." The characteristics of the formation and the technology used for producing the field are described as being very similar to those at "Butane."

The first explosion on September 2, 1981, was a 3.2-kt explosion placed at a depth of $2088 \mathrm{~m}$, below the oil-bearing section. The second and third explosions were carried out three years later on August 28, 1984, timed to be five minutes apart. The yields and depths were similar to those for the first explosion. The last two explosions in Project "Helium" were fired about three years later on April 19, 1987, again five minutes apart with similar yields and depths of burial.

Available results of production testing are limited to the numbers in Table 4, which indicate a production increase of 60-80\% after the stimulation explosions. All of the explosions were reported to have been successfully contained, and the site is under active exploitation. ${ }^{79}$

Projects "Angara and Benzene." The Soviets acknowledge carrying out two additional oil stimulation explosions, Projects "Angara" and "Benzene," both of which were in western Siberia in the middle of the great Ob' River basin. The first, Project "Angara," was sponsored by the Geology Ministry and was carried out on December 10, 1980, in the Yesi-Yegovskii oil field. It employed a 15-kt explosion at a depth of $2485 \mathrm{~m}$. The second, Project "Benzene," was sponsored by the Oil Ministry and was fired on June 18, 1985, in the Sredne-Balykskii oil field. It was a 2.5-kt explosion at a depth of $2859 \mathrm{~m}$. No data have been published on the results of these projects, except that the "Angara" site is closed, but the "Benzene" site is under active development. Both were successfully contained. 80

76 V. I. Musinov, Production of Oil and Gas with the Aid of Nuclear Explosions, Priroda, 1991, No. 1, pp. 25 33.

77 O. L. Kedrovskiy, M. C. Lykin, V. I. Musinov, Ye. M. Simkin, "A Study of the Influence of the Electrical Field on the Filtration of Oil in a Low Permeability Layer," Neftyanoe Khozyaistvo, 1986, No. 12, pp. 45-48. Dubasov, et al., "Underground Explosions," pp. 21-22 (see footnote 25).

79 Mikhailov, Nuclear Explosions in the USSR, p. 42 (see footnote 13).

80 Ibid., p. 41. 
Summary of Oil and Gas Stimulation. Overall, the Soviet PNE program carried out 5 projects directed at the stimulation of oil production, all from limestone or dolomite reservoirs. Three of the projects utilized multiple explosions with yields between 2.3 and $7.6 \mathrm{kt}$. Results over 10-20 year production periods indicate an increase in production of about $40-80 \%$ over that projected for the fields before stimulation. Two oil stimulation projects using a single explosion have been carried out, but no results have been published. All of the explosions were completely contained, and no problems with radioactive contamination of the site or product have been reported except for Project "Grifon," where product and ground water contamination appears to be a growing problem.

The Soviet program to stimulate the production of natural gas appears to have consisted of two projects, only one of which produced results that have been reported. This project, "Neva," utilized six 13- to 16-kt explosions for stimulating a dolomite reservoir and one 3.2-kt explosion in salt, presumably for storage or disposal of waste. Results over a 15-year production history indicate a recovery rate more than 20 times normal, results about 2 times more favorable than those for U.S. experience. All explosions were contained. Although the gas would be expected to contain a low level of tritium, no problems with product contamination have been reported.

As was done by the U.S. Plowshare Program, special explosives were developed by the Soviet weapons laboratories to meet the unique requirements of stimulating oil and gas reservoirs. The great depths of such reservoirs (1000-2000 m) place great value on reducing the diameters of the explosives and building them so they can withstand the elevated pressures and temperatures experienced at those depths. There is also a great premium on reducing the tritium produced in the explosive and the surrounding medium to reduce problems of contaminating hydrocarbon products with tritium. To meet these requirements, the Soviets developed special explosives with a 30- to $60-\mathrm{cm}$ diameter and the appropriate yields capable of withstanding the emplacement and rough transport conditions. 81

Mention should be made of a magnitude 4.4 seismic event at 9:00:06 GMT on July 19, 1982, $120 \mathrm{~km}$ northeast of Kotlas in the southeast corner of the Komi Republic. Russian geoscientists in the Schmidt Institute and the Institute for Dynamics of the Geosphere have associated this event with the Soviet PNE program and have referred to it by the name "Komipetroleum" indicating their belief that its purpose was oil stimulation. ${ }^{82}$ Publications by the MinAtom make no reference to this event.

\section{Cavity Technology Development}

Project "Halite." Early in the development of the Soviet PNE program, perhaps in reaction to the earlier U.S. explosions in salt that produced standing cavities Gnome and Salmon, the decision was made to develop the technology of creating cavities in salt. They chose a site about

81 Mikhailov, Nuclear Explosions in the USSR, p. 42 (see footnote 13).

82 D. D. Sultanov et al., Investigation of Seismic Efficiency of Soviet Peaceful Nuclear Explosion Conducted in Various Geological Conditions, Part 1, Russian Federation Institute for Dynamics of Geospheres, Moscow, 1993. 
$180 \mathrm{~km}$ north of the city of Astrakhan at the north end of the Caspian Sea. The site for these studies was near the small village of Azgir in the middle of a large semi-desert area. The geologic medium at Azgir consisted of two large salt diapirs, the Western and Eastern Azgir Domes, that go to great depth but with relatively thin alluvial cover (5-200 m). The water table in the area is fairly shallow, near the top of the salt formation. 83

A-1. The first experiment in this program, code-named "Halite," was A-1, a 1.1-kt explosion fired on April 22, 1966, in the Western Azgir Dome at a depth of $161 \mathrm{~m}$, a scaled depth of about $155 \mathrm{~m} / \mathrm{kt}^{1 / 3}$. It produced a cavity about $25 \mathrm{~m}$ in diameter and a volume of $11,200 \mathrm{~m}^{3}$.

As with all nuclear explosions in salt that produce cavities, radioactive debris from the explosion initially is embedded in the walls of the cavity that are covered with molten salt. Within a few minutes after the explosion, the molten salt on the walls runs to the bottom of the cavity, carrying the refractory radioactive debris with the salt. The molten salt forms a segmentshaped puddle at the bottom of the cavity about a third of a cavity radius deep at the center, which ultimately solidifies, trapping the refractory radioactive debris in the resolidified salt. Gaseous radionuclides appear in the gases filling the cavity.

Shortly after the explosion, the A-1 cavity began filling with water, apparently the result of poor sealing of the emplacement hole and extensive fracturing above the cavity by spalling of the ground surface. The roof also collapsed some $8000 \mathrm{~m}^{3}$ of rock salt into the cavity, hampering efforts to study the cavity. In addition, gaseous radioactivity from the cavity escaped into nearby instrument holes and leaked to the surface, contaminating the local environment.

A-2. The second "Halite" explosion, A-2, was carried out two years later on July 7, 1968, in the same Western Azgir Salt Dome but about $8 \mathrm{~km}$ north of A-1 at a somewhat greater scaled depth. It consisted of a 27-kt explosion at a depth of $597 \mathrm{~m}$, a scaled depth of burial of about $200 \mathrm{~m} / \mathrm{kt}^{1 / 3}$. It produced a spherical cavity with a radius of about $32 \mathrm{~m}$ and a volume of about $140,000 \mathrm{~m}^{3}$. This cavity also began to leak around the emplacement hole and ultimately filled with water, but there was no early vent of gaseous radionuclides.

A-1 and A-2 were thoroughly explored and provided very useful experience in making and working with explosion cavities in salt that led to ideas for using such cavities for a number of applications. A-2 was repeatedly used in a series of experiments designed to produce transplutonic elements (as discussed below).

A-3. The third explosion in the "Halite" series, A-3, was carried out three years later on December 22, 1971, in the Eastern Azgir Salt Dome about $16 \mathrm{~km}$ east of A-1 and A-2. This time, the yield was $64 \mathrm{kt}$, and the depth-of-burial $986 \mathrm{~m}$ for a scaled depth-of-burial of about $245 \mathrm{~m} / \mathrm{kt}^{1 / 3}$. The explosion produced a spheroidal cavity that had a horizontal radius of $38 \mathrm{~m}$ and

83 V. V. Adushkin, et al. Characteristics of Seismic Waves from Soviet Peaceful Nuclear Explosions in Salt, UCRL-CR-120929, April, 1995. 
a vertical radius of about $33 \mathrm{~m}$. The radius of an equivalent sphere would be $36.2 \mathrm{~m}$. The cavity remained dry and was subsequently used for a seismic decoupling experiment (see below). ${ }^{84}$

\section{Extinguishing Runaway Gas Well Fires}

Shortly after the Soviet PNE Program was established, an urgent industrial problem was brought to the leaders of the program-could an underground nuclear explosion be used to put out a gas well fire that had been raging for some 3 years? (See Section B.2, Appendix B.)

Urtabulak. On December 1, 1963, while drilling gas Well No. 11 in the Urtabulak gas field in Southern Uzbekistan about $80 \mathrm{~km}$ southeast of Bukhara, control of the well was lost at a depth of $2450 \mathrm{~m}$. This resulted in the loss of more than 12 million $\mathrm{m}^{3}$ of gas per day through an 8-inch casing, enough gas to supply the needs of a large city, such as St. Petersburg. Formation pressures were about 270-300 atmospheres. $85,86,87$

Over the next three years, many attempts were made using a variety of techniques to cap the well at the surface or to reduce the flow and extinguish the flames. However, because the bottom $1000 \mathrm{~m}$ of the casing had not yet been cemented, such attempts led to diversion of the gas into nearby wells and to serious personnel safety problems because of the high $\mathrm{H}_{2} \mathrm{~S}$ content of the gas. Underground attempts were hampered by the fact that the location of the lower portion of the hole had not been logged at the time control was lost.

Finally, in the fall of 1966, a decision was made to attempt closing the well with the use of a nuclear explosive. It was believed that a nuclear explosion would squeeze close any hole located within 25-50 $\mathrm{m}$ of the explosion, depending on the yield. Two 44.5-cm (13.5-in) diameter slant wells, Holes No. 1c and 2c, were drilled simultaneously. They were aimed to come as close as possible to Hole No. 11 at a depth of about $1500 \mathrm{~m}$ in the middle of a 200-m-thick clay zone. This depth was considered sufficient to contain the 300-atmosphere pressure in the gas formation below. A number of acoustic and electromagnetic techniques were used to estimate the distance between Hole No 11 and inclined explosive emplacement hole at $1450 \mathrm{~m}$. The final estimate for the closest distance between Hole No. 11 and Hole No. 1c was $35 \pm 10 \mathrm{~m}$.

The location for the explosive in Hole 1c was cooled to bring it down to a temperature the explosive could withstand. A special 30-kt nuclear explosive developed by the Arzamas nuclear

84 V. V. Adushkin, et al., "Overview of the Experimental Data and Theoretical Simulations of Underground Nuclear Explosions Decoupled by Large Air-Filled Cavities," Reports of the Russian Academy of Sciences, 327, No. 1, 1992.

85 V. G. Vasil'ev, Gas Deposits in the Soviet Union, Nedra, Moscow, 1968, pp. 626-628.

86 V. I. Igrevskiy and K. I. Mangyushev, Prevention and Elimination of Oil and Gas Fountains, Nedra, Moscow, 1974.

87 Early references such as Ref. 71 show the runaway well as No. 11 in the Urtabulak field, but later sources give the name as $1 \mathrm{P}$ in the Pioneer field. 
weapons laboratory for this event was emplaced in Hole 1c and stemmed. It was detonated on September 30, 1966. Twenty-three seconds later the flame went out, and the well was sealed. ${ }^{8}$

Pamuk. A few months after the closure of the Urtabulak No. 11 hole, control was lost of another high-pressure well in a similar nearby field, Hole No. 2-R in the Pamuk gas field. In this case, drilling had progressed to a depth of $2748 \mathrm{~m}$ before the gas-containing horizon was encountered, and gas pressures were significantly higher than those at Urtabulak (580 atm). A month and a half after the runaway well started, it blocked itself at a depth of 800-1000. Remedial work was done in the well and appeared to have resolved the problem when, four months later, gas started coming to the surface through other holes and through the ground itself.

After several unsuccessful attempts to seal the well by hydraulic fracturing from a slant-drilled well, it was decided to again use a nuclear explosive to pinch off the runaway well. A new inclined hole, No. 10-N, was drilled to intersect Hole 2-R in the middle of a salt formation that overlay the gas producing formation. Measurements after it had been drilled indicated that the minimum separation distance at a depth of $2440 \mathrm{~m}$ was $30 \pm 5 \mathrm{~m}$.

This time, a special explosive developed by the Chelyabinsk nuclear weapons laboratory was used, one that had been designed and tested to withstand the high pressures and temperatures in excess of $100^{\circ} \mathrm{C}$ expected in the emplacement hole. It also was designed to be only $24 \mathrm{~cm}$ in diameter and about $3 \mathrm{~m}$ long to facilitate its use in conventional gas and oil field holes. Its yield was $47 \mathrm{kt.}^{89}$

The explosive was inserted into Hole 10-N and detonated on May 21, 1968, at a depth of $2440 \mathrm{~m}$. Because of the large amount of gas that had infiltrated the overlying strata during the preceding two years, the flow continued for seven days before it finally died out and the seal was complete. The second "success" gave Soviet scientists great confidence in the use of this new technique for rapidly and effectively controlling runaway gas and oil wells.

"Crater and Fakel." Some four years later, two more opportunities arose for the use of nuclear explosions to extinguish runaway gas well fires. The first, code-named "Crater," was in the Mayskii gas field about $30 \mathrm{~km}$ southeast of the city of Mary in Central Asia. Control of the gas well was lost on May 11, 1970, and about $700,000 \mathrm{~m}^{3}$ of gas was lost per day. The producing horizon in this field was at the 3000-m level. No details have been made public about this application, except that on April 11, 1972, a 14-kt explosion at a depth of $1720 \mathrm{~m}$ in an argillite formation was used to successfully seal the runaway well.

On July 7, 1972, another runaway gas well in the Ukraine, about 20 north of the city of Krasnograd and $65 \mathrm{~km}$ southwest of Karkov, was sealed with a nuclear explosion. The runaway well was in the Krestishche gas formation at a depth of over $3000 \mathrm{~m}$. No additional information has been made available except that for this event, named "Fakel," a 3.8-kt explosion at a depth

88 Personal communication with B. Litvinov, May 1994.

89 Ibid. 
of $2483 \mathrm{~m}$ in a salt formation was used. The small yield would indicate that the location of the runaway well was well known, and the explosive emplacement hole was drilled to be very close to it at shot depth.

"Pyrite." The last attempt to use this application occurred in 1981 on a runaway well in the Kumzhinskiy gas deposit in the northern coast of European Russia near the mouth of the Pechora River, $50 \mathrm{~km}$ north of the city of Nar' yan Mar. Control of the well was lost on November 28, 1980, resulting in a loss of about 2,600,000 $\mathrm{m}^{3}$ of gas per day. On May 5, 1981, a 37.6-kt nuclear explosion, code-named "Pyrite," was detonated at a depth of $1511 \mathrm{~m}$ in a sandstone-clay formation near the runaway well. However, the nuclear explosion did not seal the well, perhaps because of poor data on the position of the runaway well. No additional details have been published on the results of the nuclear attempt or of subsequent efforts to close the well by other means. 90

Of the Soviet attempts to extinguish runaway gas wells, MinAtom reports that all were completely contained, and no radioactivity above background levels was detected at the surface of the ground during post-shot surveys. ${ }^{91}$

\section{Underground Cavities for Storage of Gas Condensate}

Building on their experience with creating the two cavities in salt at Azgir in 1966 and 1968, Soviet scientists began to consider possible use of such cavities within the industrial sectors for underground storage. In the late 1960s, contacts were established with specialists at the Ministries of Oil, Gas, Chemistry and Oil Refining to assess their future requirements for underground storage and their interest in exploring the use of nuclear explosions to help meet those needs. The greatest interest was found in the Oil Production Ministry, and plans were quickly developed for a program to develop this application (see Section B.4, Appendix B).

The experience at Azgir with the "Halite" A-1 and A-2 explosions clearly identified two of the most significant technical issues that had to be dealt with: isolation of the cavity from access to any source of water through fractures, cracks, or the emplacement or other holes near the cavity; and finding a depth that would be great enough to contain the required explosive yield without exacerbating problems of cavity stability against collapse or compression by the lithostatic pressure. Any leakage of water into the cavity, as occurred in both the early cavities at Azgir, could quickly lead to leaching of the radioactivity trapped in the recongealed salt lens at the bottom the cavity and contamination of any product stored in the cavity.

Project "Magistral'." The first experiment specifically directed at the use of underground nuclear explosion cavities for storage, Project "Magistral'," was carried out in the Sovkhoz gas

90 Mikhailov, Nuclear Explosions in the USSR, pp. 50-51 (see footnote 13).

91 Ibid. p. 151. 
deposit about $70 \mathrm{~km}$ northeast of Orenburg, and $100 \mathrm{~km}$ south of the first oil stimulation project at the "Butane" site (see Fig. 5).92

The "Magistral" explosion had a yield of $2.3 \mathrm{kt}$ and was emplaced at a depth of $702 \mathrm{~m}$ in a bedded salt formation. It was fired on June 25,1970 , and produced a cavity with a volume of $11,000 \mathrm{~m}^{3}$ (radius $\approx 14 \mathrm{~m}$ ). After several months, the cavity was entered through the emplacement hole, and after some 6 months it was filled with natural gas from the nearby Sovkhoz gas field to a pressure of $8.4 \mathrm{MPa}(84 \mathrm{~atm}) .93,94$

The "Magistral"" cavity stayed in industrial use for the next 18 years. 95 Deactivation and decontamination of the site began in 1993 to clean up radiation levels reported to be 30-40 $\mu \mathrm{R} / \mathrm{hr}$ in the immediate vicinity. ${ }^{96}$ About 3000 tons of soil have been contaminated, to an average level of about $5 \times 10^{5} \mathrm{pCi}$, by spillage while pumping radioactive solutions from the cavity. Beyond the industrial site, the radiation levels are described as "background."

Project "Sapphire." Following the success of the "Magistral" project, scientists from the Soviet PNE program and the Gas Production Ministry turned their attention to another site about $100 \mathrm{~km}$ southwest of "Magistral" and $40 \mathrm{~km}$ south-southwest of Orenburg (see Fig. 5). The new site, Project "Sapphire," was a bedded salt formation that overlay the Orenburg gas condensate deposit, one of the largest in the Soviet Union at the time of its discovery in 1967.

Gas condensate is a very high-quality hydrocarbon that is a mixture of hydrocarbon gases (propane, butane, and pentane) that are liquid at high pressure. Gas condensate is quite valuable, but in some fields it is contaminated with hydrogen-sulfide and dissolved gases, which makes it very expensive to store on the surface, requiring high-pressure corrosion-resistant metal tanks. At

92 Although all sources state that Project "Magistral" was the first nuclear explosion directed at the development of underground storage technology, all MinAtom lists carry an event code-named "Tavda" on October 10, 1967 as the first storage explosion. This explosion had a yield of only $0.3 \mathrm{kt}$ and was at a depth of $172 \mathrm{~m}$. It was located on the east side of the Urals, about $70 \mathrm{~km}$ north-northeast of Tyumen near the Tavda River.

93 Mikhailov, Nuclear Explosions in the USSR, pp. 35-39 (see footnote 13). This reference gives the gas pressure in the cavity as $8.4 \mathrm{~Pa}$ (Pascals). This would appear to be an error. Since lithostatic pressure would be expected to be about 140 atmospheres (14 megaPascals), this author has assumed the units should have been MPa (megaPascals).

94 A 1972 paper presented at the IAEA by K. V. Myasnikov describes testing an explosion cavity at lithostatic pressure, presumably "Magistral," with both oil and gas, leading to the conclusion that its effective volume for storage of liquids was $10 \%$ larger than its geometric volume; for gases at lithostatic pressure it was $24 \%$ larger.

95 Reference 13 says the site was in industrial exploitation for 11 years on p. 37 and 18 years in Appendix 1. Reference 12, p. 23, says the site was in exploitation for 18 years.

96 Although the Ref. 13 text refers to these radiation levels as "above background," they would appear to be at or near normal levels. 


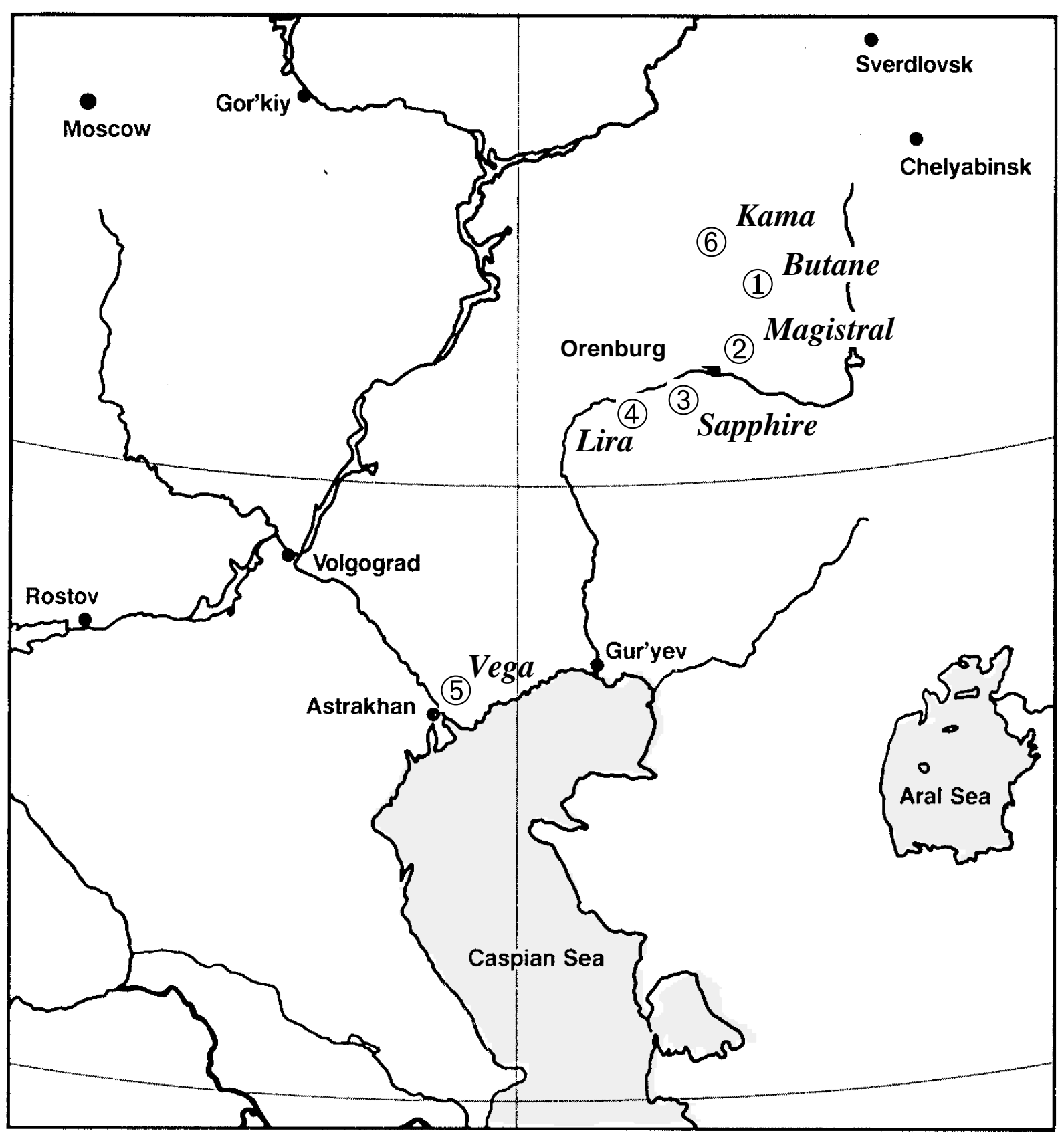

Figure 5. Map showing various PNE sites north of the Caspian Sea. (1) Butane is the first oil stimulation project. (2) Magistral, (3) Sapphire, (4) Lira, and (5) Vega are gas condensate storage projects. (6) Kama is the toxic waste storage project. 
Orenburg, the hydrogen sulfide content was reported to be $2.7 \%$. It appeared that storage in salt cavities would eliminate the corrosion problems and permit the dissolved gas to outgas before he gas condensate was sent to the refinery for processing. Moreover, additional storage capacity was required because the initial capacity of the gas-condensate processing plant at Orenburg did not match the peak processing capability of the natural-gas processing plant. 97

The first of two "Sapphire" explosions was detonated on October 22, 1971, at a depth of $1142 \mathrm{~m}$ in the middle of the bedded salt formation. The gas producing formation was at a depth of $1400-1800 \mathrm{~m}$. The nuclear explosion with a yield of $15 \mathrm{kt}$ produced a $50,000-\mathrm{m}^{3}$ volume cavity. Reentry was made through the emplacement hole, and after flushing and cooling of the cavity with natural gas, the cavity was tested to a pressure of $8.4 \mathrm{MPa}(84 \mathrm{~atm})$ for 30 days and found to be tight.

A second explosion was detonated at the "Sapphire" site two years later on September 9, 1972, a 10-kt explosion at a depth of $1145 \mathrm{~m}$, again in the bedded salt formation. It produced a similar but somewhat smaller cavity.

Both of these explosions preceded the construction of the gas-processing complex, one of the largest in the world, that was subsequently built at Orenburg by a consortium of western engineering firms. It actually consists of three plants, each with a capacity of processing 17 billion $\mathrm{m}^{3}$ per year. Upon completion of the first phase of the gas-processing complex in 1974, gas condensate was introduced into the cavities, and the storage reservoirs were turned over to industrial use. It was operated at a working pressure of $8 \mathrm{MPa}(80 \mathrm{~atm})$ with the gas condensate being removed by gas displacement.

Use of both of these sites was temporarily stopped in 1993 to permit repair and decontamination work to clean up specific locations of above-background radiation in the industrial area. No contamination of the products stored in the cavities has been reported. Beyond the limits of the industrial area, radiation levels are reported to be at background. 98

Project "Vega." In 1980, the Soviet PNE Program and Gas Production Ministry began an extensive application of the underground storage technology proven in "Sapphire" at a new site about $700 \mathrm{~km}$ south of "Sapphire," $40 \mathrm{~km}$ north-northeast of the city of Astrakhan at the north end of the Caspian Sea (see Fig. 5). This new project, called "Vega," was located on the southern edge of the newly discovered Astrakhan gas-condensate field, one of the largest gas-condensate fields discovered in the Soviet Union, many times larger than the Orenburg deposit. The Astrakhan field had a very high level of hydrogen-sulfide (25\%), almost an order of magnitude greater than that at Orenburg, contaminating the gas. In addition, the Astrakhan field was reported to have very high levels of carbon dioxide (12\%) that had to be separated out before the natural gas could be put in the distribution system. The Astrakhan gas-condensate reservoir

97 Borg, "Peaceful Nuclear Explosions" (see footnote 20).

98 Mikhailov, Nuclear Explosions in the USSR, (see footnote 13). 
occurs in a limestone formation at a depth of about $4000 \mathrm{~m}$ and is overlain by the Sentovskii salt massif that extends to about $500 \mathrm{~m}$ from the surface. 99

The first explosion at "Vega" was carried out in the salt formation on October 8, 1980, at a depth of $1050 \mathrm{~m}$. Its yield was $8.5 \mathrm{kt}$. The following year on September 26, two explosions of similar yield were carried out at about the same depth and with an interval of 4 minutes between explosions. A little over a year later, on October 16, 1982, four explosions were fired at "Vega" with an interval of 5 minutes between explosions. Russian sources give the yield for one of the explosions as $13.5 \mathrm{kt}$ with the rest being $8.5 \mathrm{kt} .{ }^{100}$ On September 24, 1983, six more explosions were carried out at the "Vega" site at intervals of 5 minutes. The yields were all $8.5 \mathrm{kt}$ at depths of about $1000 \mathrm{~m}$.

On October 27, 1984, the last two explosions were fired at the "Vega" site with a 5 minute interval between them, bringing the total at the site to 15 explosions. The depths of burial for these explosions were also $1000 \mathrm{~m}$, but their yields are given as $3.2 \mathrm{kt}$, only about a third that of the earlier explosions. Considering the very high sulfur content of the gas condensate and the size of the deposit at Astrakhan, it is suggested that these later two cavities may well be for waste storage or disposal.

The smaller yield of all the explosions at this site, in comparison with the yields at the Orenburg deposit, are attributable to the relative proximity of the large city of Astrakhan (>500,000 inhabitants) and numerous smaller towns and industrial facilities built on the Volga River delta above the Caspian Sea, all of which are susceptible to seismic damage. Seismic limitations determined the maximum single yield that was permitted, and the total storage requirements of the Astrakhan field and processing plant dictated the number of explosions. The use of several small explosions, spaced a few minutes apart, rather that one larger explosion, would allow the same storage volume to be produced with significantly lower probability of seismic damage, minimal operational costs for disruption and delay, and fewer evacuations of the local populations. The single explosion at $13.5 \mathrm{kt}$ may have been a test to see what seismic damage a larger yield would incur.

Assuming that the latter two explosions were for storage, the other 13 explosions would have produced a storage volume of about $400,000 \mathrm{~m}^{3}$, about 4 times the storage volume at Orenburg. Beginning in 1986, seven of the cavities were filled with gas condensate as part of industrial operations, two were used for waste disposal, and six were placed in reserve. The availability of these cavities reportedly permitted start-up of the production and processing of gas condensate from the Astrakhan field significantly earlier than conventional storage would have permitted.

99 Borg, "Peaceful Nuclear Explosions" (see footnote 20).

100 The first three explosions at "Vega" on Oct. 16, 1982 all had seismic magnitudes of 5.2. The last explosion was measured at 5.4. In addition, in Ref. 83, which gives the exact times for all Vega explosions, the last one at 6:15 a.m. GMT is given a yield of $13.5 \mathrm{kt}$. For these reasons, I have associated the $13.5 \mathrm{kt}$ explosion with the last of the four in Table 3. 
However, beginning in 1987, it was observed that the six empty cavities had started to converge, losing up to $40 \%$ of their volume. This was attributed to the absence of any counterpressure in the cavity and an anomolously high horizontal tectonic stress in the salt massif. Ultimately, the shrinkage led to destruction of the spherical layer of salt on the surface of the cavities, collapse of the walls into the cavity, and to fractures that allowed 5 of the 6 cavities to fill with water. The decision was made to retire the six cavities from use, and the access and other holes in the area were sealed. It is reported that none of the radioactive brine in the cavities has reached the surface. ${ }^{101}$ However, there is a published report that water from the cavities has began to appear at the surface as artesian springs containing radioactivity. ${ }^{102}$

All of the fifteen "Vega" explosions were completely contained. The areas around some of the access holes are reported to have relatively minor above-background contamination (30$40 \mu \mathrm{R} / \mathrm{hr}$ ), but beyond the industrial areas, radiation levels are at background. ${ }^{103}$ No information has been provided on possible product contamination levels.

Project "Lira." Three years after beginning Project "Vega" at the Astrakhan gas-condensate deposit, the Soviets initiated another industrial application of the underground storage technology, Project "Lira," at the Karachaganak gas-condensate field located about $140 \mathrm{~km}$ east of Uralsk and $130 \mathrm{~km}$ west of the city of Orenburg (see Fig. 5). The field, which was discovered in 1979 and actively developed in the early 1980s, is regarded as an extension of the Orenburg field and is about the same size as the Orenburg field. As at Orenburg, the natural gas and gas condensate contain high levels of hydrogen sulfide. The deep-lying Karachaganak gas reservoir field is overlain by a thick salt formation extending from near the surface in some places to depths of $4000 \mathrm{~m}$. Construction of a gas-condensate processing plant for the Karachaganak field was begun in $1983.104,105$

Project "Lira" began on July 7, 1983, with three 13.5-kt explosions at 5-minute intervals. The first two were at a depth of $917 \mathrm{~m}$, and the last at $841 \mathrm{~m}$. They were followed about a year later on July 21,1984 , by another three 13.5-kt explosions at intervals of 5 minutes. Their depths of burst were 846, 955, and $844 \mathrm{~m}$, respectively. The yields were almost double most of the yields at Astrakhan, presumably because of the distance of the "Lira" site from population centers.

These six "Lira" explosions would be expected to produce about 300,000 $\mathrm{m}^{3}$ of underground storage capacity for use in conjunction with the Karachaganak gas-condensate reservoir. At last report, four of the six, 1T through 4T, were being prepared for use for storage of gas condensate

101 A. S. Krikokhatskiy, et al., "On the Results of Nuclear Explosions Carried Out in the Astrakhan Gas Condensate Deposit for the Creation of Underground Storage," Bulletin of the Center for Public Information on Atomic Energy, 5/6, 1994, pp. 51-53, Moscow.

102 Yanshin, "The Nuclear "Genie"” (see footnote 66).

103 Mikhailov, Nuclear Explosions in the USSR, p. 148 (see footnote 13). An equally authoritative source (Ref. 66) states that there are three isolated areas with dose rates of 100-200 $\mu \mathrm{R} / \mathrm{h}$.

104 Platt's Oilgram News, 60 (214), Nov. 5, 1982.

105 L. G. Kiryukhin, "Characteristics of the Formation of Zones of Regional Highs in the Sub-Salt Complex of the Pre-Caspian Depression," Petroleum Geology, 19 (4), 1981, pp. 182-186. 
and partial separation of the natural gas, and one other, 6T, was being held in reserve. The last one to be fired, 5T, developed a leak, and the cavity and emplacement hole have filled with water. As of 1994, plans were being developed for closure of that location and sealing of the emplacement/access hole.

As with the explosions at Orenburg and Astrakhan, all "Lira" explosions were completely contained, and radiation levels are reported to be at background levels at the "Lira" site. 106

Summary of storage. Overall, the use of nuclear explosions to produce cavities in salt for the storage of liquid hydrocarbons proved to be a somewhat successful application with several serious concerns. In the three full-scale applications of the technology, over $800,000 \mathrm{~m}^{3}$ of storage were produced capable of storing some 400,000 tons of condensate. The Russians report the possibility of storing gases up to a pressure of $14 \mathrm{MPa}(140 \mathrm{~atm}$.). In all cases, the nuclear explosive emplacement hole was successfully used for post-shot access and exploitation of the cavities. Although no measurements have been reported, the Soviets report that there has been no contamination of the stored condensate product by radioactivity from the explosions.

However, the loss of six out of 23 cavities by leakage of water into the cavity raises serious questions about the safety and viability of the application. Water that leaks into a cavity will begin dissolving salt from the walls and the resolidified mass of melt at the bottom of the cavity containing the majority of the radioactive residue from the nuclear explosive. With time, the walls may begin to break up, and the water will become contaminated with soluble radioactive nuclides from the walls, puddle at the bottom of the cavity, and become hazardous to bring to the surface. Any product stored in a partially water-filled cavity will tend to absorb the water and become contaminated by the radioactivity. Only experience can define the magnitude of the environmental risk presented by this sequence of events.

\section{Deep Seismic Sounding of the Earth}

In 1971, the Soviet PNE Program, in cooperation with the Ministry of Geology, embarked on the most ambitious and far-reaching application, the use of peaceful nuclear explosions for the seismic exploration of vast reaches of the Soviet Union. In the early 1960s, the Ministry of Geology had been active in carrying out detailed studies of the Earth's crust and upper mantle in the northern Eurasian part of the Soviet Union utilizing chemical explosions spaced a few hundred kilometers apart along a line. These so-called Deep Seismic Sounding (DSS) lines permitted study of the crustal structure to depths of 30-40 km over large areas. During the late 1960s, the Ministry of Geology began a program of experimental seismic studies, recording the signals from the PNEs carried out for oil and gas stimulation and for closure of runaway gas wells. Based on this experience, they developed a program for extending their DSS program to explore geologies to much greater depths over distances of a thousand kilometers and for utilizing the much stronger seismic signals of nuclear explosions (see Section B.5 of Appendix B).

106 Dubasov, et. al., "Underground Explosions" (see footnote 25). 
Figure 6 is a map of the Soviet Union showing the location of 15 DSS lines that were carried out over the next 17 years and the location of the PNEs associated with the DSS program. Section B.5 of Appendix B provides the data for the DSS explosions and indicates the DSS lines listed in Fig. 6 with which they were associated. 107,108

Although the signals from PNEs carried out for other purposes and weapons tests at Semipalatinsk were undoubtedly utilized, ${ }^{109}$ the vast majority of data were generated by the 39 PNEs specifically fired as part of the DSS program. As can be seen in Appendix B, all of the DSS explosions were carried out at depths of burial of 500-1000 m, much greater than the minimum depth required for containment. Yields varied between 2.3 and $22 \mathrm{kt}$, with the majority less than $10 \mathrm{kt}$.

The seismic lines extended over distances that ranged from 1500 to $4000 \mathrm{~km}$, with three to four nuclear explosions typically spaced at distances of 500 to $900 \mathrm{~km}$ along those lines. Hundreds of "Taiga" portable seismometers were located along each line, many placed by helicopters because of the remoteness of the regions, at spacing of about 10-20 km. Their signals were transmitted to central recording stations.

Almost every year from 1971 to 1984, a different DSS line was investigated with three or four explosions. The explosions for a particular line were generally carried out at intervals of 10 to 30 days in the late Summer and Fall. However, in one line that involved only two explosions, they were fired about one hour apart. Shot times were often late at night or early in the morning to reduce cultural background noise. In many cases, the nuclear explosions were augmented by chemical explosions, sometimes delivered as bombs from aircraft because of the difficult terrain and lack of roads.

In the early 1970s, several DSS lines in the European and Caspian regions of the Soviet Union were explored, moving from west to east. Beginning in 1975, exploration of Siberia east of the Urals began and was the focus of activity for the next ten years.

Relatively few reports have been published describing the results of these DSS lines and the crustal and mantle structure derived from them. The few to have appeared have generally referred to the nuclear explosions as "large industrial explosions."110,111

107 H. M. Benz, et al., "Deep Seismic Sounding in Northern Eurasia," EOS, Vol. 73, No. 28, July 14, 1992 , pp. 297-300.

108 J. F. Scheimer and I. Y. Borg, "Deep Seismic Sounding with Nuclear Explosives in the Soviet Union," Science, Vol. 226, No. 4676, 16 Nov., 1984, pp. 787-792.

109 Reference 13 states that two DSS profiles used PNEs fired for other purposes, but does not identify them. Reference 107 lists the Oka (Neva) oil stimulation explosion on November 5, 1976 as a source for the Bortuoba-Tungus-Khaya Line.

110 A. V. Egorkin, "Studies of Mantle Structure of USSR Territory on Long-Range Seismic Profiles," Phys. Earth Planet Int., Vol. 25, p. 12, 1981.

111 A. V. Egorkin and V. V. Kun, Phys. Earth Planet Int., Vol. 14, p. 262, 1978. 


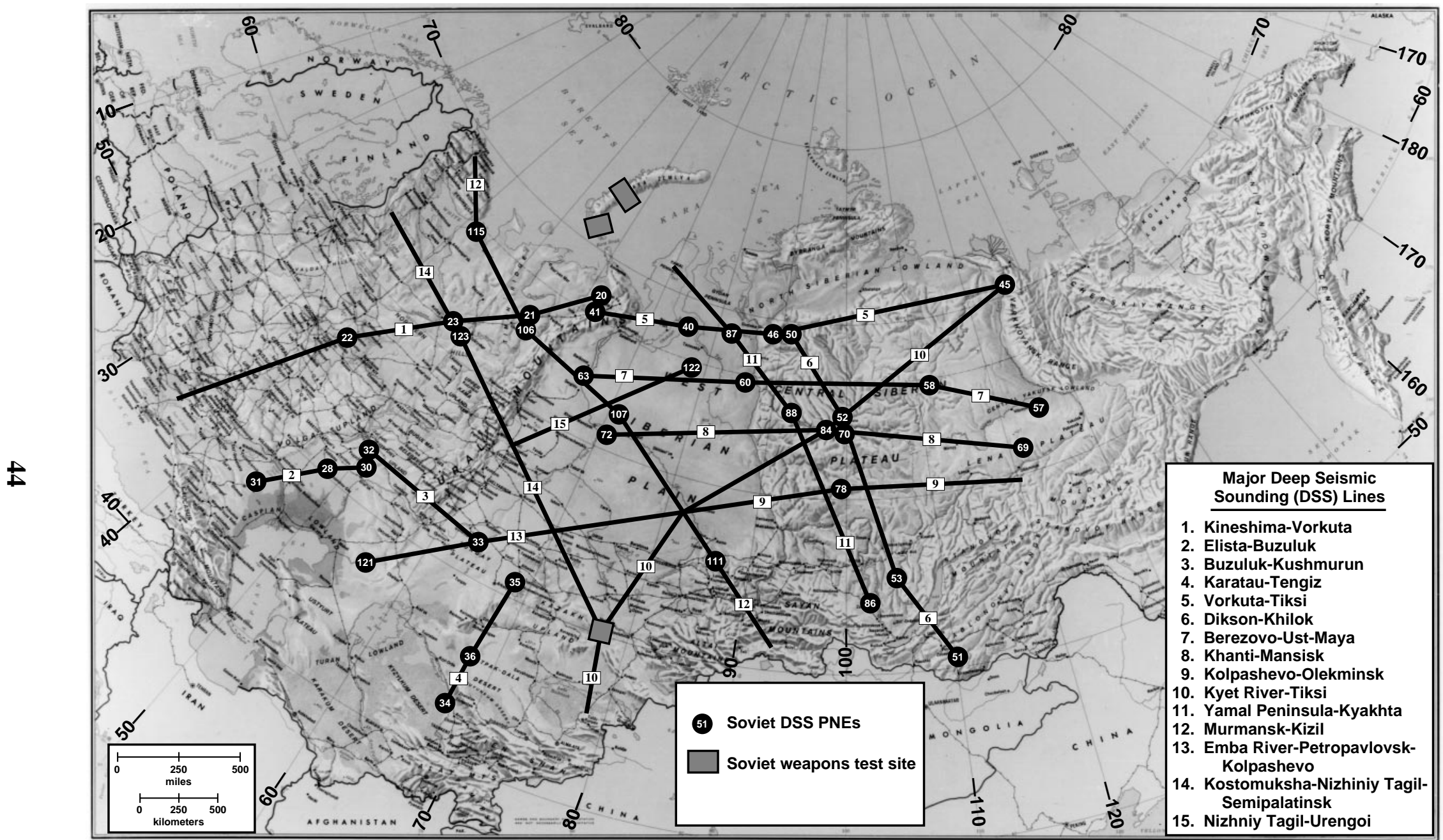

Figure 6. Map of Soviet Union showing the Deep Seismic Sounding (DSS) explosions and the DSS lines connecting them along which seismometers were placed every $10-20 \mathrm{~km}$ to record the seismic signals to learn about the structure of the crust and upper mantle. 
The first publication to include reference to one of the nuclear lines appeared in 1973,112 but it included little detail derived from the nuclear explosions. It was not until 1977-78 that results began appearing in geophysical journals. Generally, geologic profiles derived from DSS lines utilizing nuclear explosion sources are characterized by structural details and velocity profiles to depths of 200-300 km, well below the 35-km depth of the Morohovic velocity discontinuity, which generally limits the depth of conventional profiles. Papers describing the geologic structure of specific DSS lines utilizing PNEs can be found in references 108 and 109. More recent structural studies can be found in references 113-115. 113,114,115 Much of the data collected on the DSS profiles has now been made available to other agencies and, through exchange agreements, with geologists from other countries. ${ }^{116}$ The limited results from the use of these data may well be due to the limited computational capability available to the ministry of Geology who closely held the data for many years.

Although specific details have not been provided, this work is described as being of great value not only for defining the general structure of the crust but also for identifying areas with high potential for gas, oil, and mineral development. Specifically, MinAtom claims that the existence of ten gas and gas condensate deposits in the Yenisey-Khatanga Basin east of Norilsk and about ten more in the developing areas of the Vilyuysk syncline in Eastern Siberia have been confirmed through use of data from the DSS profiles.

All of the DSS explosions were carried out without escape of radioactivity, with three exceptions. The third and fourth DSS explosions on the first DSS line in 1971, "Globus-1" and "Globus-2," suffered minor leakage of gaseous radionuclides from the emplacement hole. The areas near the emplacement holes were decontaminated, and radiation levels are at or near regional background.

A more serious vent accompanied the "Kraton-3" explosion on August 24, 1978, $120 \mathrm{~km}$ from the remote village of Aikhal in Siberia. This is in a region of permafrost. In the process of drilling or stemming the emplacement hole, some of the medium adjacent to the hole was melted, which resulted in a failure of the stemming seal and a dynamic vent of gaseous radioactivity and steam to the atmosphere at the time of the explosion. Measurable radioactivity was carried over $150 \mathrm{~km}$ over unpopulated forest and tundra. Radiation surveys in 1990 showed levels of $1 \mathrm{mR} / \mathrm{hr}$ in the immediate vicinity of the hole and up to $0.2 \mathrm{mR} / \mathrm{hr}$ as far as $5 \mathrm{~km}$ in the fallout trace. Following decontamination of the area, levels are reported to be $30-50 \mu \mathrm{R} / \mathrm{hr}$ outside a $2 \mathrm{~km}$ exclusion zone, which is periodically monitored. 117,118

112 I. S. Vol'vovskiy, Seismic Studies of the Earth's Crust in the USSR, Nedra, Moscow, 1973.

113 S. M. Zverev, and I. P. Kosminskaya, Eds., Seismic Models of the Main Geostructures of the USSR Territory, Nauka, Moscow, 1980.

114 A. V. Egorkin, et al., "Results of Lithospheric Studies from Long-Range Profiles in Siberia, Seismic Studies of the Continental Lithosphere," Tectonophysics, 140, pp. 29-47, 1987.

115 V. Ryaboy, Upper Mantle Structure Studies by Explosion Seismology in the USSR, Delphic Press, 1989.

116 Benz, et al., "Deep Seismic Sounding” (see footnote 107).

117 Personal Communication, V. Simonenko, 1993.

118 Dubasov, et. al., "Underground Explosions" (see footnote 25). 


\section{Breakage of Ore}

As experience was gained with underground nuclear explosions in hard rocks from the nuclear weapons tests, the idea of using PNEs to assist with mining ores and other minerals from the earth quickly developed both in the U.S. and the Soviet Union. In the late 1960s, the Soviet PNE Program began looking for a good site to apply this new technique. The U.S. Plowshare Program had looked at several techniques for using nuclear explosions to break up large ore bodies for insitu processing to recover the valuable resource. Most of these techniques envisaged placing a 10- to 20-kt nuclear explosion at the bottom of a deposit and, depending on the collapse of the explosion cavity to form a collapsed chimney of broken rock, above the explosion point. Recovery would be carried out utilizing drifts mined back through the chimneys.

Soviet PNE scientists at Chelyabinsk, in cooperation with engineers from the Moscow Mining Institute and the All-Soviet Institute of Industrial Technology (VNIPI), developed a concept for using much smaller explosions (2-4 kt), which were more suitable for the more widespread small deposits. ${ }^{119},{ }^{120}$ This concept involved mining vertical slots about $45-60 \mathrm{~m} / \mathrm{kt}^{1 / 3}$ distant from the explosion to provide a free surface that would reflect the shock wave from the explosion, greatly enhancing the volume and extent of breakage of the rock and reducing the compaction. It was expected that five to ten times more rock would be fractured in this way than would be found in the chimney from the same yield explosion. The slot would also weaken the shock wave and help to protect any other workings or structures beyond the slot. A network of crossdrifts would be mined below the body of broken ore for recovery by the usual stope-mining methods. ${ }^{121}$

Project "Dnepr." The first experiment using this concept was carried out on September 4, 1972, in the Kuel'por apatite (phosphate) ore deposit about $21 \mathrm{~km}$ north of the city of Kirovsk on the Kola Peninsula, about $150 \mathrm{~km}$ from the Finnish border (see Section B.6 of Appendix B). A 2.1-kt nuclear explosion was positioned immediately below the ore body, which was $60-80 \mathrm{~m}$ thick and sloping into the mountain at about a 25- to 35-degree angle. A 50-m-high vertical slot was mined about $50 \mathrm{~m}$ away on the opposite side of the deposit (see Fig.7a). The shock wave produced a volume of about $100,000 \mathrm{~m}^{3}$ of broken ore.

In an effort to reduce the possibility of contaminating the ore body with radioactivity from the explosion, "with the aid of a special device the radioactive products from the explosion cavity were ejected into barren rock" some $120 \mathrm{~m}$ away from the ore body. This technique was first tested by the Chelyabinsk Laboratory in the "148/1" test in the Degelen Mountains at the Semipalatinsk Test Site a year and a half earlier on April 9, 1971. No information is available on

119 V. A. Bychenkov, "Effect of the Slit Position and Width on the Amount of Rock Crushed by an Explosion," Fiziko-Tekhnicheskie Problemy Razrabotki Iskopaemykh, No. 2, pp. 53-58, 1973.

120 V. R. Imenitov, "Questions on the Use of Nuclear Explosions for Underground Ore Production," Gornyi Zhurnal, No. 12, p. 33-36, 1973.

121 M. D. Nordyke, “A Review of Soviet Data on the Peaceful Uses of Nuclear Explosion,” (see Ref. 19). 


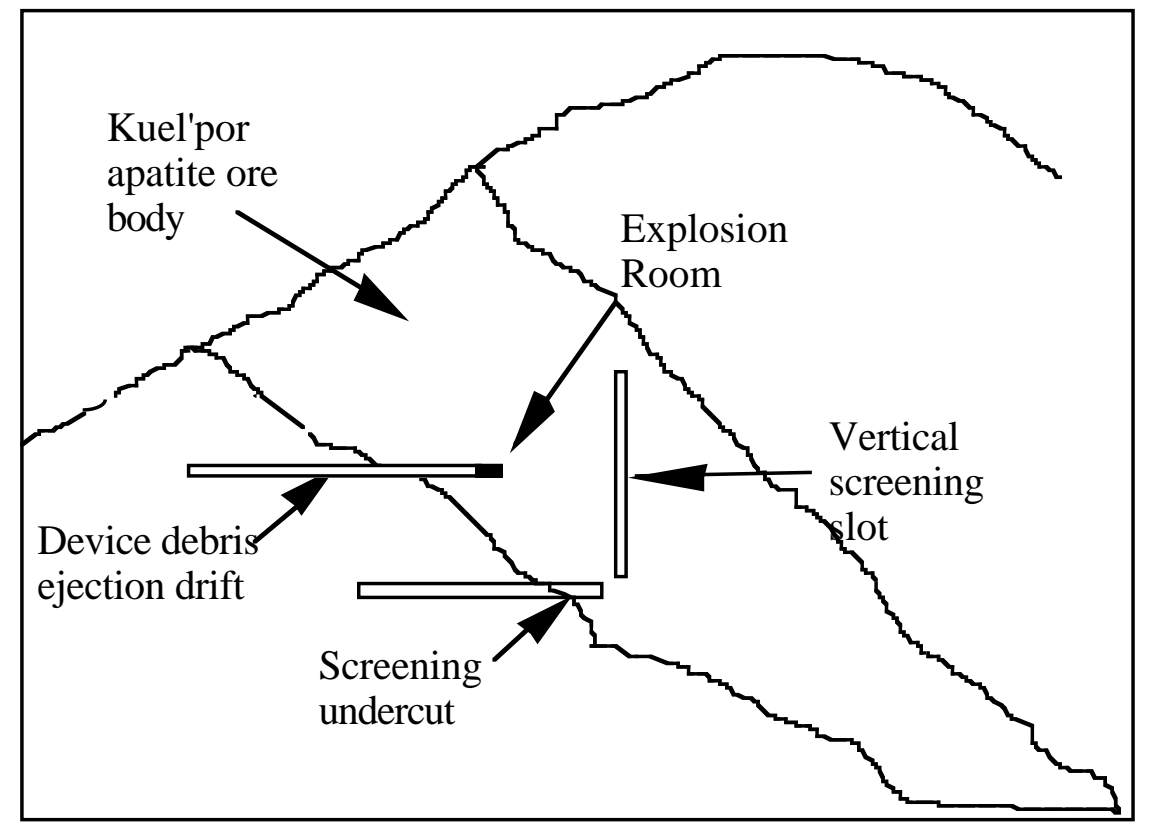

Figure 7a- Schematic of "Dnepr-1" Experiment

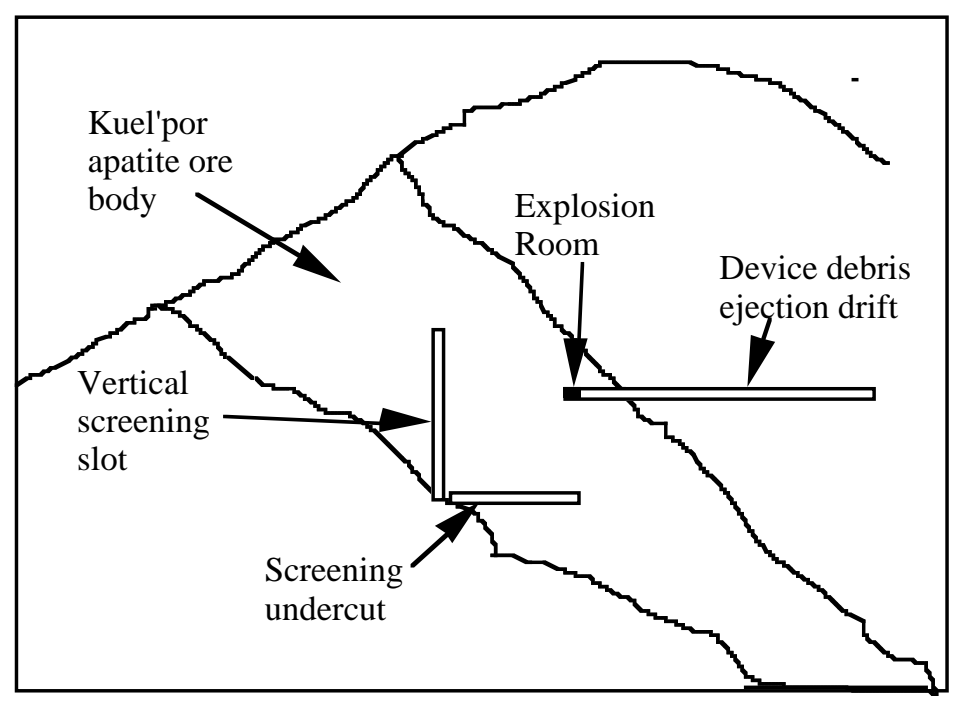

Figure 7b - Schematic of "Dnepr-2" Experiment

Figure 7. Schematic of (a) the "Dnepr-1" experiment and (b) the "Dnepr-2" experiment. 
how well this technique worked, but an additional test of the idea was carried out at Degelen in the "148/5" event on December 16, 1974, this time by the Arzamas Laboratory. 122,123 (See Appendix C.)

Twelve years later, a second explosion, "Dnepr-2," was carried out in the mine on August 27, 1984. For this experiment, two 1.8-kt explosions were fired simultaneously in separate drifts $75 \mathrm{~m}$ apart. The scheme for ejecting the device debris out of the cavity and down a 120-m tunnel was again utilized to remove radioactivity from the region of broken ore. Although details have not been provided, the method of ejecting the radioactive debris from the explosion down a tunnel and out of the valuable ore deposit is described by MinAtom as a success. ${ }^{124}$

Again, in preparation for this explosion, a vertical screening slot was constructed about $50 \mathrm{~m}$ from the explosions that was $125 \mathrm{~m}$ wide and extended $40 \mathrm{~m}$ above the explosion horizon and $50 \mathrm{~m}$ below. Screening drifts were also mined below this block of ore (see Fig. 7b). The shock wave from the "Dnepr-2" explosions fractured about 500,000 to $600,000 \mathrm{~m}^{3}$ of ore. In total, the two experiments were calculated to have broken over one and a half million tons of apatite ore.

A total of 396,000 tons of ore broken by "Dnepr-1" and "Dnepr-2" were removed from the Kuel'por mine over the period from 1972 to 1990 using standard stope-mine practices in the drifts below the blocks by the explosions. Secondary blasting required only about 12-13 g of HE per ton to break up oversized blocks instead of the $80-100 \mathrm{~g}$ per ton required by the usual mining practice in this deposit.

Immediately after the "Dnepr-1" explosion, leakage of gaseous radionuclides led to exposures in the city of Kirovsk of 30-40 mR, about $10 \%$ of annual background doses, during its passage and dissipation. Leakage from the 1984 explosion was delayed by up to 10 hours and led to little exposure off site.

Radiation conditions in the mines were reported to be essentially the same as in normal mining operations and did not exceed established safety norms; thus, no special measures were required for miner safety beyond standard practices. Radioactivity levels in the ore were also reported to be below permissible levels. Air and water within the mine and in the nearby rivers and lakes were routinely monitored for various radionuclides such as $\mathrm{Sr}^{90}, \mathrm{Cs}^{137}, \mathrm{Pu}^{239}$, and tritium. MinAtom reports that no radioactivity levels above maximum permissible dosage were observed, except for tritium in water from the ore body, which exceed maximum permissible levels by a factor of 1.5 to 2 on occasion. In general, radiation levels in the area surrounding the site are reported to be at background levels. 125

122 Mikhailov, Nuclear Explosions in the USSR, p. 64 (see footnote 13).

123 Ibid., p. 91.

124 Ibid., p. 64.

125 Ibid., pp. 63-66. 
The "Dnepr" site has been closed since 1992, but it is subject to periodic monitoring. Overall, the experiments are described by MinAtom as being successful, although, as of 1994, the mined ore was awaiting the construction of an access road before it could be sent to a refinery for processing. However, as information about the "Dnepr" experiments became public in the late 1980s and early 1990s, environmental organizations in the area have raised protests and called for an end to any further such experiments. 126

\section{Disposal of Toxic Waste}

Industrial development in the Soviet Union over the last 60 to 70 years has left a legacy of industrial contamination that is probably unparalleled in the modern world. Contamination of water supplies by dumping industrial wastes of chemical and oil industries into rivers and lakes has endangered the drinking water supplies of many towns and cities. In an effort to develop a technology that could be used to dispose of some of the worst types of industrial effluents and buy time for the development of better industrial waste treatment procedures and facilities, early in the 1970s the scientists from the Soviet PNE Program and the Ministry of the Oil Refining and Oil Chemical Industries proposed two experiments using nuclear explosions to produce deep disposal facilities (see Section B.7, Appendix B).

Deep-well disposal utilizes the fact that a 5- to 10-kt nuclear explosion creates a large fractured region, which, in some cases, extends to 100-200 $\mathrm{m}$ from the explosion, and that the chimney produced by the collapse of the cavity would contain 100,000 to $150,000 \mathrm{~m}^{3}$ of broken and crushed rock and 30,000 to $50,000 \mathrm{~m}^{3}$ of void space. The large central chimney provides surface area and volume for the deposition of suspended particulates, and the large fracture radius provides an enormous area for liquids to percolate into the surrounding formation. To assure that percolation of the chemical wastes or any radioactivity leached from the glassy melt would not contaminate potable water supplies, the geologic layer must be deep and isolated from any mobile water layers.

Project "Kama." The sites chosen for the two "Kama" waste-disposal experiments were not far from the first oil stimulation site ("Butane") and the gas-condensate storage sites ("Magistral," "Sapphire," and "Lira") in the Bashkir Republic, $30 \mathrm{~km}$ west of the city of Sterlitimak. A depth of burial about 2000-2100 m was selected that would place the explosion and chimney in the middle of a 400-m-thick, dense carbonate section (dolomite), which was isolated from potable water sources. Both explosions used special 10-kt devices, sufficiently small that the size of the emplacement holes were determined by pumping requirements.

The first "Kama" explosion, "Kama-2," was fired on October 26, 1973. Exploitation of the site did not begin until 1976, when industrial waste began to be pumped from the Sterlitimak soda factory into the chimney through three holes. Flow from the soda factory contained 50-100 mg/L of suspended solids that were chemically incompatible with the water in the injection layer resulting in the precipitation of more than $1000 \mathrm{mg} / \mathrm{L}$ of additional solids. In a normal injection

126 “Leakage of Radiation after 1974 Explosion on Kola Peninsula,” USSR Today, Oct. 28, 1991, p. 20. 
hole, this would have rapidly led to plugging of the hole. However, in the case of "Kama-2," more than 23,000,000 $\mathrm{m}^{3}$ of industrial wastes carrying more than 1000 tons of suspended solids have been disposed of in the period between 1976 and 1993. Use of the "enlarged" disposal hole continues with an average flow of 4,000-5,000 $\mathrm{m}^{3}$ per day. Savings to the environment over that same period of time through the use of this site have been put at more than 70 million rubles (1990).

The second "Kama" explosion, "Kama-1," was fired 10 months later on July 8, 1974. Exploitation of this site did not begin until 1983 when the disposal of highly toxic waste flows from the Salavat oil refinery began. This waste contained suspended particulate with resinous materials having an exceptionally high capability to clog pores in any conventional disposal site. These flows contained between 100 and $1000 \mathrm{mg} / \mathrm{L}$ of these particulates and were not disposable by any other method known at the time. In the period between 1983 and 1993, about 700,000 $\mathrm{m}^{3}$ of industrial waste from the Salavat oil refinery were disposed at an estimated savings to the environment of 100 to 200 million rubles (1990).

Observation holes are being used to monitor water tables in the area for the transport of waste materials and radionuclides from the sites. To date, no industrial waste material has been detected in the water layers overlying the injection layer. Observation holes 500-1000 m from the explosion sites at the depth of the injection layers detected radioactivity in the water flowing out of the chimney into the carbonate formation, but within 5 to 6 months after injection began, the gamma activity level was essentially at background.

The explosions were completely contained with no prompt vent or leakage of radioactivity. Although there are some slightly contaminated areas near the emplacement holes-probably due to re-entry drilling and water table observation holes-beyond the industrial area the radiation levels are reported to be at background. ${ }^{127,128}$

Overall, this would appear to be a highly successful application. For that reason, it is curious that it was not used at any other sites in the Soviet Union or Russia in more recent times.

\section{Transplutonic Element Production}

From the beginning, Soviet scientists at the nuclear weapons laboratories were interested in the possibilities of using the large flux of neutrons generated in a nuclear explosion for scientific purposes and to breed new, heavier elements. Interest in such applications played a key role early in the U.S. Plowshare Program. Such applications are the subject of papers at both the first and

127 A. P. Vasil'ev, N. K. Prikhod'ko, and V. A. Simonenko, "Underground Nuclear Explosions for Improvement of Ecological Conditions," Priroda, 1991, No. 2, pp. 36-42.

128 Mikhailov, Nuclear Explosions in the USSR, pp. 54-57 (see footnote 13). 
second Plowshare Symposiums in 1957 and 1959129,130 and of the design of the first U.S. Plowshare experiment, Project "Gnome."131 As discussed above, interest by the U.S. in using the high flux of neutrons focused on designing special nuclear devices to produce new, super-heavy elements well beyond uranium and plutonium through multiple neutron capture. The ultimate goal was to determine the physical properties of any new elements produced and to advance our understanding of the atomic nucleus.

Early on, the interest of Soviet scientists in the use of large neutron fluxes was directed at the possibility of using them to produce trace quantities of transplutonic actinide elements through multiple neutron capture as well as useful quantities of plutonium 238 and 239 and uranium 232 and 233 through single or double neutron capture. Any such elements produced would then be recovered and used for isotope production or as fissile material. Such elements can be produced internal to a nuclear device as well as by capturing the neutrons produced by a nuclear explosion in a uranium 238 or thorium 232 blanket placed around the nuclear device. The difficult problem is recovering the isotopes in an economical and timely fashion. The Arzamas Laboratory was the lead laboratory for this program (see Section B.8, Appendix B). ${ }^{132}$

One of the primary purposes of the first two explosions in the salt domes at the Azgir site, "Halite A-1" and "Halite A-2," was to provide an experimental site for studying the potential of salt cavities for use in the production of these new isotopes. A nuclear explosion detonated in a large water-filled cavity will deposit the vast majority of its energy in the water. A small portion of the water would be immediately vaporized, but if the cavity is sufficiently large, the average temperature of the water in the cavity will be elevated only a few degrees. For example, if a 1-kt explosion were detonated in the "Halite A-2" cavity containing 140,000 $\mathrm{m}^{3}$ of water, it would raise the temperature of the water about $7^{\circ} \mathrm{C}$. The water would then cool and congeal the vaporized debris of the device and any material close to it. The condensed debris would then settle to the bottom of the cavity where it could be easily recovered.

“Halite A-2-1 to A-2-6." Beginning in April 1975, Soviet scientists began carrying out small explosions in the water-filled "Halite A-2" cavity, using nuclear explosives designed to enhance neutron capture for the production of transplutonic and other actinide elements. The first test, A2-1, was $0.35 \mathrm{kt}$ at a depth of $583 \mathrm{~m}$, about $14 \mathrm{~m}$ above the center of the 32-m-radius cavity. Access was through the original emplacement hole. It has not been reported whether attempts were made to recover debris from the bottom of the cavity for this explosion, but two years transpired before the next experiment.

129 J. A. Wheeler, "Plutonium Breeding, Collection of Materials," in Industrial Uses of Nuclear Explosives, UCRL-5253, Sept. 8, 1958, pp. 79-81.

130 M. W. Nathans, "Recovery of Isotopes," in Proceedings of the Second Plowshare Symposium, Part III, UCRL-5677, May, 14, 1959, pp. 24-32.

131 C. E. Violet, "Project Gnome," in Proceedings of the Second Plowshare Symposium, Part III, UCRL-5677, May, 14, 1959, pp. 4-12.

132 Personal communication, Vadim Simonenko. 
The next experiment, A-2-2, was a 0.10-kt explosion carried out in the A-2 cavity on October 14,1977 , which was quickly followed by the third explosion, A-2-3, an explosion of only $0.01 \mathrm{kt}$ 16 days later on October 30. Again, no information is available on whether any recovery was attempted between these two explosions.

The last three transplutonic element experiments were carried out about two years later. On September 12, 1978, a 0.08-kt explosion was again detonated in the A-2 cavity. Three months later, on November 30, a 0.06-kt explosion followed. Two months later, on January 10, 1979, the last explosion in this series was fired. It was the largest of the six at $0.5 \mathrm{kt}$.

All of these explosives were fired at a depth of about 581-585 m, which would place them about $14 \pm 2 \mathrm{~m}$ above the center of the initial cavity. Since the resolidified melt occupies a spherical segment on the bottom of the cavity about $10 \mathrm{~m}$ thick, such a position for the explosions would place them approximately in the center of the water volume.

Unfortunately, no further information has been provided by MinAtom on the details of the experiments, the methods used to recover debris from the explosions, or to what extent the program was successful in producing transplutonic and other actinide elements.

All of the transplutonic explosions were carried out without venting. However, recovery operations undoubtedly resulted in some contamination of the general area around the emplacement hole. The "Halite A-2" cavity has now been closed, and the area has been decontaminated. Beyond the working area, radiation levels are at natural background levels. ${ }^{133}$

"Halite A-4 to A-11." About a year after the first transplutonic element experiment, the Soviets began to carry out a series of large-yield explosions in the Eastern Azgir salt dome. The first of this series, A-4 on July 7, 1976, was a 58-kt explosion at a depth of $1000 \mathrm{~m}$, an almost exact duplicate of the A-3 explosion in 1971. It was followed a little over a year later on September 9, 1977, by A-5, a 9.3-kt explosion at a depth of $1503 \mathrm{~m}$.

Over the next two years, the Soviets carried out five more large yield explosions, A-7 to A-11, in the Eastern Azgir Dome with yields that varied from 21 to $103 \mathrm{kt}$ at depths that ranged from 630 to $1500 \mathrm{~m}$.

As with the cavities created for gas-condensate storage, the Soviets experienced unexpected results in at least one case. The cavity created by A-9, the largest yield of all the explosions at Azgir, collapsed at an early time. and the collapse propagated to the surface. This resulted in the formation of a subsidence crater $500 \mathrm{~m}$ in diameter and $18 \mathrm{~m}$ deep. However, there was no release of radioactivity during or after the collapse. The other six cavities initially were sealed with respect to water leakage and stable.

133 Mikhailov, Nuclear Explosions in the USSR, p. 146 (see footnote 13). 
MinAtom has not reported on the purpose for the series of seven explosions, but there are several possibilities. They could well have been intended to be a stockpile of cavities for possible use in future production of fissile materials, using the "breeding" ideas then being studied in the transplutonic production experiments in the A-2 cavity. However, the great variation in the yield and size of the resultant cavities would be somewhat inconsistent with such use. Alternatively, they could have been weapons tests diverted from the Semipalatinsk Test Site. If so, it would explain why the yields are so variable. This view is supported by the fact that the A-10 event on October 24, 1979, has recently been reported to consist of two explosions, one less than $20 \mathrm{kt}$, and the other greater than $20 \mathrm{kt}$. The total yield is reported to be $33 \mathrm{kt} .{ }^{134}$ Finally, they could be a combination, weapons tests that were used to create cavities at Azgir for future industrial use.

Table 5 summarizes the data on the Halite cavities at Azgir together with calculated radii and volumes using the formula developed in the U.S. Plowshare program. ${ }^{135}$

Table 5. Summary of Data on the "Halite" Cavities at Azgir.

\begin{tabular}{|l|c|c|c|c|c|}
\hline $\begin{array}{c}\text { Cavity } \\
\text { name }\end{array}$ & $\begin{array}{c}\text { Yield } \\
(\mathbf{k t})\end{array}$ & $\begin{array}{c}\text { Depth } \\
(\mathbf{m})\end{array}$ & $\begin{array}{c}\text { Actual radius } \\
(\mathbf{m})\end{array}$ & $\begin{array}{c}\text { Calc. radius } \\
(\mathbf{m})\end{array}$ & $\begin{array}{c}\text { Calc. volume } \\
(\mathbf{m} \mathbf{3})\end{array}$ \\
\hline A-1 & 1.1 & 161 & $12-14$ & 17 & 19,400 \\
A-2 & 27 & 597 & 32 & 32 & 137,500 \\
A-3 & 64 & 986 & 36.2 & 37 & 204,050 \\
A-4 & 58 & 1000 & & 35 & 182,900 \\
A-5 & 9.3 & 1503 & & 17 & 21,040 \\
A-7 & 73 & 971 & & 38 & 235,400 \\
A-9 & 103 & 630 & & 49 & 487,200 \\
A-8 & 65 & 995 & & 37 & 205,500 \\
A-11 & 21 & 982 & & 25 & 68,600 \\
A-10 & 33 & 982 & & 29 & 106,900 \\
& & & & Total volume & $=1,668,490$ \\
\hline
\end{tabular}

Although there is relatively little agreement for A-1, which was poorly documented because of collapse, the agreement for A-2 and A-3 is excellent. Of particular interest is A-5, which had an order-of-magnitude greater yield than A-1 but which, because of the much greater depth of burial, produced a cavity about the same size as A-1. The total volume calculated for all the cavities at Azgir is about 1,670,000 $\mathrm{m}^{3}$, in good agreement with the MinAtom number of $1,600,000 .{ }^{136}$ In all, nine standing cavities with diameters ranging from 34 to $76 \mathrm{~m}$ were formed with a total volume of about $1,200,000 \mathrm{~m}^{3}$, two of which are full of water.

134 USSR Nuclear Weapons Tests and Peaceful Nuclear Explosions, 1949 through 1990 , RFCN-VNIIEF, Sarov, ISBM-85165-062-1, 1996.

135 G. H. Higgins and T. R. Butkovich, Effect of Water Content, Yield, Medium, and Depth of Burst of Cavity Radii, Lawrence Livermore Laboratory, UCRL- 50203, Feb. 1967.

136 Yu. V. Krivokhatskiy, et al., "Radiation Manifestations of Underground Explosions for Peaceful Purposes at the Bolshoy Azgir Deposit," Bulletin of the Center for Public Information on Atomic Energy, 9/93, pp. 4959, 1994, Moscow. 
All of the Azgir explosions in this series were completely contained except for A-8, which experienced early leakage of inert radioactive gases at $60 \mathrm{~min}$. Of particular interest is A-5, which had almost an order-of-magnitude greater yield than the emplacement hole. During planned reentry into the explosion cavities for post-shot examination and utilization, a total of $4.7 \mathrm{mCi}$ of radionuclides were vented to the atmosphere under controlled conditions.

At present, five of the nine standing cavities (A-1, A-2, A-3, A-4, and A-5) have been flooded by water leaking in from overlying aquifers. By late 1990, sites A-1, A-4, A-7, A-8, and A-11 had been closed and decontaminated. Radiation levels in the areas near the emplacement/access hole were 8-20 $\mu \mathrm{R} / \mathrm{hr}$, about equal to background. As of April 1993, sites A-2, A-3, A-5, and A10 were being closed and decontaminated, if necessary. The A-10 cavity is being used for burial of soil from throughout the Azgir complex. The radiation conditions of the entire site have been well documented and are under periodic radiation monitoring. ${ }^{137}$

\section{Seismic Decoupling Experiment}

Early in the history of test ban discussions between the U.S. and the Soviet Union, the concept of decoupling or reducing the seismic signal from a nuclear explosion was introduced. In the Fall of 1958 at the Geneva Conference on Banning Nuclear Tests, the U.S. submitted the argument that any test ban agreement must take into consideration the possibility that a nuclear weapon test carried out inside a large cavity would have its seismic signal reduced by a factor of 100-300, making it very difficult to detect by seismic means. ${ }^{138}$ The Soviet Union very strongly rejected the concept and refused to consider any of the theoretical arguments made by U.S. scientists.

In an effort to prove the feasibility of the decoupling concept, the U.S. Vela Program sponsored a pair of tests in the mid-1960s. In the 1964 SALMON explosion, the U.S. fired a 5.3kt device at a depth of $828 \mathrm{~m}$ in a salt dome near Hattiesburg, Mississippi, to create a 34-mdiameter cavity. ${ }^{139}$ Two years later, in the STERLING test, a 0.35-kt nuclear explosion was detonated in the SALMON cavity. The scaled radius of the cavity was only $24 \mathrm{~m} / \mathrm{kt}^{1 / 3}$. The seismic signal was partially decoupled by a factor of about 72 , confirming the decoupling concept although not testing the full decoupling capability of the technique. That would have required a larger cavity or a smaller-yield decoupling explosion. ${ }^{140}$

In the Spring of 1976, the Soviets decided to carry out a similar seismic-decoupling experiment in the A-3 cavity (see Section B.9, Appendix B). On March 29, they fired "Halite A-

137 Ibid.

138 In this context, it was argued that the radius of the cavity in meters would have to be equal to 30-40 times the cube root of the yield of the explosion being decoupled in order to fully decouple.

139 G. Werth and P. Randolph, “The SALMON Seismic Experiment,” J. Geophys. Res., 71:3405-13, Jul. 1966; D. Rawson, et al., "Review of the SALMON Experiment - A Nuclear Explosion in SALT,"

Naturwissenschaften, 54: 525-31, Oct. 1967.; and D. Rawson, et al., "Post-Explosion Environment resulting from the SALMON Event,” J. Geophys. Res., 71:3507-21, Jul. 1966.

140 This decoupling factor is based on relatively close-in seismic data (less than $110 \mathrm{~km}$ ), which are the only data available. 
3-1," a 10-kt nuclear explosion at a depth of $990 \mathrm{~m}$ in the A-3 cavity. ${ }^{141}$ That depth would place it approximately at the center of the cavity. The scaled radius of the cavity was only $16 \mathrm{~m} / \mathrm{kt}^{1 / 3}$ in terms of the decoupled explosion yield. Because of the smaller scaled radius of the cavity relative to the STERLING explosion, it was decoupled even less.

Figure 8 is a plot of the seismic body wave magnitudes recorded for most of the explosions in salt at Azgir, including the transplutonic production explosions in the water-filled A-2 cavity as well as the signal from A-3-1, the decoupled explosion in the A-3 cavity. Also shown is a

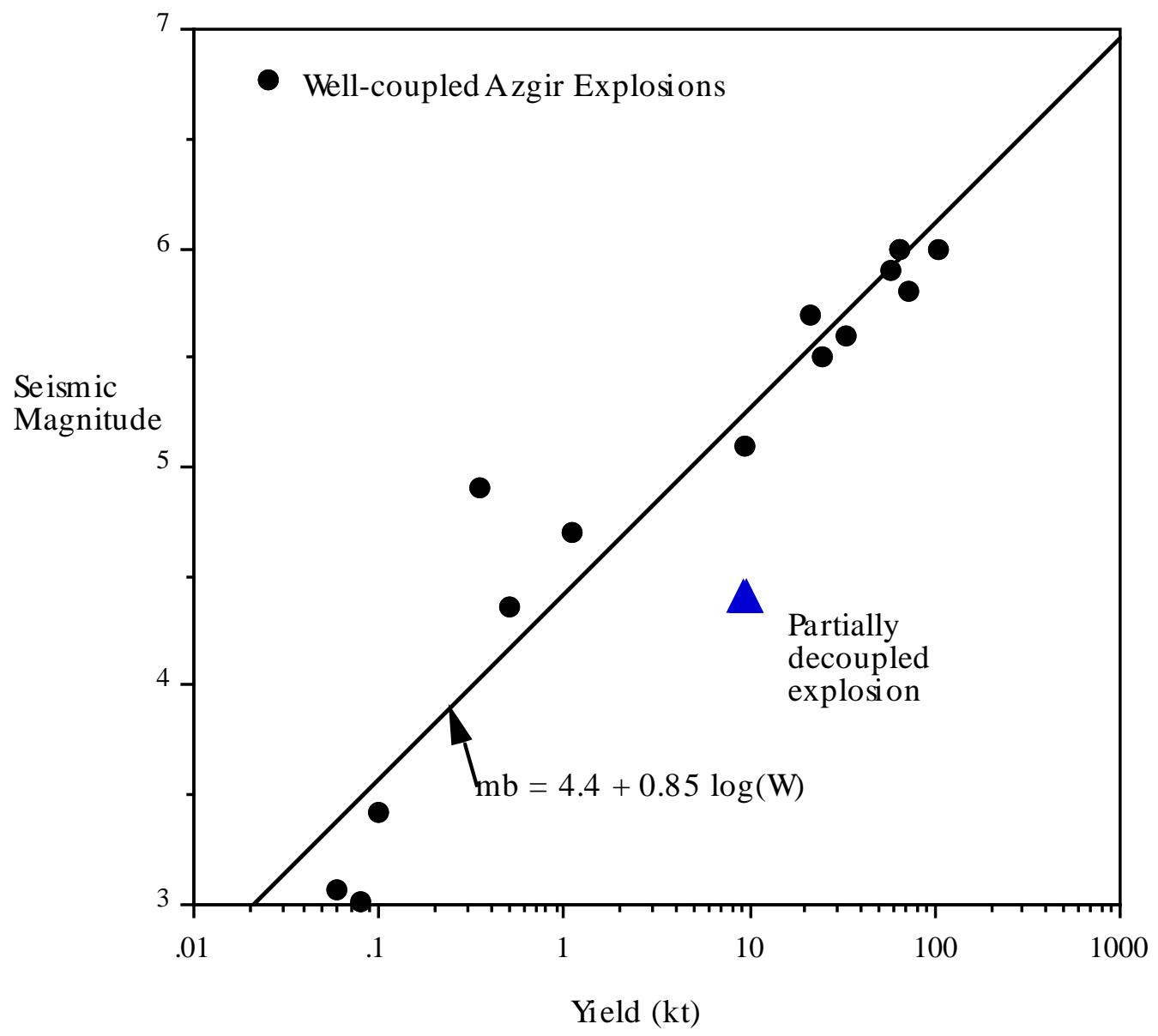

Figure 8. Plot of seismic magnitude vs yield for well-coupled "Halite" explosions at the Azgir site as well as the partially decoupled A-3-1 explosion. Also shown is a regression fit to the well-coupled Azgir explosions.

141 Reference 84 gives the yield of this explosion as $8 \mathrm{kt}$, based on a hydrodynamic measurement in the cavity. However, a chief weapons designer at Arzamas Laboratory has privately stated (See Ref. 142) that the yield, measured by a much more reliable method (radiochemistry) was $11.5 \mathrm{kt}$. The yield given in the text and used in this paper is the one provided by MinAtom in Ref. 13. 
regression fit to the fully-coupled Azgir data. Based on calculations by U.S. scientists, the decoupling factor for A-3-1, using a yield of $10 \mathrm{kt}$, would be about 15 based on teleseismic data, and 23 based on close-in data (recorded at less than $100 \mathrm{~km}$ ). ${ }^{142}$

The relatively low degree of decoupling produced by this equipment would contribute little to the issue of how full decoupling could be used to hide weapons tests under a comprehensive ban on testing, raising questions as to whether this was the primary purpose of this test. An alternative rationale, reported by Vitaly Adushkin, Director of the Russian Institute for Dynamics of the Geosphere, is that the purpose of the second explosion in the cavity was for investigating how much additional volume such a secondary explosion could produce in a cavity with minimal seismic disruption to the surrounding territories. Some of the locations being considered for storage applications were sufficiently close to populated regions that the permissible yields were severely limited. In an effort to produce the required storage volume with a minimum number of seismic disruptions of the region, the concept of enlarging small cavities with partially decoupled secondary explosions was under consideration in the mid-1970s. Unfortunately, results of this experiment showed that little additional volume was produced, and no subsequent application of the idea was made. 143

\section{Mine Gas Dispersal}

Coal mining in the Donets Basin of the Ukraine has long suffered from the dangers of rock bursts and explosions resulting from pockets of methane gas, which has resulted in the deaths of miners by explosions and suffocation. As the coal mines in this area went to deeper and deeper levels, the problem worsened. By the end of the 1970s, the number had reached over 200 explosions or rock bursts per year. At some point in the late 1970s, scientists from the Ukrainian Academy of Sciences' Fuel Physics Institute and the All-Soviet Institute of Scientific Industrial Technology suggested using a relatively small nuclear explosion to open incipient fractures and equalize stresses in the rock to avoid these sudden and dangerous occurrences. A similar effect had been observed in the Sakhalin area of Siberia as a result of frequent earthquakes in that area (see Section B.10, Appendix B).

Project "Cleavage." The site chosen for the "Cleavage" experiment, sponsored by the Soviet Coal Ministry, was in the "Young Communist" coal mine $5 \mathrm{~km}$ east of the Ukrainian village of Enakievo. A 0.3-kt nuclear device was emplaced in the "Yunkom" mine in a sloping drift between two of the most dangerous layers, $45 \mathrm{~m}$ below a layer named "Devyatka" and $31 \mathrm{~m}$ above the "Kirpichevka" layer. The yield was small to minimize damage to the mine and underground structures as well as the housing in the "Yunkom" area and the town of Enakievo. The particular location in a sandstone rock was chosen to assure that the resolidified melt containing about $95 \%$ of the radioactivity of the explosion would be insoluble in water to minimize the transport of radioactivity from the explosion area. The inclined shaft was sealed

142 Glenn, L. A. and P. Goldstein, "Seismic Decoupling with Chemical and Nuclear Explosions in Salt,"

J. Geo. Res., 99, June 10, 1994, pp. 11723-30.

143 Personal communication, Vitaly Adushkin, Sept. 12, 1996. 
with concrete to prevent release of the gaseous radionuclides to the surface or into other workings in the mine. Radiation levels in the air and water within the mine and at the surface were continuously monitored.

The explosive was fired at 05:00 local time on September 16, 1979, at a depth of $903 \mathrm{~m}$. Postshot inspection of the mine revealed little structural damage beyond the immediate vicinity of the explosion. Mining in the "Devyatka" layer in 1980-82 indicated that the effective radius of the explosion for elimination of the dangerous blowouts was about $150 \mathrm{~m}$, but there was a significant reduction of the number and intensity of bursts beyond that distance as well. The occurrence of bursts in this time frame are reported to have been reduced to less than one per million square meters, and the intensity of any single burst to less than 50 tons, a factor of 4-5 less than that reported earlier.

Radiation levels in the coal mined from the "Devyatka" layer near the explosion were reported to be at background levels. Work in the mine in subsequent years proceeded with no complications from the explosion, and production increased significantly from 1980 through 1982.144

Unfortunately, the test was carried out without the knowledge of the local population, and much suspicion of the results remains in the local area. Several recent articles in the popular press have cast doubts on the efficacy of the test, quoting the director of the "Yunkom" mine, V. G. Revskovo, as saying there were essentially no positive results of the explosion in the mine and claiming that the high residual radiation levels from Chernobyl have made it difficult to confirm the statements made by the ministry of Atomic Energy regarding radiation conditions. ${ }^{145,146,147}$ The fact that in the nine years following "Cleavage," there were no subsequent nuclear explosions for this purpose in "Yuncom" or any other mine, would suggest that the results were less favorable than expected.

\section{E. Overall Seismic Coupling}

Figure 9 is a plot of the seismic magnitude, determined by the National Earthquake Information Service or the International Seismic Center, versus the MinAtom yield for 102 of the Soviet contained PNEs. Several of the contained PNEs were not detected by the world-wide seismic networks because of the small yield or "noise" from large earthquakes. The two "Dnepr" mining shots are also not included because of their relatively shallow burial. The six explosions in the water-filled A-2 cavity have been included because they would have been very well coupled. Also shown is the decoupled explosion "Halite A-3-1" fired in the A-3 cavity.

144 Mikhailov, Nuclear Explosions in the USSR, pp. 58-60 (see footnote 13).

145 “Secret Nuclear Test in Donbass Mine Revealed," Kiev Radio Ukraine World Service, August 5, 1992, from JPRS-TAC-92-026, August 31, 1992, pp. 41-42.

146 Viktor Goncharov and Sergei Peteshov, "The Experiment under Code-Name "Cleavage:," in Atom bez Gripha "Sekretno: Tochki Zreniya, pp. 65-67, Moscow-Berlin, 1992.

147 Izvestiya, 27 June, 1992. 
The solid line in Fig. 9 is a least-squares regression fit to the 102 well-coupled PNE explosions. The standard error is about 0.29 , corresponding to a factor of about 2.5 in yield. The large scatter of the data can be attributed to the wide variation in the depths of burial and types of geology, ranging from porous carbonates to high-coupling granites and salt. The dashed line is the magnitude-yield equation used for many years to determine the yield of Soviet nuclear explosions from seismic magnitudes. ${ }^{148,149}$ Virtually all of the Soviet PNEs have yields much less than those predicted by the dashed curve, some by up to an order of magnitude or more. Use of the dashed curve or even one with a constant 0.1 or 0.2 units higher would have consistently overestimate the yield of most Soviet PNEs.

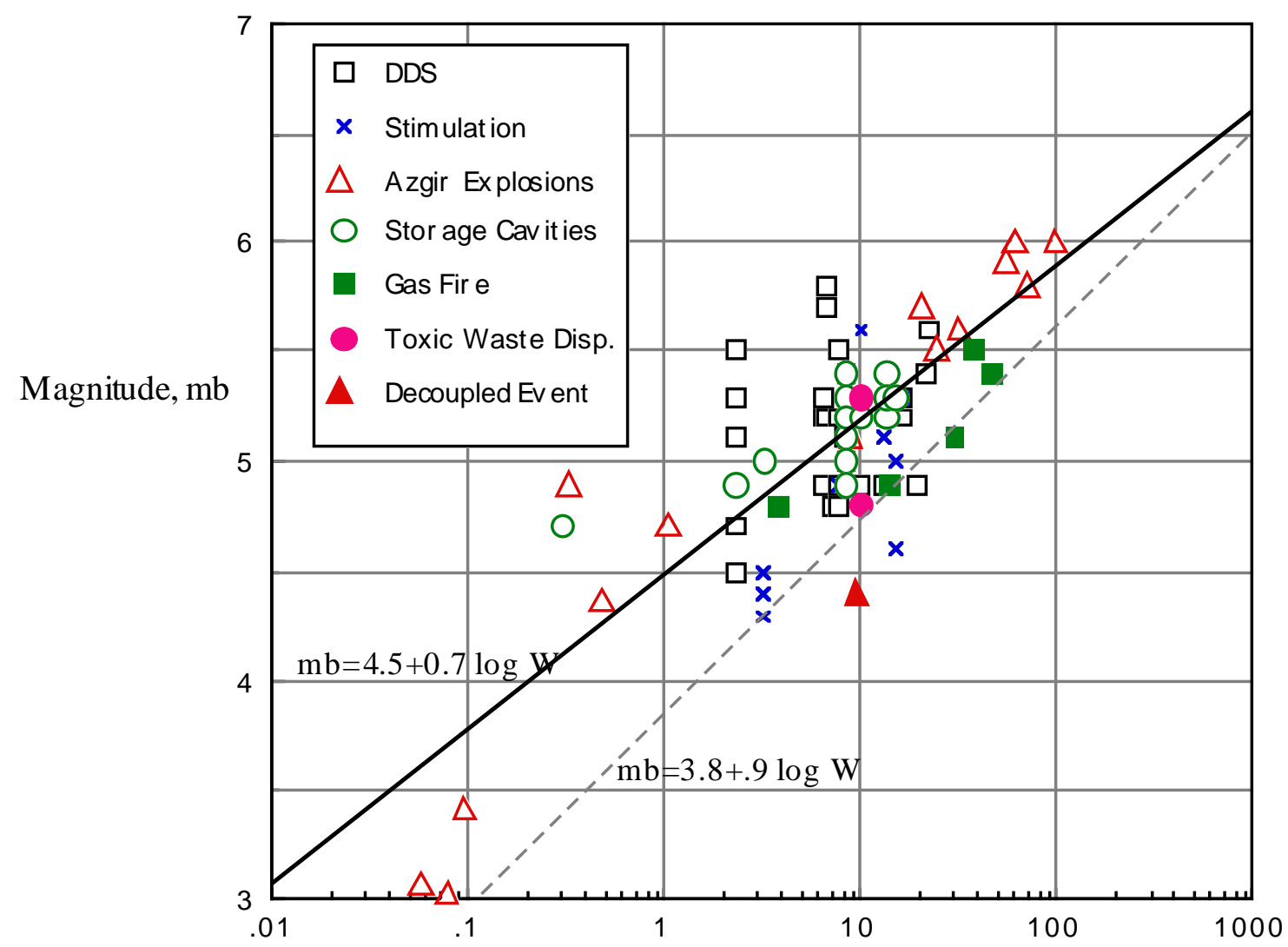

Yields (kt)

Figure 9. Plot of seismic magnitudes vs yield for 102 contained Soviet PNEs. (Many data points do not appear on the plot because they have the same coordinates and are on top of one another.) The various symbols indicate the purpose of the PNEs. Also shown is a regression fit to the PNE data (solid line) and, for comparison purposes, a fit often associated in the past with estimates of the yields of Soviet weapons tests and PNEs (dashed line).

148 Paper CCD/388 Aug. 24, 1972 in Documents on Disarmament 1972, pp. 590-615.

149 Progress and Problems in Seismic Verification Research, Defense Advanced Research Projects Agency, (TIO-73-3), 1973, p. 79. 


\section{Arms Control Aspects of the Peaceful Uses of Nuclear Explosions}

\section{A. Conference on the Discontinuance of Nuclear Weapons Tests}

Almost from the beginning, the concept of using nuclear explosions for peaceful purposes was recognized as an impediment to the achievement of a ban on the development and testing of nuclear weapons. Early in the 1958 Geneva Conference on the Discontinuance of Nuclear Weapons Tests, U.S. Ambassador James Wadsworth noted, inter alia, the U.S. interest in retaining the capability to carry out peaceful nuclear explosions under a ban on nuclear weapons tests. In a paper on the basic provisions for a control regime, Ambassador Wadsworth included the provision that one of the responsibilities of the Control Commission would be to authorize PNEs subject to unspecified inspection and control requirements. The Soviets did not respond, at least initially, to this U.S. suggestion.

The fundamental problem posed by permitting PNEs to be carried out under a ban on all testing of nuclear weapons devices is how to prevent nuclear explosions carried out for peaceful purposes from contributing knowledge useful to the development of nuclear weapons. Whereas PNE and weapon devices could well have different design requirements in terms of size, weight, radiation output, and residual radioactivity, learning how to design better PNE devices would directly contribute to designing better weapons. Development of "cleaner" explosives with much lower fission-to-fusion ratios were essential for nuclear excavation applications. How could the side conducting PNEs be prevented from testing new device design ideas, with or without diagnostic measurements of device performance, even if such improvements were prohibited? The final yield or radiochemical analysis of microscopic particles of the debris from a PNE explosive could provide sufficient proof of the validity of many new ideas, but only to those who designed the device.

Initial ideas within the weapons laboratories for how these problems might be handled included four ideas:

1. Using whatever device a country desired for the PNE, under observation by representatives of the U.N. and other countries, including the Soviet Union, but without diagnostics to measure the device performance.

2. Establishing an international stockpile with each country desiring to conduct PNEs, placing some number of devices in the stockpile on the date a test ban went into effect.

3. Using only devices provided by the Soviet Union for PNEs conducted by the U.S. and the U.K., and vice versa.

4. Using devices that were subject to inspection by all the nuclear weapons states party to the test ban, including the U.S.S.R. 
The first idea would obviously have been the best for those interested only in PNE applications, but it had the major difficulty of how to convince the other parties that no militarily useful information would be gained absent obvious diagnostic measurements. On the other hand, it was recognized that the other three ideas would most probably lead to the use of obsolete devices for Plowshare projects without any prospect of using low-fission excavation explosives yet to be developed. ${ }^{150}$ The USAEC ultimately recommended the international stockpile option to the interagency group developing the U.S. negotiating position. ${ }^{151}$

When the U.S. tabled specific language in December, 1958, that called on the future Control Commission to "establish procedures ... for the surveillance of nuclear devices and observation of nuclear detonations for peaceful purposes," 152 the Soviet representative Semyon Tsarapkin immediately took issue, arguing that "the purpose of our Conference is to work out a treaty on the cessation of nuclear weapons tests everywhere and for all time, and to adopt the necessary measures to ensure that the parties to the treaty comply with it. Our contention is that no nuclear detonations should be set off for any purpose whatsoever." 153

This blanket Soviet opposition to any testing for any purpose under a test ban was rather shortlived when 10 days later, on December 25, in a speech to the Supreme Soviet, Foreign Minister Andrei Gromyko said it might be possible to have nuclear detonations for peaceful purposes under a test ban if, among other conditions, there would be an equal number of such shots between East and West and if all the devices to be used were subject to complete internal and external examinations. ${ }^{154}$ Nine months earlier, Edward Teller had made a similar suggestion in testimony before Congress that "in order to have an effective international inspection [of peaceful nuclear explosions] it is necessary not only to have the explosion inspected, but to open up the explosive, look into it and see that it is an ordinary type of nuclear explosive. This could be done, but it certainly would give away a lot of information which at present is kept very closely guarded."155 This statement was part of a long list of reasons why he believed a test ban was a bad idea, a motive that may well have been the reason the Soviets picked up on the same idea.

Perhaps heartened by this apparent change in the Soviet point of view, on January 30, 1959, Ambassador Wadsworth presented a draft article containing suggested procedures for carrying out PNEs based roughly on the second of the four ideas listed above. Four months before the PNE explosion, the party proposing the test would be required to provide a description of the project, including the purpose, the date and location, the expected yield, the measurements and

150 Teletype message from H. Brown, LRL, to Starbird, AEC, Ideas for PNE Devices under a Moratorium, COPD 58-73, September 25, 1958.

151 Teletype message from Starbird, AEC, to E. Teller, LRL, L-2347-58, Nov. 7, 1958.

152 Conference on the Discontinuance of Nuclear Weapons Tests, GEN/DNT PV.25, Dec. 15, 1958, p. 11.

153 Conference on the Discontinuance of Nuclear Weapons Tests, GEN/DNT PV.26, Dec. 16, 1958, p. 23.

154 Jacobson and Stein, p. 156, and Pravda, Dec. 26, 1958, pp. 9-10.

155 "Control and Reduction," Testimony of Edward Teller in Hearings before a Subcommittee of the Senate Committee of Foreign Relations, March 16, 1958. 
experiments to be carried out in conjunction with the explosion, and "the measures taken to assure that there will be no substantial fall-out outside the immediate vicinity."156

Further, the U.S. proposal called for the establishment of a depository, under the surveillance of the Control Commission, in which any of the parties to the agreement, prior to the effective date of the agreement, could place a stockpile of nuclear explosives planned for use in their PNEs. To meet concerns about safety and reliability, it provided for checks by the depositing party of any devices in the depository under the watchful eye of the other parties.

As an alternative to this procedure, the U.S. proposed that new nuclear devices could be used at any time so long as the other parties could inspect "the internal and external features of the nuclear device, including ... detailed drawings." Presumably this provision was aimed at permitting the U.S. to carry out nuclear excavation projects with new devices with significantly lower fission yields than those available in 1959. As noted above, development of such devices was one of the principle elements of the U.S. Plowshare Program.

Wadsworth argued that the end result of the provisions on the devices to be used for PNE projects would "be to ensure either that devices based on past technology will be used, thus foreclosing the possibility of advancing weapons' design by the detonation, or that the other ... parties will be given detailed knowledge of the device, thus assuring there will be no military advantage to the party detonating. The first method requires the use of devices which have been developed before the agreement to discontinue nuclear weapons testing goes into effect..." and "the second method ... is intended to confine the devices used under that option to relatively obsolete designs and to designs especially developed which could be, perhaps because of weight or bulk, not useful militarily and which could, therefore, be revealed to the other nuclear powers, but would allow the non-military purposes of such explosions to be carried on more efficiently and more cheaply."157

Three weeks later on February 23, 1959, Ambassador Tsarapkin made a more formal reply to the U.S. proposal. Leading off with a condemnation of any proposal to permit PNEs under a test ban, he noted that their "position is clear that the direct and only task of this Conference is to prepare a treaty on the cessation of all types of nuclear weapons tests forever. We cannot agree with the attempt of the United States delegation to transform this Conference on the discontinuance of tests into a conference on the legalization, in one form or another, of the continuation of nuclear tests." 158

However opposed the Soviet Union was to including PNEs in the test ban, Tsarapkin paradoxically went on to say that the Soviets were nevertheless willing to allow them, but under their own set of conditions, which he then placed on the table. The conditions provided for equal numbers of PNEs between the U.S. and U.K. on the one hand and the Soviet Union on the other.

156 Conference on the Discontinuance of Nuclear Weapons Tests, GEN/DNT PV.46, Jan. 30, 1958, p. 7.

157 Ibid., pp. 8-10.

158 Conference on the Discontinuance of Nuclear Weapons Tests, GEN/DNT PV.60, Feb. 23, 1959, p. 30. 
Such a procedure would have effectively given the Soviet Union veto power over any Western PNE projects and was clearly unacceptable.

Rather than creating a stockpile of PNE explosives, Tsarapkin proposed:

"(a) submitting beforehand to the other [party] a complete description and the blueprints" and

"(b) permitting the inspection of the internal and external construction of the device to be exploded." 159

Little was said by the U.S. in response to this Soviet proposal at the time, although the requirements for internal inspection and turning the blueprints of U.S. devices over to the Soviets for their perusal would have, at first hand, appeared to be out of the question. Nevertheless, the U.S. accepted the proposal for the time being, and later that year announced at the U.N. that "agreement in principle has been reached that nuclear explosions for peaceful purposes will be allowed ... under carefully prescribed conditions under international observation." 160 During the ensuing two years, most of the discussion at the Conference was directed toward the development of a joint program of seismic research using nuclear explosions, to be carried out under the existing moratorium. However, each country's position on where the nuclear explosives to be used would come from was based on their previous positions regarding PNE explosives. Finally, on March 21, 1961, the U.S. accepted the Soviet position providing for full disclosure and inspection of devices to be used for seismic experiments as well as for PNEs. ${ }^{161}$

Little more was done on the development of an accommodation for PNEs during the Geneva Conference before it ended in January 1962, following the August 1961 Soviet decision to end their moratorium and resume nuclear weapons testing, or in the U.N. Committee on Disarmament which followed.

\section{B. Limited Test Ban Treaty (Moscow Treaty)}

Eighteen months later in July 1963, ad hoc negotiations in Moscow resulted in the Limited Test Ban Treaty (LTBT) (or Moscow Treaty), which banned "any nuclear weapon test explosion, or any other explosion, at any place under its jurisdiction or control:...if such explosion causes radioactive debris to be present outside the territorial limits of the State under whose jurisdiction or control such explosion is conducted...." The initial U.S. draft had contained a provision to allow PNEs in the prohibited environments if there was unanimous agreement and if they were carried out in accordance with provisions of an annex which had not yet been drafted, but

159 Ibid., pp. 33-34.

160 Statement by the United States Representative, Henry Cabot Lodge, to the First Committee of the General Assembly, Oct. 14, 1959, in DOD, 1945-59, p. 1493.

161 Conference on the Discontinuance of Nuclear Weapons Tests, GEN/DNT PV.274, Mar. 21, 1961, pp. $16-27$. 
presumably along the lines of what the Soviets had suggested at earlier Geneva discussions. 162 However, the Soviets demurred, and the provision was dropped.

The construction of the above article clearly was intended to apply to nuclear explosions for peaceful purposes as well as for weapons. However, the choice of words, "...radioactive debris to be present outside the territorial limits..." were interpreted by the AEC as allowing a nuclear cratering explosion so long as it did not result in "a quantity of radioactive debris delivered outside the country's territorial limits in amounts sufficient to establish that such contamination resulted from a recent test within that country."163 All of the U.S. nuclear crater experiments after 1963 were carried out within this interpretation of the LTBT, although AEC Chairman Seaborg made the point during ratification testimony that it would be impossible to carry out a major project, such as excavating a new Trans-Isthmian Canal in a small country, without renegotiating the treaty. As noted above in Section III, C.2, and in footnote 47, the Russian language version of this particular section of the treaty is much more permissive than the English language version, although probably not sufficient to permit major projects such as the KamaPechora Canal to be carried out.

Concerns about possible violations of the LTBT, if the they were to carry out the KamaPechora Canal project, led the Soviet Union to participate in a series of bilateral technical meetings on PNEs with the U.S. during 1969-76. In these meetings, they hoped to reach a joint understanding with the U.S. for interpretation or amendment of the LTBT language, which would allow large-scale nuclear excavation projects to be carried out under appropriate radiation safety guidelines, rather than the "detection-level" standard of the LTBT. Although several concepts were discussed, there was no resolution of the issue. 164

\section{Non-Proliferation Treaty (NPT)}

Later in the 1960s, at the time of the negotiation of the Non-Proliferation Treaty, the Plowshare Program was still under active development in the U.S. as was the Soviet "Program for the Use of Nuclear Explosions in the National Economy," although at a less developed stage. This treaty provides for the nonnuclear weapons states of the world to forego any effort to acquire nuclear weapons and the nuclear weapons states not to transfer any weapons, materials, or technology useful for weapons to the nonnuclear weapons states. In exchange for the nonnuclear weapons states giving up the right to acquire nuclear weapons, the NPT committed the nuclear weapons states to make available the peaceful uses of nuclear uses of nuclear energy - the materials and the technological information - under appropriate safeguards through the International Atomic Energy Agency (IAEA).

162 Glenn T. Seaborg, Kennedy, Khrushchev and the Test Ban, Univ. of Calif. Press, 1981, p. 244

163 Ibid., p. 268.

164 M. D. Nordyke, Technical Summary of the Third Stage of the Soviet-American Talks on the Peaceful Uses of Nuclear Explosions, UCRL-51113, August 23, 1971. 
In an effort to meet demands and build support for the NPT among some of the more reluctant nonnuclear weapons states (e.g., India, Argentina, and Brazil), the U.S. suggested, and the Soviet Union readily supported, the inclusion of a provision, Article V, which explicitly committed the nuclear weapons states to make available the "potential benefits from any peaceful applications of nuclear explosions...on a non-discriminatory basis...pursuant to a special international agreement..." or "...pursuant to bilateral agreements." Although several international projects were subsequently studied by the U.S. jointly with other countries, no international projects were ever carried out. ${ }^{165}$ Article V of the NPT did lead to the establishment of an office within the IAEA for coordinating international interests in peaceful uses of nuclear explosions. It also led to five international panels or technical meetings on PNEs between 1970 and 1976, which provided a forum for technical interaction of scientists from the U.S., the Soviet Union, and other countries. 166

\section{Threshold Test Ban (TTB) and the Peaceful Nuclear Explosion Treaties (PNET)}

The conflict between the efforts to achieve an arms control agreement and the potential promise of peaceful nuclear explosions next arose in the negotiations of the Threshold Test Ban Treaty in June 1973. By this date, the Plowshare Program in the U.S. was rapidly fading, while its star was just beginning its ascent in the Soviet Union. The roles of the two countries regarding the desirability of an exemption for PNEs was beginning to be reversed.

The U.S. adamantly supported the position that any yield limit on nuclear weapons tests should equally apply to PNEs, whether they were fired on the weapons test site or not. The Soviet Union was represented by Igor Morokhov, the First Deputy Chairman of the State Committee for the Utilization of Atomic Energy and one of the leading advocates for PNEs in the Soviet Union. Equally adamantly, he supported the Soviet position that the yields of PNEs away from the test sites should not be held to the same limit as weapons, or else the limit should be placed high enough (400-600 kt) that PNE projects such as the Kama-Pechora Canal could be done. In the end, it was agreed a 150-kt limit would be imposed on all tests at the declared weapons test sites, and a separate PNE agreement would be negotiated over the next 18 months before the TTBT went into effect. The subsequent PNE agreement was to provide for extensive exchange of information on geology and other details regarding forthcoming PNEs and, for the

165 A plan for nuclear excavation of a canal connecting the Gulf of Siam with the Strait of Malacca in Southern Thailand was jointly studied by the U.S. and Thai Governments in 1973-75 (see IAEA Ref. in footnote 166 below, January, 1995). Similarly, a plan for using nuclear excavation to connect the Qattara Depression and the Mediterranean Sea was jointly studied by the U.S., West Germany, and Egypt in the mid1970s ("Development of the Qattara Project, Egypt," in Peaceful Nuclear Explosions V, IAEA-TC-81-5/6, November 22-24, 1976).

166 See Peaceful Nuclear Explosions, Phenomenology and Status Report, 1970, 2-6 March, 1970; Peaceful Nuclear Explosions II, Their Practical Application, 19-22 January, 1971; Peaceful Nuclear Explosions III, Applications, Characteristics and Effects, 27 November-1 December, 1972; Peaceful Nuclear Explosions IV, 20-24 January, 1975; Peaceful Nuclear Explosions V, 22-24 November, 1976. 
first time in any U.S. arms control agreement, was to include on-site observation of PNE activities by the other party.

Negotiation of the PNE Treaty required the full 18 months and resulted in one of the most detailed agreements for the exchange of information and conduct of on-site observations in the history of arms control to that date. The PNET, signed in May 1976, provided for a single device yield of $150 \mathrm{kt}$ but permitted simultaneous group explosions with a total yield of up to $1500 \mathrm{kt}$. For any explosion with an aggregate yield greater than $150 \mathrm{kt}$, the other side would be allowed to place sensors in holes near the explosion, which would allow them to measure the yield of individual explosions in the group.

Although the TTB and PNET were not ratified, both sides agreed to observe the limitations pending ratification. However, by the time the PNET was signed in May of 1976, the U.S. Plowshare Program was dead, and the Soviet Union's interest in the Kama-Pechora Canal project had waned. As a result, neither side has ever carried out a PNE with a yield large enough to trigger the on-site provisions of the PNET. The Protocols to the TTBT and PNET were subsequently renegotiated in the late 1980 s to tighten the verification provisions, requiring onsite inspection of any PNE with an aggregate yield greater than $35 \mathrm{kt}$ and on-site hydrodynamic yield measurement for any PNE with an aggregate yield greater than $50 \mathrm{kt}$. The revised TTBT and PNET were ratified in the Fall of 1990, but neither party has carried out a weapons test or PNE that was subject to the provisions of the treaties since they went into effect.

\section{E. Comprehensive Test Ban Treaty Negotiations (CTBT), 1977-80}

In the Fall of 1976, the U.S. and the USSR once again began negotiations of a comprehensive ban on all nuclear weapons tests, this time with the participation of the U.K. The issue of PNEs very quickly became one of the principal issues with the Soviet Union, again represented by Igor Morokhov, strongly pushing for some kind of separate agreement that would permit PNEs. This time, the U.S., with U.K. support, was adamant in refusing to consider any such agreement, and the issue became one of the major sticking points in the negotiations.

After several weeks of serious discussion of the issue, it became apparent that a major decision regarding the PNE issue was being developed on the Soviet side. One night, in informal conversations outside the negotiations, Morokhov and his deputy on the delegation, Roland Timerbaev, asked several members of the U.S. delegation to consider three possible alternatives for carrying out PNEs under a CTBT:

1. The Soviet Union would use U.S. devices for their PNE projects, and vice versa.

2. The U.S. would have complete access to the design of any devices used by the Soviet Union in a PNE, and vice versa.

3. The U.S. and the Soviet Union would undertake a joint program of developing and manufacturing the devices to be used in any PNE. 
The first two proposals were similar to those discussed in 1958-59 at the Geneva Conference, but the last one was an idea that would have been unthinkable at that time. The U.S. delegation gave little attention to Morokhov's overture. Within two weeks, on November 2, 1977, Soviet General Secretary Brezhnev announced that the Soviet Union would accept a moratorium on all PNEs for the duration of the CTBT. Shortly thereafter, Morokhov was replaced as head of the Soviet Delegation by Andronik Petros'yants, Morokhov's superior as Chairman of the State Committee for the Utilization of Atomic Energy. Although the PNE issue had been resolved, other issues led to a stalemate in the negotiations before they were abandoned by the Reagan Administration in 1981.

\section{F. Current CTBT Negotiations}

On October 19, 1989, the Soviet Union began an unannounced year-long moratorium on nuclear weapons tests. As with an earlier announced 18-month moratorium on weapons testing during 1985-86, the Soviet Union carried out no PNEs during this moratorium. Although the Soviet Union carried out one last weapons test in October, 1990, no additional PNEs have been fired since September 6, 1988.

Following several extensions of the Soviet Union's moratorium, testing limitations imposed by the U.S. Congress, and a French moratorium, negotiations among the five nuclear weapons states on a Comprehensive Test Ban Treaty were begun in January 1994 in Geneva. As in earlier negotiations, the PNEs immediately became a significant issue. From the beginning of these negotiations, the U.S. and U. K. advocated a ban on all nuclear explosions, including any for "peaceful purposes." France, which studied the potential of PNEs for use in and around their country in the early 1970s, also supported a ban on PNEs. Although China had never evinced any previous interest in the use of nuclear explosions for peaceful purposes, it began the negotiations with a demand for inclusion of a provision that would permit PNEs at some future date. Russia took the position of acquiescing in their elimination, but not actively advocating it. All of the nuclear weapons states maintained their initial positions on PNEs throughout 1994 and 1995, but on June 6, 1996, China yielded to the growing pressure for an agreement and dropped its insistence on an exclusion for PNEs in the comprehensive test ban agreement, proposing instead that the question of PNEs should be reconsidered at a review conference, expected to be held in 10 years. 


\section{Summary}

During a period of some 23 years between 1965 and 1988, the Soviet Union's "Program for the Utilization of Nuclear Explosions in the National Economy" carried out 122 nuclear explosions to study and put into industrial use some 13 applications. In all, 128 explosives with yields ranging from 0.01 to $140 \mathrm{kt}$ were used, with the vast majority being between 2 and $20 \mathrm{kt}$ (see Table 6).

\section{Table 6. Frequency Distribution of Soviet PNE Yields.}

\begin{tabular}{|c|c|}
\hline $\begin{array}{c}\text { Yield range } \\
(\mathbf{k t})\end{array}$ & $\begin{array}{c}\text { Number of } \\
\text { explosions }\end{array}$ \\
\hline$<0.25$ & 8 \\
$0.25-0.5$ & 3 \\
$0.5-1.0$ & 1 \\
$1.0-2.0$ & 6 \\
$2.0-5.0$ & 23 \\
$5.0-10$ & 40 \\
$10-20$ & 30 \\
$20-50$ & 9 \\
$50-100$ & 6 \\
$>100$ & 2 \\
\hline
\end{tabular}

Most peaceful applications of nuclear explosions in the Soviet PNE Program were explored in depth with a number of tests, but unfortunately little has been reported on the technical results other than general outcomes. Two applications, deep seismic sounding of the Earth's crust and upper mantle and the creation of underground cavities in salt for the storage of gas condensate, found widespread use, representing over $50 \%$ of all the explosions. Explosions to explore the technical possibilities of stimulating the production of oil and gas reservoirs accounted for an additional $17 \%$.

The deep seismic sounding program produced an enormous volume of seismic data that still are being analyzed to better understand the deep geologic structure of the vast reaches of the Russian subcontinent. Although it may assist in the discovery of a few new major hydrocarbon or mineral resources in the future, its main value will probably be in the geotectonic area.

The two main projects to create underground storage for gas condensate from newly developing gas fields appear to be a quite valuable resource for the industries involved, and may have expedited their development. However, the failure of almost half of the explosion cavities created in salt at the "Vega" and Azgir sites raises serious questions about the general applicability and long-term viability of this or any other application utilizing such cavities. Clearly, the leakage of water into salt cavities is a serious problem because of possible loss of the 
cavity as well as the leachability of radionuclides trapped in the fused salt and the surface contamination that will inevitably result.

The studies of oil and gas stimulation were much broader and longer-term than those carried out in the U.S. The results reported to date are quite favorable in terms of increased production versus costs, but the application was not used on an industrial scale in the Soviet Union. The reason may be due to the contamination problems encountered at the "Grifon" field, but, more likely, it is because of the same difficulties experienced in the U.S. Plowshare program-the necessity of large-scale utilization for a significant impact on the national oil or gas industry, and the resistance of the public to accept a product containing any added radioactivity, no matter how minimal the level.

The use of nuclear explosions for closure of four runaway gas wells that defied all other techniques available in the Soviet Union proved to be a valuable application. It is possible that these wells could have been closed with conventional techniques available in the U.S., but the experience of the Soviet PNE Program in this area is unique and may prove useful in some future emergency somewhere in the world. It is important that Russians make available more information on why the attempt at Nar'yan Mar failed.

The "Dnepr" ore-breakage experiments on the Kola peninsula appeared to have been successful, but the lack of implementation on a broader scale raises questions about the acceptability of the application. Similarly, the "Cleavage" mine gas-dispersal explosion would appear to be an application with limited applicability, significant problems of acceptability, and little support within the industry.

The use of nuclear explosions to produce actinide and transplutonic elements in water-filled cavities is an interesting and imaginative application, but it is difficult to imagine that such a procedure could produce significant quantities of such nuclides in comparison to nuclear reactors. On the other hand, such an approach might prove quite useful in a heavy-element production program similar to that carried out by the U.S. in the 1960s to produce super-heavy elements beyond element 110. ${ }^{167}$ Many of the heavy elements produced by multiple neutron capture within a nuclear explosive have very short half-lives. Through the use of this technique, significant quantities of transplutonic elements produced in an initial heavy-element explosive could be rapidly recovered from a cavity, processed, and incorporated as target nuclei in a second heavy-element explosion. Similarly, any super-heavy elements produced in the second explosion could be rapidly recovered and processed, maximizing the possibility of detecting any short-lived isotopes.

One of the most useful applications, from the standpoint of Russia and other countries with serious environmental contamination problems, would appear to be the "Kama" experiments demonstrating the use of deeply buried nuclear explosions for the deep-well disposal of toxic

167 R. W. Hoff and E. K. Hulet, “The Recovery and Study of Heavy Nuclides in a Nuclear Explosion - The HUTCH Event," in Engineering with Nuclear Explosives (Proc. ANS Symp., Las Vegas, January 1970). 
industrial flows. Results from these two experiments indicate that such facilities can be used for the disposal of large quantities of very hazardous chemical pollutants over long periods without significant problems. In view of the apparent success of these experiments, it is difficult to see why there have been no subsequent use of this application at other sites.

The nuclear excavation element of the Soviet PNE Program proved to be relatively short-lived, suffering from the world-wide growth of public concerns about environmental issues and atmospheric radioactivity and the disappointing "Taiga" experiment. In addition, the Soviets had serious concerns about dealing with the restrictions of the Limited Test Ban Treaty on the release of radioactivity from nuclear explosions across national boundaries, particularly for a project the size of the Kama-Pechora Canal. In the early 1970s, environmental concerns about diversion of water from the Arctic Ocean led to the loss of governmental support for the Kama-Pechora Canal. In addition, the slumping of the "Taiga" cratering experiment in 1971 demonstrated that the geology along much of the alignment of the canal was not suitable for nuclear excavation. Although the project continued to be included in future plans for several years, it ultimately was dropped, and with it, any further support for the Soviet nuclear excavation program.

An important element in the Soviet PNE Program was the effort by both the Arzamas and Chelyabinsk weapons laboratories to develop special nuclear explosives designs to reduce the radioactivities and fielding costs associated with specific applications. The earliest effort was the development of small-diameter, high-temperature explosives for use in the closure of runaway gas wells. At the same time in the late 1960s and early 1970s, a major effort was put into developing a very low-fission explosive for nuclear excavation projects. Unfortunately, the Russians have not provided any details on the extent to which they succeeded in meeting their objectives in these device development programs.

In 1971 and 1974, the Soviets carried out two experiments at the test site to explore the possibilities for ejecting the radioactivity from an explosion down a tunnel to separate it from the physical effects of the explosion. The results of these tests were subsequently used in the "Dnepr 1 and 2" mining experiments. These tests were similar in geometry to the 1967 Marvel test in the U.S. Plowshare Program, although the purpose of Marvel was to drive hydrodynamic energy, not radioactivity, $100 \mathrm{~m}$ down a 1-m-diameter tube. In the mid-1970s, emphasis in the Soviet device development program presumably was on the development of small-diameter, low-tritiumproducing explosives for hydrocarbon applications, such as oil and gas stimulation and gas condensate storage. MinAtom says this program was successful in meeting its goals, but it provides no details. ${ }^{168}$

The Soviet programs to develop low-fission excavation and hydrocarbon explosives mirrored device development programs in the U.S. Plowshare Program in the mid-1960s and early 1970s. The Russians have not provided any information on whether the devices used in the transplutonic element production program were specially designed for that purpose as were the devices used in the U.S. heavy element program.

168 Mikhailov, Nuclear Explosions in the USSR, p. 44 (see footnote 13). 
With the exception of the cratering explosions at the test site and at "Taiga" on the KamaPechora canal alignment, the vast majority of the other 112 Soviet PNEs were completely contained (camouflet) explosions. Five resulted in the prompt release of radioactivity, the most serious of which was "Kraton-3," a DSS explosion in Siberia, which suffered a prompt vent of gas and particulate radioactivity when the permafrost around the emplacement hole melted. The "Crystal" retarc dam in Siberia also resulted in the escape of gaseous radioactivity, as had been expected in the design of the experiment. Three other explosions, "Globus-1," "Globus-3," and "Halite A-8," suffered leaks of gaseous radionuclides at early times as a result of leaks in the emplacement hole stemming. In all, there was escape of gaseous radioactivity at 26 sites, largely during operations to re-enter the cavities or chimneys or during industrial exploitation of the sites. In all cases of camouflet explosions, except "Kraton-3" and "Crystal," the sites have been decontaminated, and radiation levels outside the limited industrial areas are at regional background.

The Soviet PNE Program was conducted as a "secret" program in the Soviet Union, as were many other governmental operations during that time. Although a few articles appeared in the popular press in the 1970s, there were no details on the number or location of explosions. As a result, local populations were seldom informed of the nature or scope of PNE activities in their vicinity. With the arrival of "Glasnost"" in the late 1980s, many "exposes" began to appear in Russian newspapers and journals listing the many PNEs that had been carried out throughout the country and, in many cases, viewing with alarm their consequences. Because of the generally low standards of industrial safety and environmental protection in the Soviet Union and Russia, the public is quite prepared to believe the worst. The lack of hard data from MinAtom on the good and bad results of their PNE experiments has made it difficult to develop a rational discussion of their costs, risks, and benefits.

The Soviet PNE Program was many times larger than the U.S. Plowshare Program in terms of both the number of applications explored with field experiments and the extent to which they were introduced into industrial use. Several PNE applications, such as deep seismic sounding and oil stimulation, have been explored in depth and appear to have had a positive cost benefit at minimal public risk. Several others, such as storage, developed significant technical problems that cast a shadow on their general applicability. Some, such as closure of runaway gas wells, demonstrated a unique technology that may yet find application in a situation where all other techniques fail. Still others were the subject of one or two tests but were not explored further for reasons that have not been explained. Overall, the program represents a significant technical effort to explore a promising new technology, and it generated a large body of data that appears to be quite favorable, although only a small fraction of the data has been made public.

However, the fundamental problem with PNEs-first identified by James Schlesinger shortly after he became Commissioner of the U.S. AEC in 1971 - is the fact that, if they are to be economically significant, there must be widespread use of the technology, and such use must inevitably involve large numbers of sites, each of which presents a potential source of radioactivity to the environment in general and to nearby communities in particular. Russia now 
has more than 100 sites where a significant amount of high-level radioactivity has been buried, albeit at a deep, safe environment. However, activities at these sites must be restricted and monitored forever. Even though each site can be operated well within appropriate radiationsafety standards, and the industrial products exported from the sites may be many times below maximum permissible levels, experience over the last 20 years in the U.S. and in today's Russia shows that it is virtually impossible to gain public acceptance of such applications of nuclear energy.

In addition to the problems of political and economic acceptability, PNEs also pose a difficult problem in the arms-control arena in the context of a total ban on nuclear weapons tests. In the absence of any other form of nuclear testing, any nuclear explosion for peaceful purposes has the potential for providing useful information to those who designed and constructed the nuclear device. Thus, under a CTB, any country conducting PNEs would, in appearance if not in fact, receive information useful for designing new nuclear weapons or maintaining an existing nuclear stockpile, information denied to the other parties to the treaty. Although several imaginative ideas for reducing this risk have been offered in the course of negotiations on a CTBT over the last 40 years, none have been suggested that would appear to overcome this critical problem. 



\section{Appendix A}

\section{Peaceful Nuclear Explosions in the Soviet Union (By Date)1}

\begin{tabular}{|c|c|c|c|c|c|c|c|}
\hline 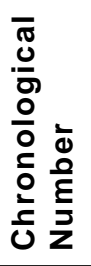 & $\begin{array}{c}\text { Ministry } \\
\text { of } \\
\text { Atomic } \\
\text { Energy } \\
\text { (MAE) } \\
\text { Name }\end{array}$ & Date & $\begin{array}{l}\text { Time } \\
\text { (GMT) }\end{array}$ & $\begin{array}{l}\text { Latitude } \\
\qquad\left({ }^{\circ} \mathrm{N}\right)\end{array}$ & $\begin{array}{l}\text { Longitude } \\
\left({ }^{\circ} \mathrm{E}\right)\end{array}$ & $\begin{array}{c}\text { Seismic } \\
\text { Magni- } \\
\text { tude } \\
\left(m_{\mathrm{b}}\right)\end{array}$ & Geographic Vicinity \\
\hline 1 & Chagan & 01-15-65 & 05:59:59 & $\begin{array}{l}49.89 \\
49.9350\end{array}$ & $\begin{array}{l}78.97 \\
79: 0094\end{array}$ & 6.0 & Semipalatinsk Test Site, Kaz. ASSR ${ }^{2}$ \\
\hline 2 & Butane & $03-30-65$ & 08:00 & $\begin{array}{l}- \\
53.10\end{array}$ & $\begin{array}{l}- \\
55.87\end{array}$ & & $15 \mathrm{~km} \mathrm{nw}$ of Meleyz, Bashkir, ASSR ${ }^{3}$ \\
\hline 3 & Butane & $06-10-65$ & 07:00 & - & - & & $15 \mathrm{~km} \mathrm{nw}$ of Meleyz, Bashkir, ASSR ${ }^{3}$ \\
\hline 4 & Sary-Uzen' & $10-14-65$ & 04:00 & - & - & & Semipalatinsk Test Site, Kaz. ASSR ${ }^{2}$ \\
\hline 5 & Halite A-1 & $04-22-66$ & $\begin{array}{l}02: 58: 04 \\
02: 58: 00.3\end{array}$ & $\begin{array}{l}47.86 \\
47.8292\end{array}$ & $\begin{array}{l}47.72 \\
47.9347\end{array}$ & 4.7 & $180 \mathrm{~km} \mathrm{n}$ of Astrakhan, Gur'yev Ob. ${ }^{4}$ \\
\hline 6 & Urta-Bulak & $09-30-66$ & 05:59:53 & 38.80 & 64.50 & 5.1 & $80 \mathrm{~km}$ s of Bukhara, Bukhara Ob. \\
\hline 7 & Tavda & $10-06-67$ & 07:00:03 & 57.69 & 65.27 & 4.7 & $70 \mathrm{~km}$ nne of Tyumen, Tyumen Ob. \\
\hline 8 & Pamuk & $05-21-68$ & 03:59:12 & 38.916 & 65.159 & 5.4 & 70 km w of Karshi, Kashkadar'in Ob. \\
\hline 9 & Halite A-2 & $07-01-68$ & $\begin{array}{l}\text { 04:02:02 } \\
04: 02\end{array}$ & $\begin{array}{l}47.922 \\
47.9086\end{array}$ & $\begin{array}{l}47.950 \\
47.9119\end{array}$ & 5.5 & $180 \mathrm{~km} \mathrm{n}$ of Astrakhan, Gur'yev Ob. ${ }^{4}$ \\
\hline 10 & Tel'kem-1 & $10-21-68$ & 03:52 & - & -78.4863 & & Semipalatinsk Test Site, Kaz. ASSR ${ }^{2}$ \\
\hline 11 & Tel'kem-2 & $11-12-68$ & 07:30 & - & $\begin{array}{l}- \\
78.4613\end{array}$ & & Semipalatinsk Test Site, Kaz. ASSR ${ }^{2}$ \\
\hline 12 & Grifon & $09-02-69$ & 04:59:57 & 57.415 & 54.860 & 4.9 & 10 km s from Osa, Perm Ob. \\
\hline 13 & Grifon & $09-08-69$ & 04:59:56 & 57.365 & 55.108 & 4.9 & 10 km s from Osa, Perm Ob. \\
\hline 14 & Stavropol' & $09-26-69$ & $06: 59: 56$ & 45.890 & 42.472 & 5.6 & 100 km nne of Stavropol', Stav. Kr. \\
\hline 15 & Hole 2T & $12-06-69$ & 07:02:57 & 43.832 & 54.783 & 5.8 & $\begin{array}{l}100-115 \mathrm{~km} \text { sse of Sai-Utes, } \\
\text { Mangyshlak Ob. }\end{array}$ \\
\hline 16 & Magistral' & $06-25-70$ & 04:59:52 & 52.201 & 55.692 & 4.9 & $70 \mathrm{~km}$ ne of Orenburg, Orenburg Ob. \\
\hline 17 & Hole 5T & $12-12-70$ & 07:00:57 & 43.851 & 54.774 & 6.1 & $\begin{array}{l}100-115 \text { km sse of Sai-Utes, } \\
\text { Mangyshlak Ob. }\end{array}$ \\
\hline 18 & Hole 1T & $12-23-70$ & 07:00:57 & 43.827 & 54.846 & 6.1 & $\begin{array}{l}100-115 \mathrm{~km} \text { sse of Sai-Utes, } \\
\text { Mangyshlak Ob. }\end{array}$ \\
\hline 19 & Taiga & 03-23-71 & $06: 59: 56$ & 61.287 & 56.466 & 5.6 & $\begin{array}{l}100 \mathrm{~km} \text { nnw of Kras-novishersk, Perm } \\
\text { Ob. }\end{array}$ \\
\hline 20 & Globus-4 & 07-02-71 & 17:00:02 & 67.66 & 62.00 & 4.7 & 30 km sw of Vorkuta, Komi Rep. \\
\hline 21 & Globus-3 & 07-10-71 & $16: 59: 59$ & 64.168 & 55.183 & 5.3 & 140 km sw of Pechora, Komi Rep. \\
\hline 22 & Globus-1 & 09-19-71 & $11: 00: 07$ & 57.777 & 41.098 & 4.5 & $30 \mathrm{~km}$ ene of Kineshma, Ivanovsk Ob. \\
\hline 23 & Globus-2 & $10-04-71$ & 10:00:03 & 61.613 & 47.116 & 5.1 & $80 \mathrm{~km}$ ene of Kotlas, Arkh. Ob. \\
\hline
\end{tabular}




\begin{tabular}{|c|c|c|c|c|c|c|c|}
\hline 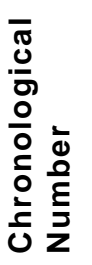 & $\begin{array}{c}\text { Ministry } \\
\text { of } \\
\text { Atomic } \\
\text { Energy } \\
\text { (MAE) } \\
\text { Name }\end{array}$ & Date & $\begin{array}{l}\text { Time } \\
\text { (GMT) }\end{array}$ & $\begin{array}{l}\text { Latitude } \\
\qquad\left({ }^{\circ} \mathrm{N}\right)\end{array}$ & $\begin{array}{l}\text { Longitude } \\
\left({ }^{\circ} \mathrm{E}\right)\end{array}$ & $\begin{array}{c}\text { Seismic } \\
\text { Magni- } \\
\text { tude } \\
\left(m_{b}\right)\end{array}$ & Geographic Vicinity \\
\hline 24 & Sapphire & $10-22-71$ & 05:00:00 & 51.575 & 54.536 & 5.3 & $40 \mathrm{~km}$ wsw of Oren-burg, Orenburg OB \\
\hline 25 & $\begin{array}{l}\text { Halite } \\
\text { A-3 }\end{array}$ & $12-22-71$ & $\begin{array}{l}06: 59: 56 \\
07: 00\end{array}$ & $\begin{array}{l}47.872 \\
47.8967\end{array}$ & $\begin{array}{l}48.222 \\
48.1333\end{array}$ & 6.0 & $180 \mathrm{~km} \mathrm{n}$ of Astrakhan, Gur'yev Ob. ${ }^{4}$ \\
\hline 26 & Crater & 04-11-72 & 06:00:05 & 37.367 & 61.996 & 4.9 & $30 \mathrm{~km}$ se of Mary, Mary Ob., Turkmen. \\
\hline 27 & Fakel & 07-09-72 & 06:59:58 & 49.78 & 35.42 & 4.8 & 20 km n of Krasnograd, Kharkov Ob. \\
\hline 28 & Region-3 & 08-20-72 & 02:59:49 & 49.462 & 48.179 & 5.7 & 310 km sw of Uralsk, Uralsk Ob. \\
\hline 29 & Dnepr-1 & 09-04-72 & 07:00:04 & 67.689 & 33.445 & 4.6 & 20 km n of Kirovsk, Murmansk Ob. \\
\hline 30 & Region-1 & $09-21-72$ & 09:00:01 & 52.127 & 51.994 & 5.1 & $80 \mathrm{~km}$ ssw of Buzuluk, Orenburg Ob. \\
\hline 31 & Region-4 & $10-03-72$ & 08:59:58 & 46.848 & 45.010 & 5.8 & 80 km ne of Elista, Kalmyk Rep. \\
\hline 32 & Region-2 & $11-2472-$ & 09:00:08 & 52.779 & 51.067 & 4.7 & $90 \mathrm{~km}$ ssw of Buzuluk, Orenburg Ob. \\
\hline 33 & Region-5 & $11-24-72$ & 09:59:58 & 51.843 & 64.152 & 5.2 & 160 km sse of Kustanay, Kust. Ob. \\
\hline 34 & Meridan-3 & $08-15-73$ & 01:59:58 & 42.711 & 67.410 & 5.3 & $90 \mathrm{~km}$ sw of Turkestan, Chimkent Ob. \\
\hline 35 & Meridan-1 & $08-28-73$ & 02:59:58 & 50.550 & 68.395 & 5.3 & 100 km e of Arkalyk, Turgai Ob. \\
\hline 36 & Meridan-2 & $09-19-73$ & 02:59:57 & 45.635 & 67.850 & 5.2 & $\begin{array}{l}230 \mathrm{~km} \text { s of Dzhez-kazgan, Chimkent } \\
\text { Ob. }\end{array}$ \\
\hline 37 & Sapphire & 09-30-73 & 04:59:57 & 51.608 & 54.582 & 5.2 & $40 \mathrm{~km}$ wsw of Oren-burg, Orenburg Ob. \\
\hline 38 & Kama-2 & $10-26-73$ & 05:59:58 & 53.656 & 55.375 & 4.8 & $30 \mathrm{~km}$ w of Sterlitmak, Bashkir ASSR \\
\hline 39 & Kama-1 & 07-08-74 & 06:00:02 & 53.80 & 55.20 & 4.6 & $30 \mathrm{~km}$ w of Sterlitimak, Bashkir ASSR \\
\hline 40 & Horizon-2 & 08-14-74 & 14:59:58 & 68.913 & 75.899 & 5.5 & 190 km nw of Tazovskiy, Tyumen Ob. \\
\hline 41 & Horizon-1 & $08-29-74$ & 15:00:00 & 67.233 & 62.119 & 5.2 & 70 km sw of Vorkuta, Komi Rep. \\
\hline 42 & Crystal & $10-02-74$ & 00:59:56 & 66.1 & 112.65 & 4.6 & $70 \mathrm{~km}$ ne of Aikhal, Yakutia-Sakha \\
\hline 43 & Lazurite & $12-07-74$ & 06:00:00 & 49.92 & 77.65 & 4.7 & Semipalatinsk Test Site, Kaz. ASSR \\
\hline 44 & $\begin{array}{l}\text { Halite } \\
\text { A-2-1 }\end{array}$ & $04-25-75$ & $04: 59: 57$ & $\begin{array}{l}47.50 \\
47.9086\end{array}$ & $\begin{array}{l}47.50 \\
47.9119\end{array}$ & 4.9 & $180 \mathrm{~km} n$ of Astrakhan, Gur'yev Ob. ${ }^{4}$ \\
\hline 45 & Horizon-4 & $08-12-75$ & 15:00:00 & 70.76 & 127.12 & 5.2 & $120 \mathrm{~km}$ sw of Tiksi, Sakha \\
\hline 46 & Horizon-3 & $09-29-75$ & $10: 59: 58$ & 69.592 & 90.396 & 4.9 & $90 \mathrm{~km}$ ese of Norilsk, Taimyr AO \\
\hline 47 & $\begin{array}{l}\text { Halite } \\
\text { A-3-1 }\end{array}$ & $03-29-76$ & 07:00:29 & $\begin{array}{l}49.6 \\
47.8967\end{array}$ & $\begin{array}{l}45.0 \\
48.1333\end{array}$ & $\begin{array}{l}4.4 \\
\text { HFS }\end{array}$ & $180 \mathrm{~km} \mathrm{n}$ of Astrakhan, Gur'yev Ob. 4 \\
\hline 48 & Halite A-4 & $07-29-76$ & $\begin{array}{l}04: 59: 58 \\
05: 00\end{array}$ & 47.782 & 48.120 & 5.9 & $180 \mathrm{~km} n$ of Astrakhan, Gur'yev Ob. ${ }^{4}$ \\
\hline 49 & $\begin{array}{l}\text { Oka } \\
\text { (Neva) }\end{array}$ & $11-05-76$ & 03:59:57 & 61.53 & 112.71 & 5.3 & $90-120$ km ssw of Mirnyy, Yakut ASSR \\
\hline 50 & Meteorite-2 & 07-26-77 & $16: 59: 58$ & 69.532 & 90.583 & 4.9 & $90 \mathrm{~km}$ ene of Norilsk, Taimyr AO \\
\hline
\end{tabular}




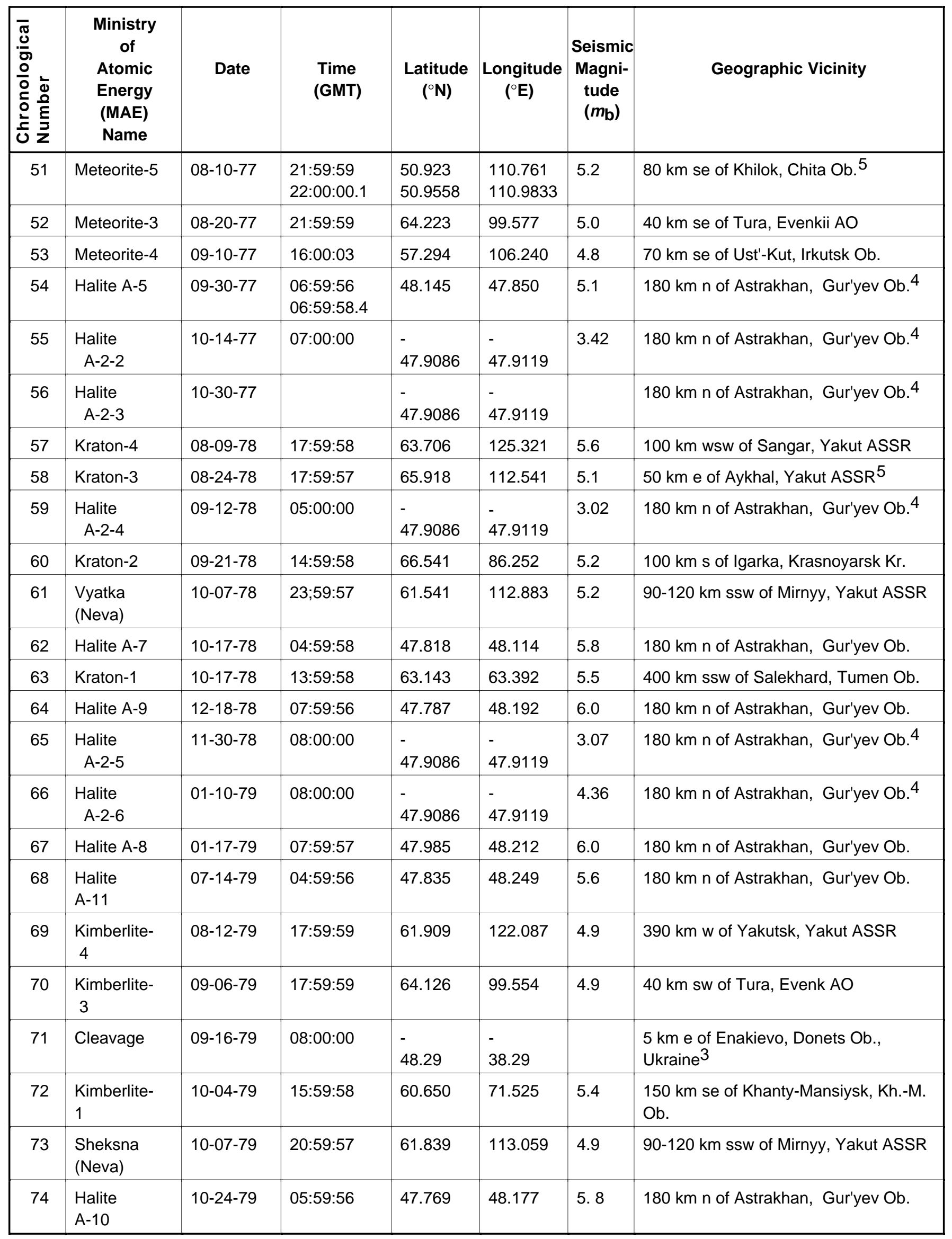




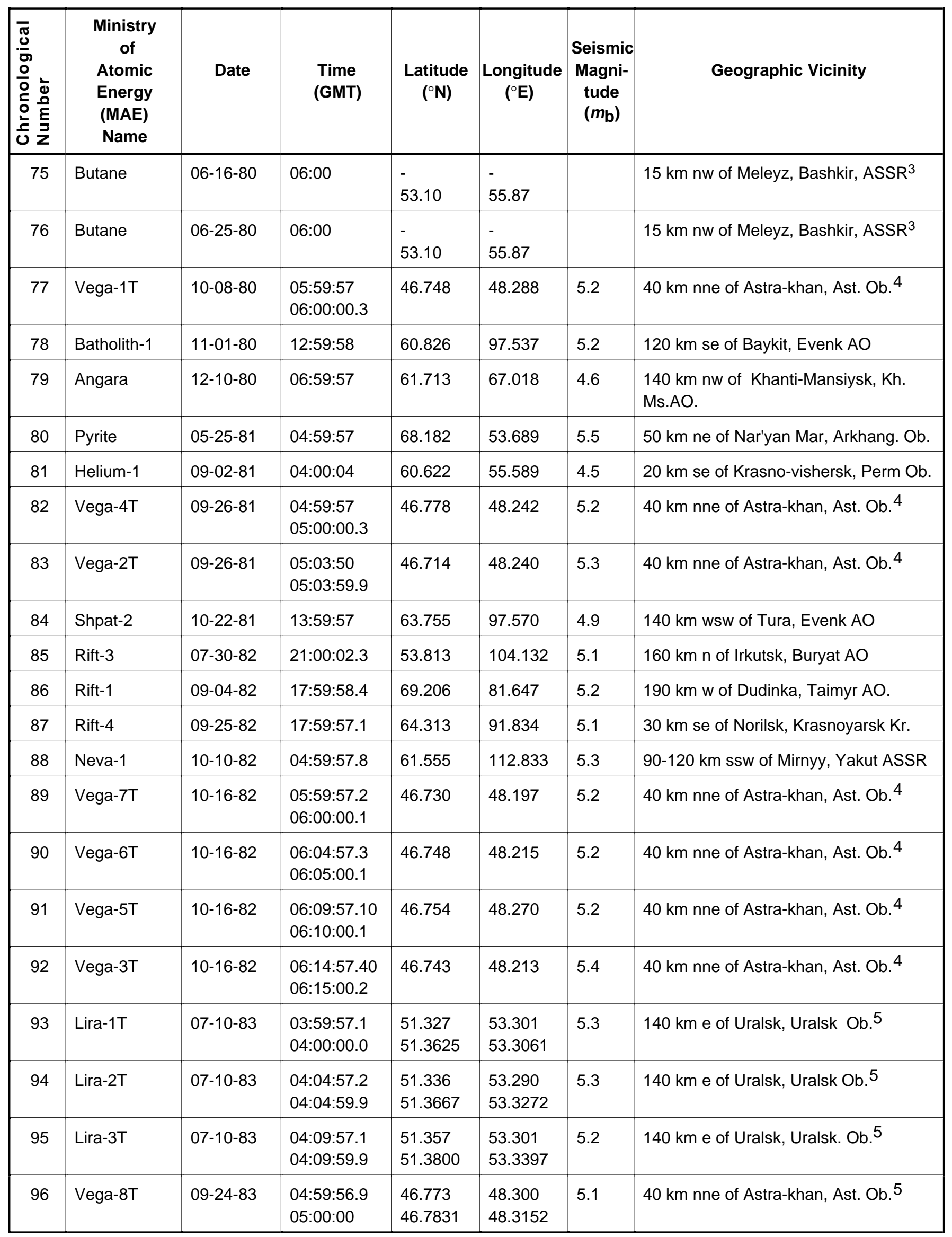




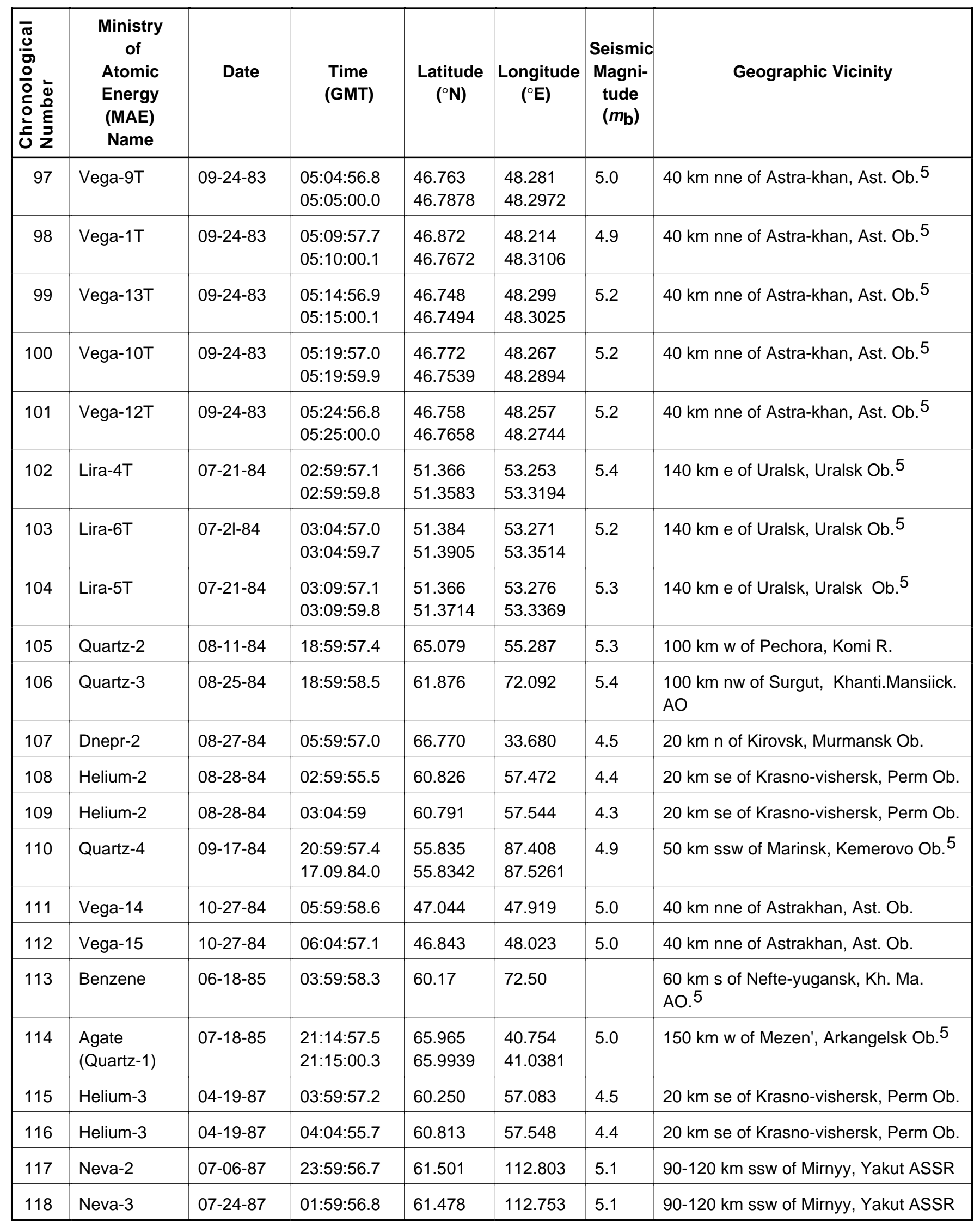




\begin{tabular}{|c|c|c|c|c|c|c|c|}
\hline 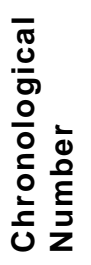 & $\begin{array}{c}\text { Ministry } \\
\text { of } \\
\text { Atomic } \\
\text { Energy } \\
\text { (MAE) } \\
\text { Name }\end{array}$ & Date & $\begin{array}{l}\text { Time } \\
\text { (GMT) }\end{array}$ & $\begin{array}{l}\text { Latitude } \\
\left({ }^{\circ} \mathrm{N}\right)\end{array}$ & $\begin{array}{l}\text { Longitude } \\
\left({ }^{\circ} \mathrm{E}\right)\end{array}$ & $\begin{array}{c}\text { Seismic } \\
\text { Magni- } \\
\text { tude } \\
\left(m_{\mathrm{b}}\right)\end{array}$ & Geographic Vicinity \\
\hline 119 & Neva-4 & $08-12-87$ & $01: 29: 56.8$ & 61.455 & 112.760 & 5.0 & $90-120 \mathrm{~km}$ ssw of Mirnyy, Yakut ASSR \\
\hline 120 & Batholith 2 & $10-03-87$ & $15: 14: 57.4$ & 47.605 & 56.227 & 5.2 & $320 \mathrm{~km}$ ssw of Aktyubinsk, Ak. Ob. \\
\hline 121 & Ruby-2 & $08-22-88$ & $16: 19: 58.2$ & 66.316 & 78.548 & 5.3 & $\begin{array}{l}40 \mathrm{~km} \text { ne of Urengoy, Yamalo-Nenetsk } \\
\mathrm{AO}\end{array}$ \\
\hline 122 & Ruby-1 & $09-06-88$ & $16: 19: 58.6$ & 61.331 & 47.955 & 4.8 & $80 \mathrm{~km}$ ene of Kotlas, Arkhangelsk Ob. \\
\hline
\end{tabular}

1 The seismic magnitudes and upper set of numbers for times and geographic coordinates are based on seismic data provided by the National Earthquake Information Service (NEIS) or the International Seismic Center (ISC) unless otherwise indicated. When there is a lower set of times and geographic coordinates, they are actual data provided by the source indicated.

2 Actual time and location based on V. S. Bocharov, S. A., Zelentsev, and B. I. Mikhailov, "Characteristics of 96 Underground Nuclear Explosions at the Semipalatinsk Experimental Test Site," Atomnaya Energiya, Vol. 67, No. 3, September 1989.

3 Actual location based on geographical description of site.

4 Actual time and/or location based on V. V. Adushkin, et. al., Characteristics of Seismic Waves from Soviet Peaceful Nuclear Explosions in Salt, Academy of Sciences, Russian Federation, Institute for Dynamics of the Geosphere, UCRLCR-120929, April 1995.

5 Actual time and/or location based on D. D. Sultanov, Investigation of Seismic Efficiency of Soviet Peaceful Nuclear explosions Conducted in Various Geological Conditions, Part 1, Academy of Sciences, Russian, Institute for Dynamics of the Geosphere, July 28, 1993. 


\section{Appendix B}

\section{Peaceful Nuclear Explosions in the Soviet Union (By Purpose)}

A. Development of Nuclear Excavation Technologies of Interest

\begin{tabular}{|c|c|c|c|c|c|c|c|c|}
\hline 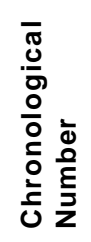 & $\begin{array}{c}\text { Ministry of } \\
\text { Atomic } \\
\text { Energy } \\
\text { (MAE) } \\
\text { Name }\end{array}$ & Date & Geographic Vicinity & $\begin{array}{l}\text { MAE } \\
\text { Yield } \\
\text { (kt) }\end{array}$ & $\begin{array}{l}\text { MAE } \\
\text { Depth } \\
\text { of } \\
\text { Burial } \\
\text { (m) }\end{array}$ & Geology & Name/Comments & $\begin{array}{c}\text { Sponsor } \\
\text { of } \\
\text { test }\end{array}$ \\
\hline \multicolumn{9}{|c|}{ A.1. Water Reservoir Development } \\
\hline 1 & Chagan & $01-15-65$ & $\begin{array}{l}\text { Semipalatinsk Test Site, } \\
\text { Kaz. ASSR }\end{array}$ & 140 & 178 & Sandstone & $\begin{array}{l}\text { Crater in bed of } \\
\text { Shagan River }\end{array}$ & $\mathrm{MMB}^{1}$ \\
\hline 4 & Sary-Uzen' & $10-14-65$ & Same as above & 1.1 & 48 & $\begin{array}{l}\text { Aleurolite, } \\
\text { Siltstone }\end{array}$ & Also called "1003" & MMB \\
\hline 15 & Hole 2T & $12-06-69$ & $\begin{array}{l}100-115 \text { km sse of Sai- } \\
\text { Utes, Mangyshlak Ob. }\end{array}$ & 31 & 407 & Chalk & Poss. new test site 2 & MMB \\
\hline 17 & Hole 5T & $12-12-70$ & Same as above & 84 & 497 & Chalk & Same as above & MMB \\
\hline 18 & Hole 1T & $12-23-70$ & Same as above & 75 & 740 & Chalk & Same as above & MMB \\
\hline \multicolumn{9}{|c|}{ A.2. Experimental Development Work on Constructing Canals } \\
\hline 10 & Tel'kem-1 & $10-21-68$ & $\begin{array}{l}\text { Semipalatinsk Test Site, } \\
\text { Kaz. ASSR }\end{array}$ & 0.24 & 30.5 & $\begin{array}{l}\text { Siltstone/ } \\
\text { Sandstone }\end{array}$ & $\begin{array}{l}\text { Also called "T-1"; in } \\
\text { Hole } 2308\end{array}$ & $\mathrm{MMB}^{1}$ \\
\hline 11 & Tel'kem-2 & $11-12-68$ & Same as above & $3 \times 0.24$ & 30.5 & $\begin{array}{l}\text { Siltstone/ } \\
\text { Sandstone }\end{array}$ & $\begin{array}{l}\text { Also called "T-2"; in } \\
\text { Holes 2305, } 2306 \text { and } \\
2307\end{array}$ & MMB \\
\hline 19 & Taiga & 03-23-71 & $\begin{array}{l}100 \text { km nnw of Kras- } \\
\text { novishersk, Perm Ob. }\end{array}$ & $3 \times 15$ & 128 & $\begin{array}{l}\text { Alluvium/ } \\
\text { Sandstone }\end{array}$ & $\begin{array}{l}\text { Explosion on Kama- } \\
\text { Pechora Canal } 3\end{array}$ & $\begin{array}{l}\text { Reclaim. } \\
\text { \& Water } \\
\text { Min. }\end{array}$ \\
\hline \multicolumn{9}{|c|}{ A.3. Experimental Development Work on Constructing a Dams with Deeply-Buried Cratering Explosions } \\
\hline 42 & Crystal & $10-02-74$ & $\begin{array}{l}70 \text { km ne of Aikhal, } \\
\text { Yakutia-Sakha }\end{array}$ & 1.7 & 98 & Limestone & Also called "Pipe"4 & $\begin{array}{l}\text { Non-Fer- } \\
\text { rous } \\
\text { Metals } \\
\text { Min. }\end{array}$ \\
\hline 43 & Lazurite & $12-07-74$ & $\begin{array}{l}\text { Semipalatinsk Test Site, } \\
\text { Kaz. ASSR }\end{array}$ & 1.7 & 75 & $\begin{array}{l}\text { Quartzite/ } \\
\text { Cherty Slate }\end{array}$ & Hole P-1 & $\mathrm{MMB}^{1}$ \\
\hline
\end{tabular}




\section{B. Contained Applications}

\begin{tabular}{|c|c|c|c|c|c|c|c|c|}
\hline 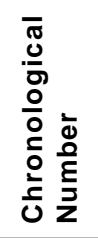 & $\begin{array}{c}\text { Ministry of } \\
\text { Atomic } \\
\text { Energy } \\
\text { (MAE) } \\
\text { Name }\end{array}$ & Date & Geographic Vicinity & $\begin{array}{c}\text { MAE } \\
\text { Yield } \\
\text { (kt) }\end{array}$ & $\begin{array}{c}\text { MAE } \\
\text { Depth } \\
\text { of } \\
\text { Burial } \\
\text { (m) }\end{array}$ & Geology & Name/Comments & $\begin{array}{c}\text { Sponso } \\
\text { of } \\
\text { test }\end{array}$ \\
\hline \multicolumn{9}{|c|}{ B.1. Stimulation of Oil Production and Increasing the Efficiency of Oil Recovery } \\
\hline 2 & Butane & 03-30-65 & $\begin{array}{l}15 \mathrm{~km} \text { nw of Meleyz, } \\
\text { Bashkir, ASSR }\end{array}$ & $2 \times 2.3$ & $\begin{array}{c}1341 \& \\
1375 \\
\end{array}$ & Limestone & $\begin{array}{l}\text { "Grachevka 1"; Holes } \\
617 \text { and } 618\end{array}$ & $\begin{array}{l}\text { Oil Prod. } \\
\text { Ministry }\end{array}$ \\
\hline 3 & Butane & 06-10-65 & Same as above & 7.6 & 1350 & Limestone & $\begin{array}{l}\text { "Grachevka 2"; Hole } \\
622\end{array}$ & $\begin{array}{l}\text { Oil Prod. } \\
\text { Ministry }\end{array}$ \\
\hline 12 & Grifon & 09-02-69 & $\begin{array}{l}10 \mathrm{~km} \text { s from Osa, Perm } \\
\text { Ob. }\end{array}$ & 7.6 & 1212 & Limestone & $\begin{array}{l}\text { Osa oil field; Hole } \\
1001\end{array}$ & $\begin{array}{l}\text { Oil Prod. } \\
\text { Ministry }\end{array}$ \\
\hline 13 & Grifon & $09-08-69$ & Same as above & 7.6 & 1208 & Limestone & $\begin{array}{l}\text { Osa oil field: Hole } \\
1002\end{array}$ & $\begin{array}{l}\text { Oil Prod. } \\
\text { Ministry }\end{array}$ \\
\hline 14 & Stavropol' & $09-26-69$ & $\begin{array}{l}100 \text { km nne of Stavropol', } \\
\text { Stav. Kr. }\end{array}$ & 10 & 712 & Clay & $\begin{array}{l}\text { Takhta-Kagulta Gas } \\
\text { Field }\end{array}$ & $\begin{array}{l}\text { Oil Prod. } \\
\text { Ministry }\end{array}$ \\
\hline 49 & Oka (Neva) & $11-05-76$ & $\begin{array}{l}90-120 \mathrm{~km} \text { ssw of Mirnyy, } \\
\text { Yakut ASSR }\end{array}$ & 15 & 1522 & Dolomite & $\begin{array}{l}\text { Also listed as DSS by } \\
\text { Benz } 5\end{array}$ & $\begin{array}{l}\text { Geology } \\
\text { Minstry }\end{array}$ \\
\hline 61 & $\begin{array}{l}\text { Vyatka } \\
\text { (Neva) }\end{array}$ & $10-07-78$ & $\begin{array}{l}90-120 \text { km ssw of Mirnyy, } \\
\text { Yakut ASSR }\end{array}$ & 13 & 1530 & Dolomite & & $\begin{array}{l}\text { Geology } \\
\text { Ministry }\end{array}$ \\
\hline 73 & $\begin{array}{l}\text { Sheksna } \\
\text { (Neva) }\end{array}$ & $10-07-79$ & Same as above & 15 & 1545 & Dolomite & Hole 47 & $\begin{array}{l}\text { Oil Prod. } \\
\text { Ministry }\end{array}$ \\
\hline 75 & Butane & $06-16-80$ & $\begin{array}{l}15 \mathrm{~km} \text { nw of Meleyz, } \\
\text { BAshkir, ASSR }\end{array}$ & 3.0 & 1400 & Limestone & & $\begin{array}{l}\text { Oil Prod. } \\
\text { Ministry }\end{array}$ \\
\hline 76 & Butane & $06-25-80$ & Same as above & 3.0 & 1390 & Limestone & & $\begin{array}{l}\text { Oil Prod. } \\
\text { Ministry }\end{array}$ \\
\hline 79 & Angara & $12-10-80$ & $\begin{array}{l}140 \mathrm{~km} \text { nw of Khanti- } \\
\text { Mansiysk, Kh. Ms.AO. }\end{array}$ & 15 & 2485 & Sandstone. & & $\begin{array}{l}\text { Geology } \\
\text { Minstry }\end{array}$ \\
\hline 81 & Helium-1 & $09-02-81$ & $\begin{array}{l}20 \mathrm{~km} \text { se of Krasno- } \\
\text { vishersk, Perm Ob. }\end{array}$ & 3.2 & 2088 & Limestone & Hole 401 & $\begin{array}{l}\text { Oil Prod. } \\
\text { Min. }\end{array}$ \\
\hline 88 & Neva-1 & $10-10-82$ & $\begin{array}{l}90-120 \text { km ssw of Mirnyy, } \\
\text { Yakut ASSR }\end{array}$ & 16 & 1502 & Dolomite & Hole 66 & $\begin{array}{l}\text { Geology } \\
\text { Ministry }\end{array}$ \\
\hline 108 & Helium-2 & $08-28-84$ & $\begin{array}{l}20 \mathrm{~km} \text { se of Krasno- } \\
\text { vishersk, Perm Ob. }\end{array}$ & 3.2 & 2065 & Limestone & Hole 402 & $\begin{array}{l}\text { Oil Prod. } \\
\text { Min. }\end{array}$ \\
\hline 109 & Helium-2 & $08-28-84$ & Same as above & 3.2 & 2075 & Limestone & Hole 403 & $\begin{array}{l}\text { Oil Prod. } \\
\text { Min. }\end{array}$ \\
\hline 113 & Benzene & $06-18-85$ & $\begin{array}{l}60 \mathrm{~km} \text { s of Nefte- } \\
\text { yugansk, Kh. Ma. AO. }\end{array}$ & 2.5 & 2859 & Argillite & & $\begin{array}{l}\text { Oil Prod. } \\
\text { Min. }\end{array}$ \\
\hline 115 & Helium-3 & 04-19-87 & $\begin{array}{l}20 \mathrm{~km} \text { se of Krasno- } \\
\text { vishersk, Perm Ob. }\end{array}$ & 3.2 & 2015 & Limestone & Hole 404 & $\begin{array}{l}\text { Oil Prod. } \\
\text { Min. }\end{array}$ \\
\hline 116 & Helium-3 & $04-19-87$ & Same as above & 3.2 & 2056 & Limestone & Hole 405 & $\begin{array}{l}\text { Oil Prod. } \\
\text { Min. }\end{array}$ \\
\hline 117 & Neva-2 & $07-06-87$ & $\begin{array}{l}90-120 \text { km ssw of Mirnyy, } \\
\text { Yakut ASSR }\end{array}$ & 13 & 1527 & Dolomite & Hole 61 & $\begin{array}{l}\text { Geology } \\
\text { Ministry }\end{array}$ \\
\hline
\end{tabular}




\begin{tabular}{|c|c|c|c|c|c|c|c|c|}
\hline 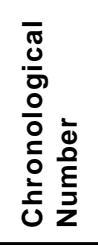 & $\begin{array}{c}\text { Ministry of } \\
\text { Atomic } \\
\text { Energy } \\
\text { (MAE) } \\
\text { Name }\end{array}$ & Date & Geographic Vicinity & $\begin{array}{c}\text { MAE } \\
\text { Yield } \\
\text { (kt) }\end{array}$ & $\begin{array}{l}\text { MAE } \\
\text { Depth } \\
\text { of } \\
\text { Burial } \\
(\mathrm{m})\end{array}$ & Geology & Name/Comments & $\begin{array}{c}\text { Sponsor } \\
\text { of } \\
\text { test }\end{array}$ \\
\hline 118 & Neva-3 & $07-24-87$ & Same as above & 13 & 1515 & Dolomite & Hole 68 & $\begin{array}{l}\text { Geology } \\
\text { Ministry }\end{array}$ \\
\hline 119 & Neva-4 & $08-12-87$ & Same as above & 3.2 & 815 & Salt & Hole 101; & $\begin{array}{l}\text { Geology } \\
\text { Ministry }\end{array}$ \\
\hline \multicolumn{9}{|c|}{ B.2. Experimental-Industrial Studies for the Development of Constructing Underground Cavities in Salt } \\
\hline 5 & $\begin{array}{l}\text { Halite A- } \\
1\end{array}$ & $04-22-66$ & $\begin{array}{l}180 \mathrm{~km} n \text { of Astra-khan, } \\
\text { Gur'yev Ob. }\end{array}$ & 1.1 & 161 & Salt & & $\mathrm{MMB}^{1}$ \\
\hline 9 & $\begin{array}{l}\text { Halite A- } \\
2\end{array}$ & 07-01-68 & Same as above & 27 & 597 & Salt & & MMB \\
\hline 25 & $\begin{array}{l}\text { Halite A- } \\
3\end{array}$ & $12-22-71$ & Same as above & 64 & 986 & Salt & & MMB \\
\hline \multicolumn{9}{|c|}{ B.3. Elimination of Runaway Gas Wells } \\
\hline 6 & Urta-Bulak & $09-30-66$ & $\begin{array}{l}80 \mathrm{~km} \text { s of Bukhara, } \\
\text { Bukhara Ob. }\end{array}$ & 30 & 1532 & Clay & Urtabulak gas field & $\begin{array}{l}\text { Geology } \\
\text { Ministry }\end{array}$ \\
\hline 8 & Pamuk & $05-21-68$ & $\begin{array}{l}70 \mathrm{~km} \text { w of Karshi, } \\
\text { Kashkadar'in Ob. }\end{array}$ & 47 & 2440 & Salt & Pamuk gas Field & $\begin{array}{l}\text { Geology } \\
\text { Ministry }\end{array}$ \\
\hline 26 & Crater & 04-11-72 & $\begin{array}{l}30 \mathrm{~km} \text { se of Mary, Mary } \\
\text { Ob., Turkmen. }\end{array}$ & 14 & 1720 & Argillite & Mary Gas Field & $\begin{array}{l}\text { Geology } \\
\text { Ministry }\end{array}$ \\
\hline 27 & Fakel & 07-09-72 & $\begin{array}{l}20 \mathrm{~km} n \text { of Kras-nograd, } \\
\text { Kharkov Ob. }\end{array}$ & 3.8 & 2483 & Salt & Krestishevo Gas Field & $\begin{array}{l}\text { Geology } \\
\text { Ministry }\end{array}$ \\
\hline 80 & Pyrite & $05-25-81$ & $\begin{array}{l}50 \mathrm{~km} \text { ne of Nar'yan Mar, } \\
\text { Arkhang. Ob. }\end{array}$ & 37.6 & 1511 & Clay & $\begin{array}{l}\text { Kumzhinskoe Gas } \\
\text { Field }\end{array}$ & $\begin{array}{l}\text { Geology } \\
\text { Ministry }\end{array}$ \\
\hline \multicolumn{9}{|c|}{ B.4. Experimental-Industrial Work on the Construction of Underground Cavities } \\
\hline 7 & Tavda & $10-06-67$ & $\begin{array}{l}70 \mathrm{~km} \text { nne of Tyumen, } \\
\text { Tyumen Ob. }\end{array}$ & 0.3 & 172 & & Seismic Source ${ }^{6}$ & $\begin{array}{l}\text { Gas Prod. } \\
\text { Ministry }\end{array}$ \\
\hline 16 & Magistral' & $06-25-70$ & $\begin{array}{l}70 \mathrm{~km} \text { ne of Oren-burg, } \\
\text { Orenburg Ob. }\end{array}$ & 2.3 & 702 & & & $\begin{array}{l}\text { Gas Prod. } \\
\text { Ministry }\end{array}$ \\
\hline 24 & Sapphire & $10-22-71$ & $\begin{array}{l}40 \mathrm{~km} \text { wsw of Oren-burg, } \\
\text { Orenburg OB. }\end{array}$ & 15 & 1142 & Salt & $\begin{array}{l}\text { Hole E-2;Also call-ed } \\
\text { "Dedurovka-1"; }\end{array}$ & $\begin{array}{l}\text { Gas Prod. } \\
\text { Ministry }\end{array}$ \\
\hline 37 & Sapphire & 09-30-73 & $\begin{array}{l}40 \mathrm{~km} \text { wsw of Oren-burg, } \\
\text { Orenburg Ob. }\end{array}$ & 10 & 1145 & Salt & $\begin{array}{l}\text { Hole E-3;Also called } \\
\text { "Dedurovka-2"; }\end{array}$ & $\begin{array}{l}\text { Gas Prod. } \\
\text { Ministry }\end{array}$ \\
\hline 77 & Vega-1T & $10-08-80$ & $\begin{array}{l}40 \mathrm{~km} \text { nne of Astrakhan, } \\
\text { Ast. Ob. }\end{array}$ & 8.5 & 1050 & Salt Dome & & $\begin{array}{l}\text { Gas Prod. } \\
\text { Ministry }\end{array}$ \\
\hline 82 & Vega-4T & $09-26-81$ & Same as above & 8.5 & 1050 & Salt Dome & & $\begin{array}{l}\text { Gas Prod. } \\
\text { Ministry }\end{array}$ \\
\hline 83 & Vega-2T & $09-26-81$ & Same as above & 8.5 & 1050 & Salt Dome & & $\begin{array}{l}\text { Gas Prod. } \\
\text { Ministry }\end{array}$ \\
\hline 89 & Vega-7T & $10-16-82$ & Same as above & 8.5 & 974 & Salt Dome & & $\begin{array}{l}\text { Gas Prod. } \\
\text { Ministry }\end{array}$ \\
\hline 90 & Vega-6T & $10-16-82$ & Same as above & 8.5 & 991 & Salt Dome & & $\begin{array}{l}\text { Gas Prod. } \\
\text { Ministry }\end{array}$ \\
\hline
\end{tabular}




\begin{tabular}{|c|c|c|c|c|c|c|c|c|}
\hline 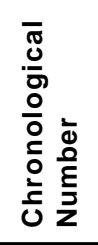 & $\begin{array}{c}\text { Ministry of } \\
\text { Atomic } \\
\text { Energy } \\
\text { (MAE) } \\
\text { Name }\end{array}$ & Date & Geographic Vicinity & $\begin{array}{c}\text { MAE } \\
\text { Yield } \\
(k t)\end{array}$ & $\begin{array}{l}\text { MAE } \\
\text { Depth } \\
\text { of } \\
\text { Burial } \\
(\mathrm{m})\end{array}$ & Geology & Name/Comments & $\begin{array}{c}\text { Sponsor } \\
\text { of } \\
\text { test }\end{array}$ \\
\hline 91 & Vega-5T & $10-16-82$ & Same as above & 8.5 & 1100 & Salt Dome & & $\begin{array}{l}\text { Gas Prod. } \\
\text { Ministry }\end{array}$ \\
\hline 92 & Vega-3T & $10-16-82$ & Same as above & 13.5 & 1057 & Salt Dome & & $\begin{array}{l}\text { Gas Prod. } \\
\text { Ministry }\end{array}$ \\
\hline 93 & Lira-1T & $07-10-83$ & $\begin{array}{l}140 \mathrm{~km} \text { e of Uralsk, } \\
\text { Uralsk Ob. }\end{array}$ & 13.5 & 917 & Salt Dome & & $\begin{array}{l}\text { Gas Prod. } \\
\text { Ministry }\end{array}$ \\
\hline 94 & Lira-2T & $07-10-83$ & Same as above & 13.5 & 917 & Salt Dome & & $\begin{array}{l}\text { Gas Prod. } \\
\text { Ministry }\end{array}$ \\
\hline 95 & Lira-3T & $07-10-83$ & Same as above & 13.5 & 841 & Salt Dome & & $\begin{array}{l}\text { Gas Prod. } \\
\text { Ministry }\end{array}$ \\
\hline 96 & Vega-8T & $09-24-83$ & $\begin{array}{l}40 \mathrm{~km} \text { nne of Astrakhan, } \\
\text { Ast. Ob. }\end{array}$ & 8.5 & 1050 & Salt Dome & & $\begin{array}{l}\text { Gas Prod. } \\
\text { Ministry }\end{array}$ \\
\hline 97 & Vega-9T & $09-24-83$ & Same as above & 8.5 & 1050 & Salt Dome & & $\begin{array}{l}\text { Gas Prod. } \\
\text { Ministry }\end{array}$ \\
\hline 98 & Vega-1T & $09-24-83$ & Same as above & 8.5 & 920 & Salt Dome & & $\begin{array}{l}\text { Gas Prod. } \\
\text { Ministry }\end{array}$ \\
\hline 99 & Vega-13T & $09-24-83$ & Same as above & 8.5 & 1100 & Salt Dome & & $\begin{array}{l}\text { Gas Prod. } \\
\text { Ministry }\end{array}$ \\
\hline 100 & Vega-10T & $09-24-83$ & Same as above & 8.5 & 950 & Salt Dome & & $\begin{array}{l}\text { Gas Prod. } \\
\text { Ministry }\end{array}$ \\
\hline 101 & Vega-12T & $09-24-83$ & Same as above & 8.5 & 1100 & Salt Dome & & $\begin{array}{l}\text { Gas Prod. } \\
\text { Ministry }\end{array}$ \\
\hline 102 & Lira-4T & $07-21-84$ & $\begin{array}{l}140 \mathrm{~km} \text { e of Uralsk, } \\
\text { Uralsk Ob. }\end{array}$ & 13.5 & 846 & Salt Dome & & $\begin{array}{l}\text { Gas Prod. } \\
\text { Ministry }\end{array}$ \\
\hline 103 & Lira-6T & $07-21-84$ & Same as above & 13.5 & 955 & Salt Dome & & $\begin{array}{l}\text { Gas Prod. } \\
\text { Ministry }\end{array}$ \\
\hline 104 & Lira-5T & $07-21-84$ & Same as above & 13.5 & 844 & Salt Dome & & $\begin{array}{l}\text { Gas Prod. } \\
\text { Ministry }\end{array}$ \\
\hline 111 & Vega-14T & $10-27-84$ & $\begin{array}{l}40 \mathrm{~km} \text { nne of Astrakhan, } \\
\text { Ast. Ob. }\end{array}$ & 3.2 & 1000 & Salt Dome & & $\begin{array}{l}\text { Gas Prod. } \\
\text { Ministry }\end{array}$ \\
\hline 112 & Vega-15T & 10-27-84 & Same as above & 3.2 & 1000 & Salt Dome & & $\begin{array}{l}\text { Gas Prod. } \\
\text { Ministry }\end{array}$ \\
\hline \multicolumn{9}{|c|}{ B.5. Deep Seismic Sounding of the Earth's Crust to Find Structures Favorable for Resource Development } \\
\hline 20 & Globus-4 & $07-02-71$ & $\begin{array}{l}30 \mathrm{~km} \text { sw of Vorkuta, } \\
\text { Komi Rep. }\end{array}$ & 2.3 & 542 & Sandstone & $\begin{array}{l}\text { Kineshma-Vorkuta } \\
\text { Line-1 }\end{array}$ & $\begin{array}{l}\text { Geology } \\
\text { Ministry }\end{array}$ \\
\hline 21 & Globus-3 & 07-10-71 & $\begin{array}{l}140 \text { km sw of Pechora, } \\
\text { Komi Rep. }\end{array}$ & 2.3 & 465 & Clay & Same as above & $\begin{array}{l}\text { Geology } \\
\text { Ministry }\end{array}$ \\
\hline 22 & Globus-1 & 09-19-71 & $\begin{array}{l}30 \mathrm{~km} \text { ene of Kinesh-ma, } \\
\text { Ivanovsk Ob. }\end{array}$ & 2.3 & 610 & Limestone & Same as above & $\begin{array}{l}\text { Geology } \\
\text { Ministry }\end{array}$ \\
\hline 23 & Globus-2 & $10-04-71$ & $\begin{array}{l}80 \mathrm{~km} \text { ene of Kotlas, } \\
\text { Arkh. Ob. }\end{array}$ & 2.3 & 595 & Aleurite & Same as above & $\begin{array}{l}\text { Geology } \\
\text { Ministry }\end{array}$ \\
\hline
\end{tabular}




\begin{tabular}{|c|c|c|c|c|c|c|c|c|}
\hline 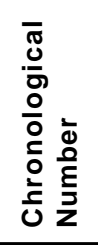 & $\begin{array}{c}\text { Ministry of } \\
\text { Atomic } \\
\text { Energy } \\
\text { (MAE) } \\
\text { Name }\end{array}$ & Date & Geographic Vicinity & $\begin{array}{c}\text { MAE } \\
\text { Yield } \\
\text { (kt) }\end{array}$ & $\begin{array}{l}\text { MAE } \\
\text { Depth } \\
\text { of } \\
\text { Burial } \\
(\mathrm{m})\end{array}$ & Geology & Name/Comments & $\begin{array}{c}\text { Sponsor } \\
\text { of } \\
\text { test }\end{array}$ \\
\hline 28 & Region-3 & $08-20-72$ & $\begin{array}{l}310 \mathrm{~km} \text { sw of Uralsk, } \\
\text { Uralsk Ob. }\end{array}$ & 6.6 & 489 & Clay & Elista-Buzuluk Line-2 & $\begin{array}{l}\text { Geology } \\
\text { Ministry }\end{array}$ \\
\hline 30 & Region-1 & $09-21-72$ & $\begin{array}{l}80 \mathrm{~km} \text { ssw of Buzuluk, } \\
\text { Orenburg Ob. }\end{array}$ & 2.3 & 485 & (Salt)?? & Same as above & $\begin{array}{l}\text { Geology } \\
\text { Ministry }\end{array}$ \\
\hline 31 & Region-4 & $10-03-72$ & $\begin{array}{l}80 \text { km ne of Elista, } \\
\text { Kalmyk Rep. }\end{array}$ & 6.6 & 485 & Clay & Same as above & $\begin{array}{l}\text { Geology } \\
\text { Ministry }\end{array}$ \\
\hline 32 & Region-2 & $11-24-72$ & $\begin{array}{l}90 \mathrm{~km} \text { ssw of Buzuluk, } \\
\text { Orenburg Ob. }\end{array}$ & 2.3 & 675 & (Salt)?? & $\begin{array}{l}\text { Buzuluk-Kushmurun } \\
\text { Line-3 }\end{array}$ & $\begin{array}{l}\text { Geology } \\
\text { Ministry }\end{array}$ \\
\hline 33 & Region-5 & $11-24-72$ & $\begin{array}{l}160 \text { km sse of Kustanay, } \\
\text { Kust. Ob. }\end{array}$ & 6.6 & 489 & Limestone & Same as above & $\begin{array}{l}\text { Geology } \\
\text { Ministry }\end{array}$ \\
\hline 34 & Meridan-3 & $08-15-73$ & $\begin{array}{l}90 \mathrm{~km} \text { sw of Turke-stan, } \\
\text { Chimkent Ob. }\end{array}$ & 6.3 & 600 & Clay & $\begin{array}{l}\text { Karatau-Tengiz } \\
\text { Line-4 }\end{array}$ & $\begin{array}{l}\text { Geology } \\
\text { Ministry }\end{array}$ \\
\hline 35 & Meridan-1 & $08-28-73$ & $\begin{array}{l}100 \mathrm{~km} \text { e of Arkalyk, } \\
\text { Turgai Ob. }\end{array}$ & 6.3 & 395 & Arg. Aleur & Same as above & $\begin{array}{l}\text { Geology } \\
\text { Ministry }\end{array}$ \\
\hline 36 & Meridan-2 & $09-19-73$ & $\begin{array}{l}230 \text { km s of Dzhez- } \\
\text { kazgan, Chimkent Ob. }\end{array}$ & 6.3 & 600 & Arg. Aleur & Same as above & $\begin{array}{l}\text { Geology } \\
\text { Ministry }\end{array}$ \\
\hline 40 & Horizon-2 & $08-14-74$ & $\begin{array}{l}190 \mathrm{~km} \text { nw of Tazov-skiy, } \\
\text { Tyumen Ob. }\end{array}$ & 7.6 & 534 & Clay & Vorkuta-Tiksi Line-5 & $\begin{array}{l}\text { Geology } \\
\text { Ministry }\end{array}$ \\
\hline 41 & Horizon-1 & $08-29-74$ & $\begin{array}{l}70 \mathrm{~km} \text { sw of Vorkuta, } \\
\text { Komi Rep. }\end{array}$ & 7.6 & 583 & Sandstone & Same as above & $\begin{array}{l}\text { Geology } \\
\text { Ministry }\end{array}$ \\
\hline 45 & Horizon-4 & $08-12-75$ & $\begin{array}{l}120 \mathrm{~km} \text { sw of Tiksi, } \\
\text { Sakha }\end{array}$ & 7.6 & 496 & & Same as above & $\begin{array}{l}\text { Geology } \\
\text { Ministry }\end{array}$ \\
\hline 46 & Horizon-3 & $09-29-75$ & $\begin{array}{l}90 \mathrm{~km} \text { ese of Norilsk, } \\
\text { Taimyr AO }\end{array}$ & 7.6 & 834 & Salt & Same as above & $\begin{array}{l}\text { Geology } \\
\text { Ministry }\end{array}$ \\
\hline 50 & Meteorite-2 & $07-26-77$ & $\begin{array}{l}90 \mathrm{~km} \text { ene of Norilsk, } \\
\text { Taimyr AO }\end{array}$ & 13 & 850 & Salt & Dikson-Khilok Line-6 & $\begin{array}{l}\text { Geology } \\
\text { Ministry }\end{array}$ \\
\hline 51 & Meteorite-5 & $08-10-77$ & $\begin{array}{l}80 \mathrm{~km} \text { se of Khilok, Chita } \\
\mathrm{Ob} .\end{array}$ & 8.5 & 494 & Granite & Same as above & $\begin{array}{l}\text { Geology } \\
\text { Ministry }\end{array}$ \\
\hline 52 & Meteorite-3 & $08-20-77$ & $\begin{array}{l}40 \mathrm{~km} \text { se of Tura, Evenkii } \\
\mathrm{AO}\end{array}$ & 8.5 & 600 & Tuff & Same as above & $\begin{array}{l}\text { Geology } \\
\text { Ministry }\end{array}$ \\
\hline 53 & Meteorite-4 & $09-10-77$ & $\begin{array}{l}70 \text { km se of Ust'-Kut, } \\
\text { Irkutsk Ob. }\end{array}$ & 7.0 & 550 & Aleur-Marl & Same as above & $\begin{array}{l}\text { Geology } \\
\text { Ministry }\end{array}$ \\
\hline 57 & Kraton-4 & 08-09-78 & $\begin{array}{l}100 \mathrm{~km} \text { wsw of Sangar, } \\
\text { Yakut ASSR }\end{array}$ & 22 & 567 & $\begin{array}{l}\text { Arg, Aleur, } \\
\text { Sandstone }\end{array}$ & $\begin{array}{l}\text { Berezovo-Ust Maya } \\
\text { Line-7 }\end{array}$ & $\begin{array}{l}\text { Geology } \\
\text { Ministry }\end{array}$ \\
\hline 58 & Kraton-3 & $08-24-78$ & $\begin{array}{l}50 \mathrm{~km} \text { e of Aykhal, Yakut } \\
\text { ASSR }\end{array}$ & 19 & 577 & Limestone & Same as above & $\begin{array}{l}\text { Geology } \\
\text { Ministry }\end{array}$ \\
\hline 60 & Kraton-2 & $09-21-78$ & $\begin{array}{l}100 \text { km s of lgarka, } \\
\text { Krasnoyarsk Kr. }\end{array}$ & 16 & 886 & Aleu., Ss. & $\begin{array}{l}\text { Berezovo-Ust Maya } \\
\text { Line-7 }\end{array}$ & $\begin{array}{l}\text { Geology } \\
\text { Ministry }\end{array}$ \\
\hline 63 & Kraton-1 & $10-17-78$ & $\begin{array}{l}400 \mathrm{~km} \text { ssw of Sale- } \\
\text { khard, Tyumen Ob. }\end{array}$ & 2.3 & 593 & Aleu., Ss. & Same as above & $\begin{array}{l}\text { Geology } \\
\text { Ministry }\end{array}$ \\
\hline 69 & Kimberlite- 4 & $08-12-79$ & $\begin{array}{l}390 \mathrm{~km} \text { w of Yakutsk, } \\
\text { Yakut ASSR }\end{array}$ & 6.5 & 962 & (Salt)? & $\begin{array}{l}\text { Khanti Mansisk- Lena } \\
\text { Line-8 }\end{array}$ & $\begin{array}{l}\text { Geology } \\
\text { Ministry }\end{array}$ \\
\hline
\end{tabular}




\begin{tabular}{|c|c|c|c|c|c|c|c|c|}
\hline 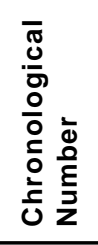 & $\begin{array}{c}\text { Ministry of } \\
\text { Atomic } \\
\text { Energy } \\
\text { (MAE) } \\
\text { Name }\end{array}$ & Date & Geographic Vicinity & $\begin{array}{l}\text { MAE } \\
\text { Yield } \\
\text { (kt) }\end{array}$ & $\begin{array}{l}\text { MAE } \\
\text { Depth } \\
\text { of } \\
\text { Burial } \\
(\mathrm{m})\end{array}$ & Geology & Name/Comments & $\begin{array}{c}\text { Sponsor } \\
\text { of } \\
\text { test }\end{array}$ \\
\hline 70 & $\begin{array}{l}\text { Kimberlite- } \\
3\end{array}$ & $09-06-79$ & $\begin{array}{l}40 \mathrm{~km} \text { sw of Tura, Evenk } \\
\mathrm{AO}\end{array}$ & 6.5 & 599 & Tuff & Same as above & $\begin{array}{l}\text { Geology } \\
\text { Ministry }\end{array}$ \\
\hline 72 & Kimberlite-1 & $10-04-79$ & $\begin{array}{l}150 \text { km se of Khanty- } \\
\text { Mansiysk, Kh.-M. Ob. }\end{array}$ & 21 & 837 & Clay & Same as above & $\begin{array}{l}\text { Geology } \\
\text { Ministry }\end{array}$ \\
\hline 78 & Batholith -1 & $11-01-80$ & $\begin{array}{l}120 \mathrm{~km} \text { se of Baykit, } \\
\text { Evenk AO }\end{array}$ & 8 & 720 & Dolomite & $\begin{array}{l}\text { Emba R.-Kolpashev- } \\
\text { Olekminsk Line-9 }\end{array}$ & $\begin{array}{l}\text { Geology } \\
\text { Ministry }\end{array}$ \\
\hline 84 & Shpat-2 & $10-22-81$ & $\begin{array}{l}140 \mathrm{~km} \text { wsw of Tura, } \\
\text { Evenk AO }\end{array}$ & 8.5 & 581 & Dolomite & Kyet R.-Tiksi Line-10 & $\begin{array}{l}\text { Geology } \\
\text { Ministry }\end{array}$ \\
\hline 85 & Rift-3 & $07-30-82$ & $\begin{array}{l}160 \mathrm{~km} \mathrm{n} \text { of Irkutsk, } \\
\text { Buryat AO }\end{array}$ & 8.5 & 854 & Dolomite & $\begin{array}{l}\text { Yamal Pen.-Kyakhta } \\
\text { Line-11 }\end{array}$ & $\begin{array}{l}\text { Geology } \\
\text { Ministry }\end{array}$ \\
\hline 86 & Rift-1 & 09-04-82 & $\begin{array}{l}190 \text { km w of Dudin-ka, } \\
\text { Taimyr AO. }\end{array}$ & 16 & 960 & Sandstone & Same as above & $\begin{array}{l}\text { Geology } \\
\text { Ministry }\end{array}$ \\
\hline 87 & Rift-4 & $09-25-82$ & $\begin{array}{l}30 \text { km se of Norilsk, } \\
\text { Krasnoyarsk Kr. }\end{array}$ & 8.5 & 554 & Gabbro-Dol. & Same as above & $\begin{array}{l}\text { Geology } \\
\text { Ministry }\end{array}$ \\
\hline 105 & Quartz-2 & $08-11-84$ & $\begin{array}{l}100 \mathrm{~km} \text { w of Pechora, } \\
\text { Komi R. }\end{array}$ & 9.5 & 759 & Clay & $\begin{array}{l}\text { Murmansk-Kizil Line } \\
12\end{array}$ & $\begin{array}{l}\text { Geology } \\
\text { Ministry }\end{array}$ \\
\hline 106 & Quartz-3 & $08-25-84$ & $\begin{array}{l}100 \mathrm{~km} \text { nw of Surgut, } \\
\text { K.M. AO }\end{array}$ & 8.5 & 726 & Clay & Same as above & $\begin{array}{l}\text { Geology } \\
\text { Ministry }\end{array}$ \\
\hline 110 & Quartz-4 & $09-17-84$ & $\begin{array}{l}50 \text { km ssw of Marinsk, } \\
\text { Kemerovo Ob. }\end{array}$ & 10 & 557 & Granite & Same as above & $\begin{array}{l}\text { Geology } \\
\text { Ministry }\end{array}$ \\
\hline 114 & Agate & $07-18-85$ & $\begin{array}{l}150 \text { km w of Mezen', } \\
\text { Arkangelsk Ob. }\end{array}$ & 8.5 & 772 & Granite & Same as above & $\begin{array}{l}\text { Geology } \\
\text { Ministry }\end{array}$ \\
\hline 120 & Batholith-2 & $10-03-87$ & $\begin{array}{l}320 \mathrm{~km} \text { ssw of } \\
\text { Aktyubinsk, Ak. Ob. }\end{array}$ & 8.5 & 1002 & Salt Dome & $\begin{array}{l}\text { Emba R.-Kolpashevo- } \\
\text { Olekminsk Line } 9\end{array}$ & $\begin{array}{l}\text { Geology } \\
\text { Ministry }\end{array}$ \\
\hline 121 & Ruby-2 & $08-22-88$ & $\begin{array}{l}40 \mathrm{~km} \text { ne of Urengoy, } \\
\text { Yamalo-Nenetsk AO }\end{array}$ & 16 & 829 & Clay & $\begin{array}{l}\text { Kostomushka-Urengoi } \\
\text { Line-13 }\end{array}$ & $\begin{array}{l}\text { Geology } \\
\text { Ministry }\end{array}$ \\
\hline 122 & Ruby-1 & $09-06-88$ & $\begin{array}{l}80 \text { km ene of Kotlas, } \\
\text { Arkhangelsk Ob. }\end{array}$ & 7.5 & 820 & $\begin{array}{l}\text { Anhydrite; } \\
\text { Dolomite }\end{array}$ & $\begin{array}{l}\text { Kostomuksha- } \\
\text { Semipalatinsk Lines- } \\
14 \& 13\end{array}$ & $\begin{array}{l}\text { Geology } \\
\text { Ministry }\end{array}$ \\
\hline \multicolumn{9}{|c|}{ B.6. Experimental-Industrial Work on the Breakage of Ore } \\
\hline 29 & Dnepr-1 & 09-04-72 & $\begin{array}{l}20 \mathrm{~km} n \text { of Kirovsk, } \\
\text { Murmansk Ob. }\end{array}$ & 2.1 & 131 & Apatite Ore & "Apatiti-1" & $\begin{array}{l}\text { Fertilizer } \\
\text { Min. }\end{array}$ \\
\hline 107 & Dnepr-2 & 08-27-84 & Same as above & $2 \times 1.8$ & 175 & Apatite Ore & "Apatiti-2" & $\begin{array}{l}\text { Fertilizer } \\
\text { Min. }\end{array}$ \\
\hline \multicolumn{9}{|c|}{ B.7. Burial of Biologically Dangerous Oil Field Wastes in Deep Geologic Formations } \\
\hline 38 & Kama-2 & $10-26-73$ & $\begin{array}{l}30 \mathrm{~km} \text { w of Sterlitmak, } \\
\text { Bashkir ASSR }\end{array}$ & 10 & 2026 & Dolomite & & $\begin{array}{l}\text { Oil Ref. \& } \\
\text { Chem. } \\
\text { Min. }\end{array}$ \\
\hline 39 & Kama-1 & $07-08-74$ & Same as above & 10 & 2123 & Dolomite & & Same \\
\hline
\end{tabular}




\begin{tabular}{|c|c|c|c|c|c|c|c|c|}
\hline 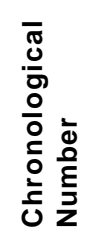 & $\begin{array}{c}\text { Ministry of } \\
\text { Atomic } \\
\text { Energy } \\
\text { (MAE) } \\
\text { Name }\end{array}$ & Date & Geographic Vicinity & $\begin{array}{c}\text { MAE } \\
\text { Yield } \\
\text { (kt) }\end{array}$ & $\begin{array}{l}\text { MAE } \\
\text { Depth } \\
\text { of } \\
\text { Burial } \\
(\mathrm{m})\end{array}$ & Geology & Name/Comments & $\begin{array}{c}\text { Sponsor } \\
\text { of } \\
\text { test }\end{array}$ \\
\hline \multicolumn{9}{|c|}{ B.8. Transplutonic Element Production } \\
\hline 44 & $\begin{array}{l}\text { Halite A- } \\
2-1\end{array}$ & $04-25-75$ & $\begin{array}{l}180 \mathrm{~km} n \text { of Astra-khan, } \\
\text { Gur'yev Ob. }\end{array}$ & 0.35 & 583 & Salt Cavity & $\begin{array}{l}\text { Exp. in water-filled A-2 } \\
\text { cavity }\end{array}$ & $\mathrm{MMB}^{1}$ \\
\hline 48 & Halite $A-4$ & $07-29-76$ & Same as above & 58 & 1000 & Salt & & $\mathrm{MMB}^{1}$ \\
\hline 54 & $\begin{array}{l}\text { Halite A- } \\
5\end{array}$ & 09-30-77 & Same as above. & 9.3 & 1503 & Salt & & $\mathrm{MMB}^{1}$ \\
\hline 55 & $\begin{array}{l}\text { Halite A- } \\
2-2\end{array}$ & $10-14-77$ & Same as above & 0.10 & 582 & Salt Cavity & $\begin{array}{l}\text { Exp. in water-filled A-2 } \\
\text { cavity }\end{array}$ & $\mathrm{MMB}^{1}$ \\
\hline 56 & $\begin{array}{l}\text { Halite A- } \\
2-3\end{array}$ & $10-30-77$ & Same as above & 0.01 & 582 & Salt Cavity & $\begin{array}{l}\text { Exp. in water-filled A-2 } \\
\text { cavity }\end{array}$ & $\mathrm{MMB}^{1}$ \\
\hline 59 & $\begin{array}{l}\text { Halite A- } \\
2-4\end{array}$ & $09-12-78$ & Same as above & 0.08 & 584 & Salt Cavity & $\begin{array}{l}\text { Exp. in water-filled A-2 } \\
\text { cavity }\end{array}$ & $\mathrm{MMB}^{1}$ \\
\hline 62 & Halite A-7 & $10-17-78$ & Same as above & 73 & 971 & Salt Dome & & $\mathrm{MMB}^{1}$ \\
\hline 64 & Halite A-9 & $12-18-78$ & Same as above & 103 & 630 & Salt Dome & & $\mathrm{MMB}^{1}$ \\
\hline 65 & $\begin{array}{l}\text { Halite A- } \\
2-5\end{array}$ & $11-30-78$ & Same as above & 0.06 & 585 & Salt Cavity & $\begin{array}{l}\text { Exp. in water-filled A-2 } \\
\text { cavity }\end{array}$ & $\mathrm{MMB}^{1}$ \\
\hline 66 & $\begin{array}{l}\text { Halite A- } \\
2-6\end{array}$ & 01-10-79 & Same as above & 0.5 & 581 & Salt Cavity & $\begin{array}{l}\text { Exp. in water-filled A-2 } \\
\text { cavity }\end{array}$ & $\mathrm{MMB}^{1}$ \\
\hline 67 & Halite A-8 & 01-17-79 & Same as above & 65 & 995 & Salt Dome & & $\mathrm{MMB}^{1}$ \\
\hline 68 & $\begin{array}{l}\text { Halite A- } \\
11\end{array}$ & 07-14-79 & Same as above & 21 & 982 & Salt Dome & & $\mathrm{MMB}^{1}$ \\
\hline 74 & $\begin{array}{l}\text { Halite A- } \\
10\end{array}$ & $24-10-79$ & Same as above & 33 & 982 & Salt Dome & $\begin{array}{l}\text { Two explosions in } \\
\text { same hole } 7\end{array}$ & $\mathrm{MMB}^{1}$ \\
\hline \multicolumn{9}{|c|}{ B.9. Decoupling Experiment } \\
\hline 47 & $\begin{array}{l}\text { Halite A- } \\
3-1\end{array}$ & $29-03-76$ & $\begin{array}{l}180 \mathrm{~km} n \text { of Astra-khan, } \\
\text { Gur'yev Ob. }\end{array}$ & 10 & 990 & Salt Cavity & $\begin{array}{l}\text { Decoupled shot in A-3 } \\
\text { cavity }\end{array}$ & $\mathrm{MMB}^{1}$ \\
\hline \multicolumn{9}{|c|}{ B.10. Experimental-Industrial Work on Preventing Sudden Blow-Out of Coal Dust and Methane } \\
\hline 71 & Cleavage & $16-09-79$ & $\begin{array}{l}5 \mathrm{~km} \text { e of Enakievo, } \\
\text { Donets Ob., Ukraine }\end{array}$ & 0.3 & 903 & Sandstone & $\begin{array}{l}\text { Ref. } 1 \text { gives time as } \\
0900 \text { GMT }\end{array}$ & $\begin{array}{l}\text { Coal } \\
\text { Prod. } \\
\text { Ministry }\end{array}$ \\
\hline
\end{tabular}

1 Ministry of Medium Machine Building, the Soviet Ministry responsible for the nuclear weapons program and the predecessor to MinAtom.

2 Oleg Stefashin, “Unknown New Test Site," Izvestiya, 23 Jan. 1991, p. 2; from JPRS-TAC-91-004, p. 33.

3 V. V. Kireev, et. al., "Group Excavation by Nuclear Explosions in Alluvial Media," IAEA-TC-1-4/14, in Peaceful Nuclear Explosions IV, IAEA Panel, pp. 399-419, 1995.

4 D. D. Sultanov, et. al., Investigation of Seismic Efficiency of Soviet Peaceful Nuclear Explosions Conducted Under Various Geological Conditions, Russian Academy of Sciences, Institute for Dynamics of the Geosphere, July 28, 1993.

5 H. M. Benz, et al., "Deep Seismic Sounding in Northern Eurasia," EOS, Vol. 73, No. 28, July 14, 1992, pp. $297-300$.

6 Boris Litvinov, private communication, May, 1994.

7 USSR Nuclear Weapons Tests and Peaceful Nuclear Explosions, 1949 through 1990, RFCN-VNIIEF, Sarov, ISBN 5-851650-062-1, 1996. 



\section{Appendix C}

\section{The Soviet Program to Develop Nuclear Explosives for Peaceful Uses}

The Russian Ministry of Atomic Energy (MinAtom) recently released a comprehensive list of all nuclear explosions conducted by the Soviet Union. ${ }^{1}$ Included is a list of the date, test-site area location, emplacement hole, or tunnel designation for each explosion. In addition, for each explosion, the list includes the general purpose and yield or yield range of the test. If the explosion involved multiple devices fired simultaneously, the purpose and yield range of each device test is given. This list reveals that during the life of the Program for the Use of Nuclear Explosions in the National Economy, the Soviet Union carried out 40 device-development tests at its nuclear weapons test sites to develop special nuclear explosives or emplacement techniques for such applications. Table C. 1 is a list of the PNE device-development explosions carried out for the development of such explosives.

All but two of these PNE device-development tests were at the Degelen, Sary-Uzen, or Balapan areas of the Semipalatinsk Test Site (STS). The other two were at the Novaya Zemlya Test Site. As noted in Table C.1, three of these explosions, on 05/28/67, 10/17/76, and 9/11/69, consisted of two PNE device-development tests fired simultaneously in the same tunnel complex. Another three PNE development tests were fired simultaneously along with one or more nuclear weapons tests.

Also shown in Table C. 1 is the seismic body wave magnitude for 37 of these explosions as reported by the International Seismic Center (ISC). Three were presumably of sufficiently low yield that they were not detected and identified as events by the ISC.

Supplemental data on the yield and/or depth of burial (DoB) of some of these events were reported earlier by two other Russian sources, ${ }^{2,3}$ both associated with MinAtom. Reference 2 provided a list of the date, location, and geology of some 96 underground explosions at STS from 1961 through 1972. Exact yields were provided for 22, with only a yield range for the remainder. Yields given for the same events as in References 1 were, with one exception, the

1 USSR Nuclear Weapons Tests and Peaceful Nuclear Explosions - 1949 through 1990, RFCN-VNIIEF, Sarov, 1996; ISBN 5-85165-062-1.

2 V. S. Bocharov, S. A. Zelentsev, and B. I. Mikhailov, "Characteristics of 96 Underground Nuclear Explosions at the Semipalatinsk Experimental Test Site," Atomnaya Energiya, Vol. 67, No. 3, 1989, pp. 210-214.

3

V. V. Gorin, et. al., "The Semipalatinsk Test Site: Chronology of Underground Nuclear Explosions and Their Primary Radiation Effects," Bulletin of the Center for Public Information on Atomic Energy, No. 9, 1993, pp. 21-32. 
Table C.1 PNE Device Development Explosions in the Soviet Union

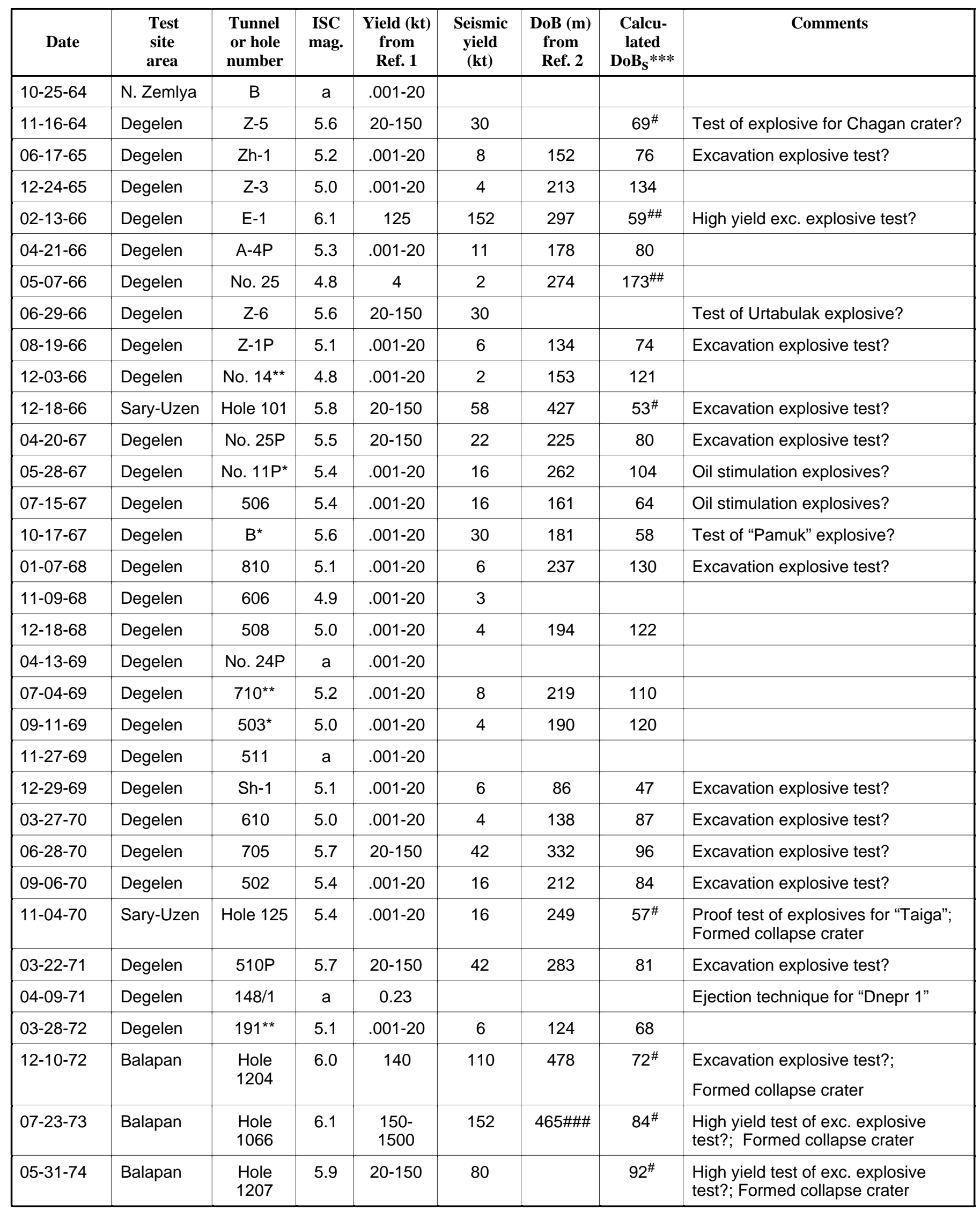

C-2 


\begin{tabular}{|c|c|c|c|c|c|c|c|c|}
\hline Date & $\begin{array}{l}\text { Test } \\
\text { site } \\
\text { area }\end{array}$ & $\begin{array}{l}\text { Tunnel } \\
\text { or hole } \\
\text { number }\end{array}$ & $\begin{array}{l}\text { ISC } \\
\text { mag. }\end{array}$ & $\begin{array}{c}\text { Yield (kt) } \\
\text { from } \\
\text { Ref. 1 }\end{array}$ & $\begin{array}{c}\text { Seismic } \\
\text { yield } \\
(\mathbf{k t})\end{array}$ & $\begin{array}{c}\text { DoB (m) } \\
\text { from } \\
\text { Ref. } 2\end{array}$ & $\begin{array}{c}\text { Calcu- } \\
\text { lated } \\
\text { DoB }_{\mathbf{S}}^{* * * *}\end{array}$ & Comments \\
\hline $06-08-75$ & Degelen & 165 & 5.5 & $.001-20$ & 22 & & & \\
\hline $08-18-83$ & N. Zemlya & $A-40^{* *}$ & 5.9 & $.001-20$ & b & & & \\
\hline
\end{tabular}

* Two PNE device-development tests were carried out simultaneously in the same tunnel.

** A PNE device-development test was fired simultaneously in the same tunnel complex with one or more weapons development, effects, or safety tests.

*** Calculated using seismic yield and DoB from Ref. 2 except in those cases where actual yields were known. Dob from Ref. 7 were used for the tests where those values appeared more reasonable.

\# $\quad$ Scaled depth of burial from Ref. 7.

\#\# Scaled depth of burial calculated using reported yield.

\#\#\# Depth of burial and yield shown are from Ref. 7. This yield of $150 \mathrm{kt}$ compares well with the seismic yield of $152 \mathrm{kt}$. However, Ref. 7 gives the scaled depth of burial as $83.9 \mathrm{~m} / \mathrm{kt}^{1 / 3}$ even though the depth of burial and yield calculate a scaled depth of burial of $87.5 \mathrm{~m} / \mathrm{kt}^{1 / 3}$.

a No seismic event was reported by ISC. Yield was presumably too small to be recorded by ISC network.

b Yield algorithm not appropriate for Novaya Zemlya.

same. ${ }^{4}$ Reference 3 provided a comprehensive list of all the underground explosions fired at STS from 1961 through 1989, including the 96 that were listed in Reference 2. Yields and yield ranges were given for all other events, which also agreed with Reference 1 and 2 with a few exceptions. 5

Using the yields from 19 explosions in Reference 2, all but four of which were weaponsdevelopment or effects tests, and their ISC seismic magnitudes, Vergino 6 calculated the following general yield-magnitude relation for explosions in any of the three areas of the STS:

$$
m_{\mathrm{b}}=4.41+0.71 \log W
$$

where

$$
m_{\mathrm{b}}=\text { seismic magnitude, }
$$

and

$$
W=\text { explosion yield }(\mathrm{kt})
$$

4 Ref. 1 gave the yield of the PNE test on 03-28-72 as being in the range of 0.001-20 kt whereas Refs. 2 and 3 give it as $6 \mathrm{kt}$. It may be significant that the PNE test was fired simultaneously with two weapons-related tests, and the $6 \mathrm{kt}$ is the total yield.

5 Ref. 3 only gives a yield range of $<20 \mathrm{kt}$ for the PNE event of 12-16-74 whereas Ref. 1 gives the yield as $3.8 \mathrm{kt}$.

$6 \quad$ E. S. Vergino, “Soviet Test Yields,” EOS, Vol. 70, No. 48, November 28, 1989. 
which has a two-sigma error of about $\pm 1.7 x$. The seismic yields shown in the sixth column of Table C.1 for the 32 PNE device-development explosions at STS with ISC magnitudes were calculated using this equation.

Reference 2 provided a depth of burial for many of the PNE device-development tests listed in Table C.1, which are shown in column seven. Using the seismic yield (or actual yields if known), the cube-root scaled depths of burial were calculated as shown in column eight, subject to the exceptions noted in the table, which arose from a recent publication by Adushkin and Spivak of the Russian Institute for Dynamics of the Geosphere. ${ }^{7}$ This report provides data on a large number of Russian nuclear explosions that were buried at depths that resulted in cratering or other disruption of the earth's surface. In addition to those PNE cratering explosions discussed in Section III of the main report, Adushkin and Spivak also include data on many such explosions at the STS, including seven of the PNE device-development tests listed in Table C.1. In some cases, their numbers are consistent with those provided by References 1-3, but in others, they are significantly different. Of particular note are the following data:

- For the 12-18-66 Hole 101 event in the Sary-Uzen Area of STS, Adushkin and Spivak give the yield as $\sim 80 \mathrm{kt}$, which is consistent with the seismic yield, but they give the depth of burial as $228 \mathrm{~m}$, significantly smaller than the $427 \mathrm{~m}$ in Ref. 2. They also describe the geology as sandstone overlain by a clay layer $40 \mathrm{~m}$ thick and sandy loam $7 \mathrm{~m}$ thick, rather than prophyrite as given in Ref. 2. Adushkin and Spivak's numbers indicate a scaled depth of burial of only $59 \mathrm{~m} / \mathrm{kt}^{1 / 3}$, which is consistent with the cratering action and venting of the explosion described by them. Reference 3 also indicates that this explosion dynamically vented. The crater produced by the explosion had a radius of $145 \mathrm{~m}$ and a depth of about $15 \mathrm{~m}$, but with a 10-m-high mound in the center.

- For the 11-04-70 Hole 125 event also in the Sary-Uzen Area of STS, Adushkin and Spivak give the yield as $19 \mathrm{kt}$, which is consistent with the seismic yield, but they give the depth of burial as $151.3 \mathrm{~m}$, significantly smaller than the $249 \mathrm{~m}$ in Ref. 2 . They describe the geology as a porphyritic massif overlain by sandy gravel and loam deposits 10-27 m thick, which is consistent with Ref. 2. Adushkin and Spivak's numbers indicate a scaled depth of burial of only $57 \mathrm{~m} / \mathrm{kt}^{1 / 3}$, which is consistent with the cratering action and venting of the explosion described by them. Reference 3 also indicates that this explosion vented. The crater produced by the explosion had a radius of 95-105 $\mathrm{m}$ and a depth of about $17.5 \mathrm{~m}$, but with an 8-m-high mound in the center. As indicated in the main report, this explosion was the final test of the explosives used for the Taiga row-cratering explosion on the alignment of the Pechora-Kama Canal.

- For the 12-10-72 Hole 1204 event in the Balapan Area of STS, Adushkin and Spivak give the yield as "about $150 \mathrm{kt}$," which is consistent with the yield of $140 \mathrm{kt}$ given

7 V. V. Adushkin, and A. A. Spivak, Geologic Characterization and Mechanics of Underground Nuclear Explosions, Defense Nuclear Agency Contract No. DNA 001-93-0026, June 1994. 
by Ref. 1, but they give the depth of burial as $378 \mathrm{~m}$, significantly smaller than the $478 \mathrm{~m}$ in Ref. 2. The geology is described as a sand-tuff formation, overlain by $20 \mathrm{~m}$ of alluvium. The explosion produced a dome that rose to $32 \mathrm{~m}$ and then collapsed, resulting in an early dynamic vent of radioactive gases and a collapse crater with a radius of $72 \mathrm{~m}$ and a depth of $26 \mathrm{~m}$.

- For the 07-23-73 Hole 1066 event in the Balapan Area of STS, Adushkin and Spivak give the yield as $150 \mathrm{kt}$ and the depth of burial as $465 \mathrm{~m}$. The explosion was fired in a granite massif overlain by alluvial clay and sandy loam $13 \mathrm{~m}$ thick. The explosion in the hard rock produced a dome that rose to a height of $19 \mathrm{~m}$ before collapsing, but there was no prompt vent. It resulted in a collapse crater with a radius of $110 \mathrm{~m}$ and a depth of $14 \mathrm{~m}$.

- For the 11-04-70 Hole 1207 event in the Balapan Area of STS, Adushkin and Spivak give only a scaled depth of burial of $92 \mathrm{~m} / \mathrm{kt}^{1 / 3}$ and indicate that the explosion was fired in a schist-type rock medium. Reference 3 reports that the explosion was completely contained, as was Hole 1066, but it also produced a collapse crater with a radius of $98 \mathrm{~m}$ and a depth of $4.5 \mathrm{~m}$.

It is of significance to note that many of the PNE device-development tests in Table C.1 were carried out at scaled depths of burial much less than that required for complete containment of the dynamic effects of the explosion and to prevent prompt venting of the radioactive gases from the nuclear explosion. Although the U.S. has essentially no experience with nuclear explosions at scaled depths of burial between 60 and $90 \mathrm{~m} / \mathrm{kt}^{1 / 3}$, it is expected that nuclear explosions in this range would result in the creation of a dome, prompt venting of radioactive gases, and a major disruption of the earth's surface, much as Adushkin and Spivak have described. Scaled depths of burial that fall in that range in Table C.1 have been highlighted in boldface. The use of such shallow scaled depths of burial with their high probability of releasing all the radioactive gases from the nuclear explosion would suggest that these explosions may well have been associated with the development of new families of low-fission excavation explosives.

As discussed in the main report, the Soviet PNE Program developed special nuclear explosives or emplacement techniques for four general purposes: low-fission explosives for excavation projects; small-diameter, high pressure and temperature explosives for closure of gas well fires; small-diameter, low-tritium explosives for hydrocarbon stimulation applications; and techniques for ejection of fission products far from the explosion site.

With these comments and the schedule of PNEs projects discussed in the main report in mind, the last column in Table C.1 presents comments on some of these PNE device-development tests and speculation on their possible purposes.

Figure C-1 is a map of the Semipalatinsk Test Site showing the location of the three major testing areas-Degelen Mountains, Balapan, and Sary-Uzen - as well as the locations as given in Ref. 3 of most of the PNE device-development tests listed in Table C.1. Also shown in Figure C-1 are the locations of the four nuclear cratering explosions at STS that were described 
in the main report: the "1004" Chagan crater, the "1003" Sary-Uzen crater, Tel'kems 1, and Tel'kems 2.

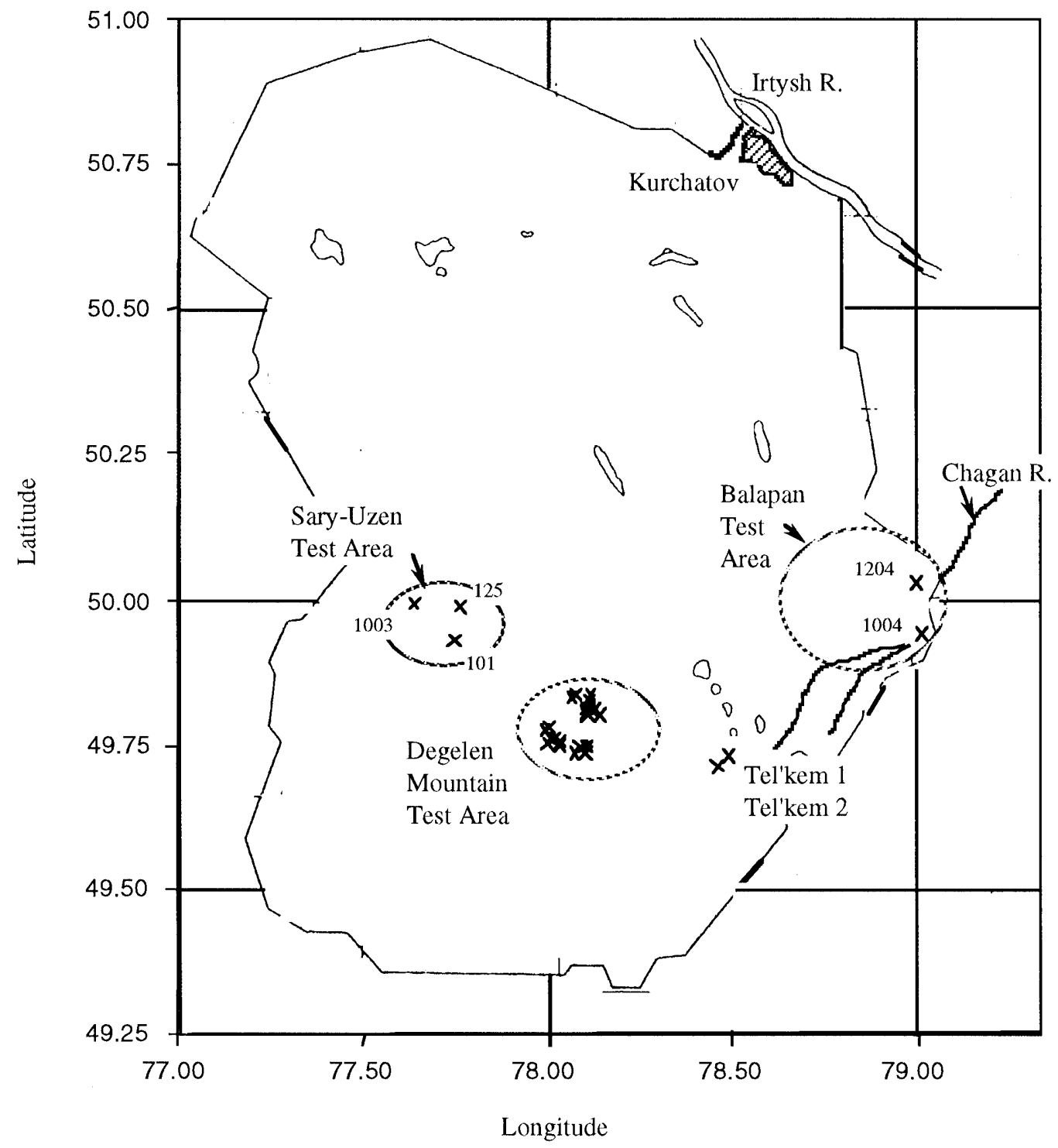

Figure C-1. Map of the Semipalatinsk Test Site (STS) showing the three major areas and the location of the PNE device-development explosions as well as the cratering explosions carried out at STS as part of the nuclear excavation technology development program discussed in the main report. 


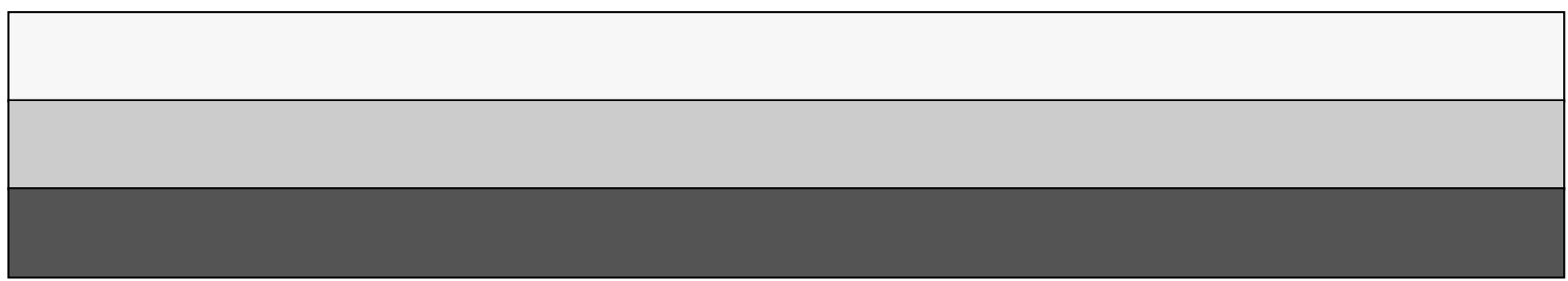

